\title{
Tear Down the Wall: Long-Form Analytical Techniques and the Music of Pink Floyd
}

Christopher Everett Jones

Follow this and additional works at: https://researchrepository.wvu.edu/etd

\section{Recommended Citation}

Jones, Christopher Everett, "Tear Down the Wall: Long-Form Analytical Techniques and the Music of Pink Floyd" (2017). Graduate Theses, Dissertations, and Problem Reports. 7098.

https://researchrepository.wvu.edu/etd/7098 
Tear Down the Wall:

Long-Form Analytical Techniques and the Music of Pink Floyd

Christopher Everett Jones

Thesis submitted

to the College of Creative Arts

at West Virginia University

in partial fulfillment of the requirements for the degree of

Doctor of Musical Arts

\author{
David Taddie, Ph.D., Chair \\ Evan MacCarthy, Ph.D. \\ Matthew Heap, Ph.D. \\ Andrea Houde, M.M. \\ Beth Royall, M.L.I.S., M.M.
}

School of Music

Morgantown, West Virginia

2017

Keywords: Music, Pink Floyd, Analysis, Rock music, Progressive Rock, Progressive Rock Analysis

Copyright 2017 


\section{Abstract \\ Tear Down the Wall: \\ Long-Form Analytical Techniques and the Music of Pink Floyd}

\section{Christopher Everett Jones}

This document examines the harmonic and melodic content of four albums by English Progressive Rock band Pink Floyd: Meddle (1971), The Dark Side of the Moon (1973), Wish You Were Here (1975), and The Wall (1979). Each of these albums presents a coherent discourse that is typical of the art music tradition. The ways in which formal cohesion is achieved includes harmonic arguments, motivic development, and textual and poetic narrative. 


\section{Part I}

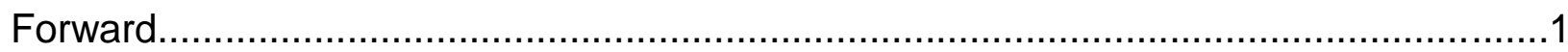

Chapter 1

Introducing Progressive Rock and Pink Floyd...............................................

Chapter 2

Contrasting Analytical Methodologies........................................................10

\section{Part II}

Chapter 3

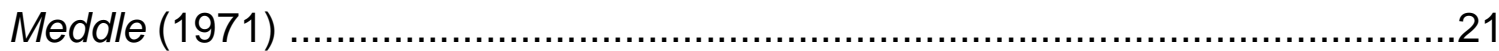

Chapter 4

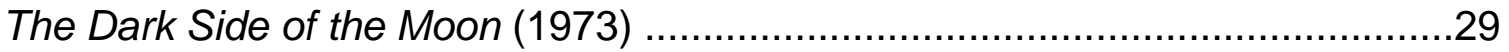

Chapter 5

Wish You Were Here (1975) ...................................................................

Chapter 6

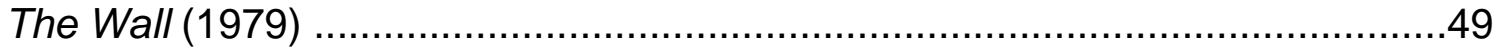

Chapter 7

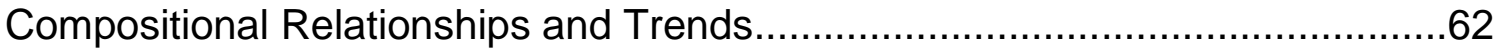

\section{Appendices}

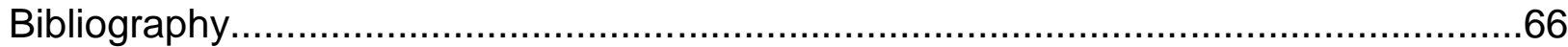

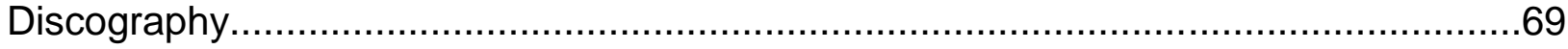




\section{Part I \\ Forward}

The first time I was introduced to the music of Pink Floyd in any real capacity, it was in the dark, dingy living room of one of my first undergraduate apartments. A friend of mine visited, bringing with them a DVD of Live at Pompeii (1972) and insisted that we watch it in its entirety. Until this point, my experience in music was limited to almost exclusively classical music. There were some exceptions. I went through a "punk" phase in high school and shortly thereafter, I found Led Zeppelin. However, my experience with these groups was cursory and superficial at best.

After I finished watching this concert DVD, I felt like I had been let in on a musical secret. I was enthralled by the ethereality of the melodies and the transcendental nature of the long improvisatory passages. The next day, I looked through a bin of old records that belonged to my roommate's girlfriend and I found a visually striking album cover that I knew I had seen before. It was all black except for the shape of a triangle in the center with a rainbow cascading out of its right side. I gingerly removed the aging vinyl from the sleeve and saw that it was Pink Floyd's 1973 release The Dark Side of the Moon. I placed it on the turntable, set the needle, and hit play. I sat at the kitchen table and listened, completely uninterrupted (except for after "the Great Gig in the Sky" when I had to turn the record over).

After that first encounter with Dark Side, I knew that I heard something in the music that I had not heard in any other rock albums that I had listened to before then. There was a sense of completeness and one-ness that I had, until that point, only associated with the great symphonists of the Nineteenth century. At the conclusion of the B side, I immediately turned over the record and listened to it again. It was not until 
about five years later that I began to understand the connections I was hearing. In that time, I became familiar with much more of Pink Floyd's discography. I felt like I was continually uncovering more connections within each album and understanding more about how to listen to them.

Eventually, this way of listening to Pink Floyd is what led me to this project, in which I look at four different albums and examine the musical connections made within each one. All of the analytical work in this document was completed aurally-there are no scores for these albums. There are some short transcriptions but only to make the discussion more fluid and easy to follow. To read this document, I highly recommend listening to the albums and paying attention to the timestamps that are included. They reference track number (as on a CD or digital download) and a time stamp in the format of minutes:seconds.

The purpose of this document is only to show the possibilities of how someone can listen to these albums and have a greater appreciation for the ways in which they are elevated from simply collections of songs to long-form works of art that unfold organically as the albums progress.

This document will cover four albums:

Meddle (1971)

The Dark Side of the Moon (1973)

Wish you Were Here (1975)

The Wall (1979)

In the analysis of each of these albums, the primary discussion concerns harmonic design and the ways in which harmonic ideas develop. Secondarily, melodic 
and motivic ideas will also be addressed where applicable. In conclusion, there will be a brief comparison of the four albums and the different rhetorical devices that are present in each one. 


\section{Chapter 1 \\ Introducing Progressive Rock and Pink Floyd}

During the late 1960 s and early 1970 s, vernacular music underwent a drastic expansion of styles. The 1960s saw the first British Invasion, a wave of British music that was the result of American popular styles synthesized with European sensibilities; notable acts included The Beatles, Led Zeppelin, The Rolling Stones, The Kinks, and The Yardbirds. ${ }^{1}$ The loud sounds of distorted guitar-driven songs filled the radios and the ears of the western world. The signature sounds of these styles were derived from the blues-based musics of American culture which had been imported into Europe during the Second World War. The raw sound of the American Blues was then further adapted to European-centric sensibilities. ${ }^{2}$

At first, the popular releases of the 1960 s all followed a very similar format that emphasized marketability and radio-friendliness. ${ }^{3}$ Songs were short (typically no longer than three minutes), simple (often only three chords), and straightforward (textually; i.e. "I want to hold your hand" 4 by the Beatles). The formal conventions of these kinds of songs relied on the presentation of alternating choruses and verses interspersed with instrumental "riffs" (motivically-driven thematic ideas). While from song to song there are

\footnotetext{
${ }^{1}$ Annie J. Randall, "British invasion." Grove Music Online. Oxford Music Online. Oxford University Press, accessed April 29, 2017, http://www.oxfordmusiconline.com/subscriber/article/grove/music/A2234548.

2 Naphtali Wagner, "'Domestication” of Blue Notes in the Beatles' Songs." Music Theory Spectrum 25, no. 2 (2003): 358. doi:10.1525/mts.2003.25.2.353.

3 David Buckley, "Single." Grove Music Online. Oxford Music Online. Oxford University Press, accessed April 29, 2017, http://www.oxfordmusiconline.com/subscriber/article/grove/music/47211.

${ }^{4}$ The Beatles, Meet the Beatles. Capitol Records ST-2047, 1963.
} 
differences, on a general level, popular songs characteristically “...[tend] to have discernable sections." ${ }^{5}$ The nature of brevity surrounding the popular music of the early 1960s was an environment in which singles thrived. Albums were built around a select handful of songs that were specifically chosen for their marketability as ear-catching and memorable. These select songs would receive radio airplay and lead to album sales. Other material on the album, material that did not receive the promotion that the chosen singles did, was often overlooked by audiences-at-large.

Progressive Rock was the genre that elevated the importance of the B-side tracks from a secondary role. ${ }^{6}$ This change was not just a change in the approach to Bside material, but an elevation of all material on an album as equally important. More broadly, this represents a point at which song-writers and composers operating in the conventions of Rock music were adopting ideals from the Art-Music spheres of influence. Progressive Rock artists were more deliberate in long-form musical construction, showing a tendency to view form as an expressive element rather than simply an existential necessity. This means that instead of having an approach to form that was exclusively for the sake of performance, the concept of form itself was elevated to a similar stature as harmony and melody and made inextricable from the musical dialectics that took place.

\footnotetext{
5 Jonathan J. Rolison and Judy Edworthy, 2013. "The Whole Song Is Greater Than the Sum of Its Parts: Local and Structural Features in Music Listening." Psychomusicology: Music, Mind \& Brain 23, no. 1: 43.

${ }^{6}$ Alexander Carpenter and Jérôme Melançon, "Is progressive rock progressive? Yes and Pink Floyd as counterpoint to Adorno." Rock Music Studies 2, no. 2: 125-147, 2015. RILM Abstracts of Music Literature (1967 to Present only).
} 


\section{Pink Floyd}

In the mid 1960s, a rock band with psychedelic musical tendencies emerged in London, England. The group known as Pink Floyd was founded by members Syd Barrett, Richard Wright, Nick Mason, and Roger Waters. Their style was rooted in the Rhythm and Blues styles popularized in the wave of musicians mentioned previously. Their popularity rose and they were soon headlining shows at the UFO club in London. Their performances were intended to be complete sensory experiences and included intricate light shows that accompanied their heavily improvisational style. This improvisational style was uniquely "Floydian" in the sense that improvisation encompassed not only melodic elements (such as in jazz and other styles in which musicians would exchange turns improvising over a repeating harmonic figure) but also textural and metric elements, such as in "Interstellar Overdrive."7

After the release of their first album, Piper at the Gates of Dawn, the future of the group was in a state of flux because of the increasingly erratic behavior of front-man Syd Barrett. Barrett's behavior on stage included such anomalies as simply standing with his guitar in hand, facing the audience, and staring blankly, refusing to perform. ${ }^{8}$ With Barrett acting unpredictably on and off stage, guitarist and vocalist David Gilmour was recruited to help cover some of the gaps left by Barrett's inability to perform. At first, Gilmour's role was limited to performing and recording music that had already been written by Barrett, but, as it soon became clear that Barrett could no longer work and

\footnotetext{
7 Pink Floyd, Piper at the Gates of Dawn. Columbia Records SCX 6157, 1967.

8 Dale Carter, "The Vegetables Turned: Sifting the psychedelic subsoil of Brian Wilson and Syd Barrett." Popular Music History 4, no. 1: 57-75, 2009. RILM Abstracts of Music Literature (1967 to Present only).
} 
function in the needed capacity, Gilmour took more of a creative responsibility with the group and began collaborating with bassist and vocalist Roger Waters on new material.

Their ultimate line-up would be solidified when, due to ongoing psychiatric issues, their original front-man and lead songwriter, Syd Barrett, was forced to permanently leave the group. Barrett was officially, and in every capacity, replaced by guitarist David Gilmour. ${ }^{9}$

Under the line-up of Waters, Gilmour, Wright, and Mason, the group made a career out of writing, recording, and touring and performing. This incarnation of Pink Floyd was active until the 2015 release of The Endless River (which was released after the death of drummer Nick Mason).

This document will present analyses of four albums released by Pink Floyd during the 1970s:

- Meddle $(1971)^{10}$

- The Dark Side of the Moon (1973) 11

- Wish You Were Here (1975) ${ }^{12}$

- The Wall (1979) $)^{13}$

These four albums demonstrate the ways in which Pink Floyd's approaches to longform composition developed over the course of the 1970s.

Meddle was not the first studio album released under the name of Pink Floyd. ${ }^{14}$ It was, however, the album that is generally recognized as the first true collaborative effort

\footnotetext{
9 Allan F. Moore, "Pink Floyd." Grove Music Online. Oxford Music Online. Oxford University Press, accessed November 15, 2014,http://www.oxfordmusiconline.com/subscriber/article/grove/music/46254. 10 Pink Floyd, Meddle. Harvest Records SHVL 795, IE 064 o 04917, 1971.

11 Pink Floyd, The Dark Side of the Moon. Harvest Records, SHVL 804, 1E 064 o 05249, 1973.

12 Pink Floyd, Wish You Were Here. Harvest Records SHVL 814, 1975.

${ }^{13}$ Pink Floyd, The Wall. Harvest Records SHDW 411, 1979.

${ }_{14}$ Meddle was preceded by The Piper at the Gates of Dawn (1967), A Saucerful of Secrets (1968), More (a film soundtrack, 1969), and Atom Heart Mother (1970).
} 
between Roger Waters and David Gilmour. Meddle was the first album released after Gilmour had replaced original front-man Syd Barrett in both performing and creative capacities. ${ }^{15}$ Its inclusion in this analytical project is to establish the origin of the collaboration between Waters and Gilmour and to present a baseline by which the later albums can be discussed.

Two other albums considered here, The Dark Side of the Moon and The Wall were the highest charting albums released by Pink Floyd, and counted among the highest-selling 100 albums of all time. ${ }^{16}$ Wish You Were Here is a compositional link between The Dark Side of the Moon and The Wall.

Meddle was released in 1971 and consists of six tracks on side 1 and one track on side 2. The total play-time is approximately 47 minutes. The Dark Side of the Moon was released in 1973 and consists of five tracks on side 1 and five tracks on side 2. Wish You Were Here was released in 1975 and consists of two tracks on side 1 and three tracks on side 2. The Wall, a double-album, was released in 1979 and consists of six tracks on side 1 , seven tracks on side 2 , six tracks on side 3 , and seven tracks on side 4. The inclusion of the concept of "sides" in an album is due to the technical limitations of vinyl (the original medium of these releases) and the impact these limitations had on the compositional process (i.e. the incorporation of the break between the two sides as a potentially important formal point in a long-form musical work).

The analysis portion of this document proceeds with an examination of musical concepts as they apply to each album in order to clearly represent the stages in the musical development of Pink Floyd and to characterize the development of the concept

\footnotetext{
${ }^{15}$ Brian Hiatt, "Pink Floyd's Journey to the Dark Side." Rolling Stone no. 1141: 44-72. 2011.

${ }^{16}$ According to Billboard.
} 
album as a long-form musical composition. In the following discussions of each album, individual songs are referred to by title not track position. Within the discussion of individual songs, sonic events may be denoted with a tracking time in this format (0:00), referring to the minute and second within the individual track on the digital recordings of each album.

The analysis will examine primarily the harmonic content of individual songs on each album (and secondarily the melodic content when the melodic content is motivically derived) and the ways in which the organization of pitch-centers contribute to the overall musical dialectic and therefore the intelligibility of form from a large perspective. 


\section{Chapter 2}

\section{Contrasting Analytical Methodologies}

This analysis will examine primarily the harmonic content and secondarily the melodic content of Meddle (1971), Dark Side of the Moon (1973), Wish You Were Here (1975), and The Wall (1979) and the ways in which the albums function as works typical

of the art music tradition. To understand the methodological approaches presented in the next chapter, this chapter will briefly discuss the languages of art music and vernacular Music. Through this discussion, it will be clear the ways in which the two genres differ and, more importantly, the ways in which they already intersect. The points at which they intersect will be the primary focus for the analytical case-studies. Specifically, the case-studies will examine the long-range harmonic design of each individual album and compare them against harmonic features found in art music.

\section{Deductive Analytical Techniques in Art Music}

In western art music of the common practice period (Baroque through the early Twentieth century), intelligibility of form is a consideration on the largest level. The construction of a piece follows a coherent method for organizing the components of the whole musical work. This concept of form on the largest level of musical analysis (looking at the entirety of a work) pertains to every one of the fundamental musical elements. These elements (melody, harmony, rhythm, texture, meter, timbre) all contribute to form the musical analogue of rhetoric. This is how music forms an 
intelligible argument. The deduction of form, therefore, is the practice of deconstructing a musical work into these components and drawing connections between them to better understand how long-form dialectics operate. ${ }^{17}$ In this document, the harmonic content (and to a lesser extent, the motivic content)

of each album will be examined for connections between large sections and the ways in which global coherence is achieved.

\section{Harmony}

The fundamental theory of tonal harmony pares down to one basic dichotomy: consonance versus dissonance. ${ }^{18}$ The idea that harmony can be either stable (consonant) or unstable (dissonant) is inextricable from common-practice tonality in western art music. The juxtaposition of consonance and dissonance is the primary way in which harmony gives the illusion of motion. The presentation of motion and stasis as it is implied by harmony (a term presented here in its most basic meaning of the simultaneous occurrence of multiple pitches) is one of the clearest ways that music can give clues that point to how larger units of a single piece fit together and relate to each other.

The most basic illustration of dissonance resolving to consonance in the context of western tonal harmony is a dominant triad resolving to a tonic triad. ${ }^{19} \mathrm{~A}$ dominant

\footnotetext{
17 Arnold Schoenberg, Fundamentals of Musical Composition, ed. G. Strang and L. Stein (London: Faber \& Faber, 1967) [written 1937-48] 1.

${ }^{18}$ Claude V. Palisca and Brian C.J. Moore, "Consonance." Grove Music Online. Oxford Music Online. Oxford University Press.

19 Steven Strunk, "Harmony (i)." The New Grove Dictionary of Jazz, 2nd ed.. Grove Music Online. Oxford Music Online. Oxford University Press.
} 
triad with the addition of a minor seventh (creating a dominant seventh chord) contains a tri-tone (either diminished fifth or augmented fourth) which is traditionally perceived as being among the most dissonant of intervals. It is through the resolution of a dominant chord to a tonic chord (V-I) that a tonic is established (tonicization). Out of every possible triadic combination in a diatonic set, the dominant triad and tonic triad only represent two of seven. The remaining five triadic configurations represent varying degrees of consonance and dissonance. The way in which consonance leads to dissonance, which leads to greater dissonance, which leads to maximal dissonance, which ultimately leads to consonance, forms what theorists refer to as the tonal hierarchy. This system is tonality; tonality breaks down (essentially) to tonicdominant-tonic. This is, perhaps, overly reductive, but represents the fundamental principle behind why tonality functions as effectively as it does. ${ }^{20}$

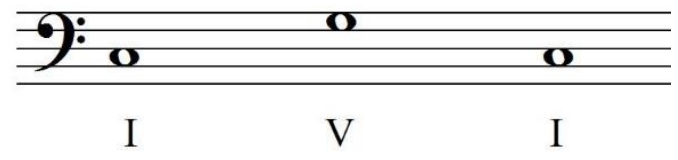

\section{Ex. 2.1 Fundamental tonic-dominant-tonic relationship}

Charles Rosen details this concept as it often appears in the context of the Classical-era sonata. The fundamental juxtapositions of consonances and dissonances, per Rosen, are the sources of tension, drama, and conflict in the works of composers, such as Mozart, Haydn, and Beethoven, exemplars of the western art music tradition. ${ }^{21}$ Rosen explains further that the motion between consonance and dissonance does not

\footnotetext{
20 Steven Strunk, "Harmony (i)." The New Grove Dictionary of Jazz, 2nd ed.. Grove Music Online. Oxford Music Online. Oxford University Press.

${ }^{21}$ Charles Rosen, "The Coherence of Musical Language.” The Classical Style. Norton \& Company. New York. 1972. Pg. 68.
} 
necessitate immediacy: in the instances of later works, this motion takes place over varying degrees of time and space, sometimes immediate and sometimes taking a great deal more time (as in Beethoven Op. 101, the A Major Piano Sonata in which there is never a cadential confirmation of A Major until the recapitulation). ${ }^{22}$ The concept of long range harmonic fulfillment will be of great importance later when examining the global harmonic design of the selected Pink Floyd albums.

\section{Melody}

In addition to the examination of vertical harmony, the discussion of form in art music often deals with the way melody is developed. A concept that is common in the musical language of western art music is the development of motives, or small fragments of melody that are strong enough in their own construction that they are easily recognizable and easily manipulated through various processes for the sake of musical progression. ${ }^{23}$

Another element common in a formal analysis that is often identified is the concept of the "promissory note," 24 i.e, certain notes presented are left unresolved in ways for which resolution was both expected and anticipated. Promissory notes leave a listener with a desire to hear something fulfilled in the way they were expecting, in a

\footnotetext{
${ }^{22}$ Charles Rosen, "The Coherence of Musical Language." The Classical Style. Norton \& Company. New York. 1972. Pg. 68.

${ }^{23}$ Arnold Schoenberg, Fundamentals of Musical Composition, ed. G. Strang and L. Stein (London, 1967) [written 1937-48] 16.

${ }^{24}$ Edward T. Cone, "Schubert's Promissory Note: An Exercise in Musical Hermeneutics." 19th-Century Music, Vol. 5, No. 3 (Spring, 1982), pp. 233.
} 
way, giving the listener a specific element for which to listen. Promissory notes are often presented in the form of a leading tone. A listener instinctively expects a leading tone to resolve in a motion that rises by one half-step (i.e. ti-do). This leading tone, in the instance that it is a promissory note, will be treated with a great insistence and emphasis, perhaps even exaggerating the expected resolution. When the leading-tone is resolved as a promissory note, the expectations of the listener are not fulfilled; the promissory note does not resolve in the way the listener expects. In the instance of a well-educated listener, the expectation is that this promissory note will be revisited afterwards and appropriately resolved in some way or another. ${ }^{25}$

\section{Musical Language of Popular Music}

Vernacular music repertories are often pitch centric (not necessarily tonal)meaning there is an aurally perceived "tonic" note or chord-but the specifics of the how these points of centricity are revealed tend to differ in some ways from the mechanical workings of art music. ${ }^{26}$

This means that the way pitches are presented and the organization of ideas from a harmonic perspective often differs between vernacular and art musics. The way that a listener perceives them on a fundamental level will likely be very similar, if not identical. For example, if a listener were to hear a piece in a common-practice tonal language and

\footnotetext{
${ }^{25}$ Edward T Cone, "Schubert's Promissory Note: An Exercise in Musical Hermeneutics." 19th-Century Music, Vol. 5, No. 3 (Spring, 1982), pp. 233.

26 "While surface-level pitch syntax and behavior in vernacular musics may differ from those of the common-practice tradition, many underlying organizational principles do not, among them pitch centricity and hierarchy, relative consonance and dissonance, and phrase structure and function. Nicole Biamonte, "Triadic modal and pentatonic patterns in rock music." Music Theory Spectrum, 32, 95-110 (2010).
} 
if a listener were to hear a rock song, in each they would most likely be able to sing what they perceive as tonic (or, more broadly, a "home" note). This is important because this document looks at the points where art music and vernacular music intersect and the ability of a listener, regardless of the formal mechanics of the music, to identify a point of pitch centricity (whether it be conventionally tonal, modal, or something different) is present in both idioms.

To observe this phenomenon within a particular context, one might look at most popular songs in the Rock genre from the mid-to-late twentieth century. Take for example the 1968 song "Sympathy for the Devil" by the Rolling Stones. The song presents E major as the aurally perceived "tonic." The song starts on an E major chord, and progresses through D major then A major in a closed progression. The perception, through repetition, is that E major is "tonic." Tonic, in the Western-Art-music sense, is established by harmonic contrast with its dominant. "Sympathy for the Devil" does not present a dominant to $E$ major during the verses of the song, yet $E$ major is still perceived as something of a pseudo-tonic. The actual harmonic motion of the verses, a closed progression from $E$ major to $D$ major to $A$ major and ending on $E$ major, is an emphasis on lower fourth relationships which has been coined a "doubleplagal" relationship. ${ }^{27}$

\footnotetext{
27 Nicole Biamonte, (2010). Triadic modal and pentatonic patterns in rock music. Music Theory Spectrum, 32, 95-110. The Rolling Stones, Beggars Banquet. London Records PS-539, 1968.
} 


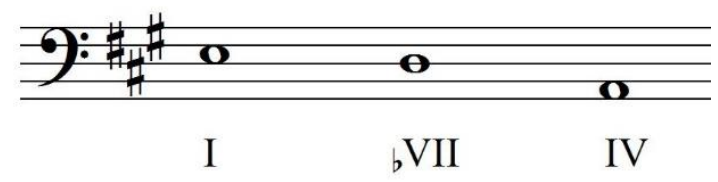

Ex. 2.2 Root progression of verses in "Sympathy for the Devil."

Although the perceived "home" pitch is $\mathrm{E}$, it is not established through the upper fifth, but the lower fifth. This technique is common in Rock music. Much of Rock music, therefore, can be considered not tonal, but modal. The abovementioned example by the Rolling Stones is in the Mixolydian mode. The central pitch is $\mathrm{E}$ but the diatonic set in which it is presented is three sharps. The art music paradigm will say that in three sharps, the reference pitch should be A, but in this case, the central scale built with the diatonic set is a rotation starting on $\mathrm{E}$, which leads to a central scale consisting of a major tetrachord and a minor tetrachord a fifth apart from one another. The relationship between different modal expressions of single pitches can have effects on long-range form in the context of an entire album. ${ }^{28}$

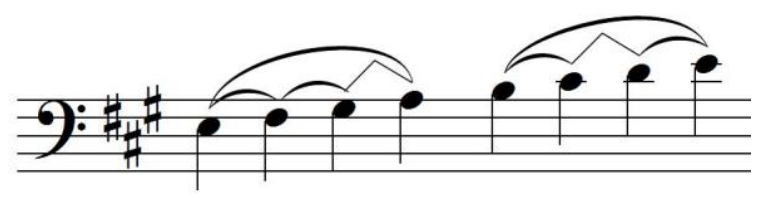

Ex. 2.3 Diatonic rotation of an A major scale starting on E showing location of whole and half steps (Mixolydian Scale)

\footnotetext{
${ }^{28}$ Brett G. Clement, 2015. "Scale Systems and Large-Scale Form in the Music of Yes." Music Theory Online 21, no. 1: 1-16. Academic Search Complete.
} 
One difference between modality and tonality is an emphasis on leading tones. In conventional tonality in which pitch centricity is formally defined by a tonic-dominant relationship, the most important and telling notes are leading tones: those that are a half step below structurally important notes. Leading tones give an aural indication about the expected direction of voice leading and set up a perceived necessity of resolution, leading to the aural phenomenon of dissonance. Modality does not necessarily rely on these same techniques. In the scale show in Example 2.3, even though the point of centricity is clearly $\mathrm{E}$ (as established by the physical parameters of the scale) there is not a $D \#$ as a leading tone that actively engages $E$ as a functional tonic in the conventional sense.

Another well-known instance of the double-plagal convention in practice is the song "Communication Breakdown" by Led Zeppelin. ${ }^{29}$ This song presents a primary instrumental theme that is an open progression from $E$ major to $D$ major to $A$ major to $D$ major. Again, this harmonic progression does not tonicize E major with a B major harmony as would be expected in a more conventional (common era tonality) practice. Instead, the sense of pitch-centricity is derived from the insistence of $E$ at the beginning of the phrase. It could even be argued that the progression tonicizes A major as a true tonic, but the actual pitch center is clearly E. ${ }^{30}$

\footnotetext{
${ }^{29}$ Led Zeppelin, Led Zeppelin. Atlantic 588171, 1968.

30 Nicole Biamonte, (2010). Triadic modal and pentatonic patterns in rock music. Music Theory Spectrum, 32, 95110.
} 


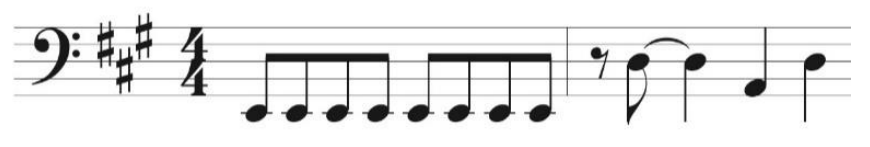

Ex. 2.4 Root progression and rhythm of main riff in "Communication Breakdown."

In Example 2.4, because of the voicing of the bass line which reflects the root progression in "Communication Breakdown," the dominant-tonic axis can clearly be seen as centered around A (although inverted). The upper fifth (dominant) and lower fifth (subdominant) indicate that the way tonic is perceived should point directly to A major. However, because this harmonic progression exists in a modal idiom rather than a tonal idiom, aurally, the "tonic" is clearly E in this instance. This is primarily because the initial presentation is $E$, and through insistence and repetition of the $E$ in the first measure, the following $D$ major chords and $A$ major chord are perceived as contrasting and therefore necessitate resolution back to $\mathrm{E}$. This results in another double-plagal axis rather than a dominant-tonic axis.

This modal technique can be presented in the context of tonal art music. When it is presented as such, however, it is more often than not subservient to the tonal hierarchy, meaning the process, known as modal borrowing, is yet another way to connect dissonances with consonances via the tonic-dominant axis and not truly modal in the sense of modality independent from functional tonality. ${ }^{31}$

\footnotetext{
${ }^{31}$ Steven Strunk, "Harmony (i)." The New Grove Dictionary of Jazz, 2nd ed.. Grove Music Online. Oxford Music Online. Oxford University Press.
} 


\section{The Intersection of Classical Technique and Vernacular Idioms}

The analytical techniques presented in this document will synthesize the concepts that have been discussed so far. The methods by which the four albums by Pink Floyd will be examined include techniques of formal analysis that are most often applied to art music and are here expanded to include analysis of rhetorical devices and processes typical of popular music analysis. ${ }^{32}$

The most important element that will be discussed is the idea of musical discourse and argument that occurs when two opposing factors are presented as having equal significance. This concept can be demonstrated in the form of a work from the body of art music literature that conforms to the sonata genre. The conventional form of a sonata relies on a musical drama unfolding over the course of three parts (an exposition, development, and recapitulation). The first part establishes at least two ideas that are in opposition to each other (most typically two tonal areas such as tonic and dominant).$^{33}$

The concept of conflict between multiple musical ideas that are similar in nature but present fundamentally opposed ideas can be synthesized with the vernacular use of modal music. Modal music can have different effects based on differing expressions of a single central pitch. ${ }^{34}$ When different modal expressions of a single pitch are presented with equal importance, musical conflict is generated. This process results in

\footnotetext{
32 Such as in: Gilad Cohen, "Expansive Form in Pink Floyd's "Dogs." Music Theory Online 21, no. 2: 1-13, 2015.

33 Arnold Schoenberg, Fundamentals of Musical Composition, ed. G. Strang and L. Stein (London, 1967) [written 1937-48] 201.

34 Daphne Tan and David Temperly, "Perception and Familiarity of Diatonic Modes." Music Perception 34, no. 3 (February 2017): 352-365.
} 
an effect that is similar to the "Double Tonic Complex" popularized by Robert Bailey in his examination of Tristan und Isolde. ${ }^{35}$

This document is not asserting that any of the works examined conform to any specific generic convention. Instead, the conventions of musical discourse via the juxtaposition of opposing ideas is integral to the long-form viability of any musical work. For example, conventionally in the art music spectrum, the notion of tonic and dominant are often seen as opposing concepts (even though they are inextricably linked because of the self-definition necessitated by their existence). When expanded to include the language and syntax of vernacular and popular music, it is more useful to broaden the scope of concepts that are oppositional. Modality and tonality are often opposed to one another (in long-form vernacular music) in the same way that tonic and dominant are (in art music). Both modality and tonality share common characteristics (as do the tonic and dominant triads) such as the concept of pitch-centricity. However, ways in which their parameters are defined differ greatly and work both in tandem and in opposition to each other to form a tangible and actively forming musical discourse.

This document will focus primarily on large-scale harmonic design as a technique in Progressive Rock music to achieve formal unity throughout an album as evidenced in Pink Floyd's Meddle (1971), Dark Side of the Moon (1973), Wish You Were Here (1975), and The Wall (1979). This concept is borrowed from the art music tradition but will be expanded to include and applied to the idiomatic language of Rock music. Melodic and motivic development will also be discussed, to a lesser extent, as a method by which music establishes a sense of formal cohesion over long stretches of time.

\footnotetext{
${ }^{35}$ Robert Bailey, The Genesis of Tristan und Isolde: And a Study of Wagner's Sketches and Drafts for the First Act. UMI, 1969.
} 


\section{Part II}

\section{Analysis}

\section{Chapter 3}

Meddle (1971)

The first song in Meddle, "One of These Days," is an instrumental track with a single spoken line. The first pitch content of this song is a B played by the bass $(0: 34)$. After this initial presentation, which is interrupted by a delayed echo, the bass repeats this same B but in continuous triplets (0:40). Harmonic support from the keyboard enters in a chordal punctuation (0:54) that establishes a point of pitch-centricity on $B$ minor. At this point there is not yet enough information to establish whether it is truly tonal. This is because, while the prevalence of the note B and the subsequent reveal of the B minor chord gives the impression of a tonic, there has not yet been any true tonicization with any chord acting as a dominant. The first contrasting harmony is an A major chord (1:09). The duration of this chord is very short only 16 beats long and, in contrast to the lengthy presentation of B minor that preceded it (approximately 45 seconds of exclusively B minor), is very short. It is at this moment that B minor is established not as a true tonic in the conventional sense, but as a modal center. The $\mathrm{bVII}$ to the $\mathrm{i}$ of $\mathrm{B}$ minor declares that the $\mathrm{B}$ minor chord has an Aeolian function rather than a tonal function. 


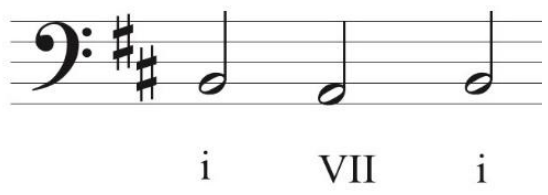

Ex. 3.1 Root Progression of "One of These Days"

Harmonically, "One of These Days" is only the alternation between B minor and A major chords. The rest of the content of this song is the presentation of textural and timbral events that will be covered in a later section.

"One of These Days" is followed by "A Pillow of Winds." This song begins with an E major chord with an added ninth presented by an acoustic guitar. Similarly to the first song on Meddle, it is not immediately clear what the function of this chord is. At the entrance of the electric guitar (0:04) the harmonic function of the E major chord is clarified by a melodic statement of B-E-D\#-B presented by an electric guitar with a slide.

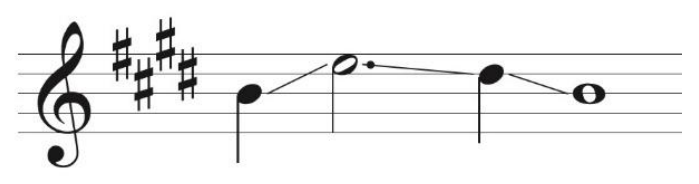

\section{Ex. 3.2 Tonicizing melody in "A Pillow of Winds"}

The rising fourth presented by the electric guitar suggests a tonal function for the note $E$ in this song. The melody rising from $B$ to $E$ suggests $E$ as a conventionally functional tonic which is then reinforced by the presentation of a leading tone (even though, as of its initial presentation, there is not yet a true melodic resolution of D\# as a leading tone). At the entrance of the vocal melody $(0: 21)$ E remains a pedal point while the harmony changes to a second inversion subdominant. This pedal $6 / 4$ conventionally resolves to 
tonic in root position. A modally borrowed bVII chord (0:50) prepares a shift from E major to $\mathrm{E}$ minor (occurring when a $\mathrm{G \#}$ is altered to become a $\mathrm{G}$ at $0: 58$ ). The parallel relationship between $\mathrm{E}$ major and $\mathrm{E}$ minor still benefits from the preparation by the root progression in "One of These Days" because there is a shared dominant-tonic axis between parallel keys. With the presentation of the first vocal melody in E minor (1:04) the presence of $D$ natural (i.e. the lack of a true leading tone to $E$ ) reveals the method of pitch-centricity establishment as a modal one rather than a tonal one. The modal nature of "A Pillow of Winds" is further concretized at the inclusion of a C\#, indicating a Dorian inflection in the middle section of the song. The return of the initial material at the end of the song indicates that "A Pillow of Winds" is conventionally ternary.

The harmonic material presented first in "A Pillow of Winds" is conventionally tonal. This is in direct contrast to the material presented throughout the entirety of "One of These Days." The immediate effect is one that sets up a conflict between modality as a concept and tonality as a concept. This is intensified when the first two tracks of Meddle are examined next to each other. The extended modality of "One of These Days" can be seen as preparatory tonicization, the roots of which tonicize E major as a tonal arrival at the beginning of "A Pillow of Winds."

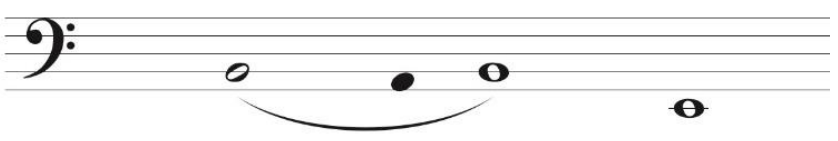

Ex. 3.3 Reduction of root progression of "One of These Days" as extended tonicization of the beginning of "A Pillow of Winds" 
This is important because it establishes tonality and modality as opposing ideas (via local juxtaposition) but also links the two and shows how the concepts relate (from a more global perspective).

"Fearless" is the next track on Meddle. A G major chord is the first harmonic material presented. The $\mathrm{G}$ major chord is sustained until tonicization occurs melodically in a scale that leads from $B$ to $G(0: 14)$.

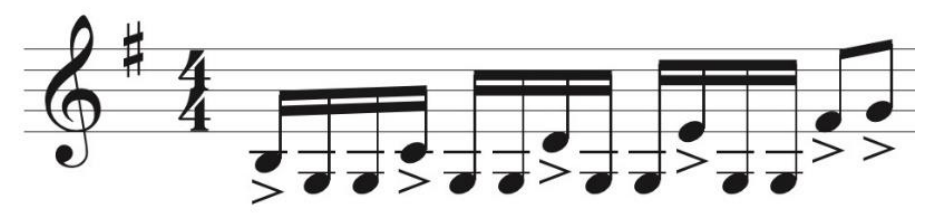

Ex. 3.4 Melodic tonicization of G major in "Fearless"

As seen in Example 3.4, the scale that establishes $\mathrm{G}$ major as tonic is broken up by a $\mathrm{G}$ pedal tone, but the accents on the rising scale from $B$ to $G$ indicate clearly that the purpose of this scale is to clarify $G$ as a true tonal center. While the clarity of $G$ as tonic is undeniable, the melodic idea from Example 3.4 is interrupted by a subdominant chord which moves in parallel motion to a modally borrowed mediant (bIII). This sustains the dialectic between modality and tonality that has been present throughout all of Meddle so far. With the exception of the modally borrowed mediant, "Fearless" is diatonic in its harmonic content and stays within the confines of $\mathrm{G}$ major.

The next track on Meddle is "San Tropez." It is also in G major. "San Tropez" has the distinction of being the first song in Meddle that begins with an overtly stated dominant to tonic tonicization. The first chord $(0: 00)$ is a $D$ major chord which is then immediately revealed to be a dominant seventh chord which resolves tonally to $G$ major. The track presents two sections of material that alternate with each other, sometimes 
with a vocal melody and other times with instrumental improvisation. The "A" section presents a tonic triad that is broken up by a common-tone diminished seventh chord. The "B" section presents a chord progression (V/IV-V/V-IV-V) the purpose of which is to tonicize $\mathrm{G}$ major. The $\mathrm{B}$ section can also be interpreted as a subdominant-dominant progression in D major, and then a subdominant-dominant progression in $\mathrm{G}$ major.

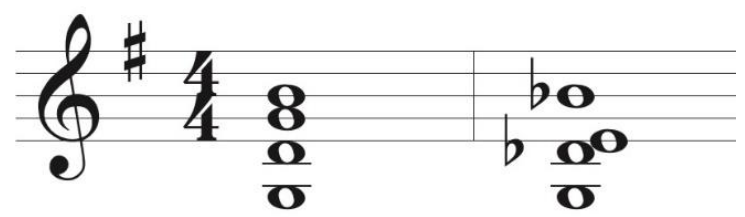

\section{Ex. 3.5 Common-tone diminished seventh chord progression in "San Tropez"}

"San Tropez" furthers the dialectic occurring between modality and tonality in a somewhat conventional way-the common-tone diminished seventh chord from the A section of the song references the modal variation of $\mathrm{G}$ major. However, the strong tonality of this song suggests a slight move away from modality as a concept equal to that of tonality.

"Seamus" is the next track on Meddle and the final track on side 1 of the album. The song is a conventional twelve-bar blues in D major. The significance of the blues in a dialectic between modality and tonality is that the form (and genre) typifies both. From chord to chord, modes such as Mixolydian and pentatonic blues scales are common. These incorporate a series of notes that change and can even be microtonal in their presentation (i.e. "blue notes"). On a global level, however, the blues (and especially a traditional 12 bar blues form) is an extended tonicization. The alternation between I and IV increases the level of dissonance until the maximal level of dissonance is achieved at 
the arrival of the dominant, which is then promptly followed by a resolution to tonic. This progression (I-IV-I-IV-I-V-(ii)-V-I in "Seamus") is a clear statement of a tonic-dominant axis and is a global expression of tonality in its purest form (while remaining modally inflected at the local level).

Side 2 of Meddle presents only one track, "Echoes." Much of this song is neither tonal nor modal, and is instead a series of psychedelically inflected sound effects. However, the beginning and ending of the song present tertian-based harmonies that satisfactorily conclude the long-form harmonic design of the album. The first note presented in "Echoes" is a B. This B is sounded by a high, plucked string instrument and repeated several times. This intentional ambiguity does not give enough information to determine the context of the note. A synthesizer sound fades in below the cascading pizzicato-like notes in a technique that sounds almost as though it was borrowed directly from a spectral score. At 1:10, an F\# minor triad is presented which quickly resolves to a $\mathrm{C \#}$ minor chord. The nature of these chords appears to be modal as there is no true tonicization. If it were tonal, the dominant-tonic axis could be centered around either C\# or F\#.

An A\# minor chord begins a chromatic descending bass-line (1:56) which ultimately leads to the tonicization of $\mathrm{C \#}$ minor as tonic. In context of the entire album, this is one of the clearest examples of a conventional tonicization yet, especially given the presence of a cadential $6 / 4$ chord. 


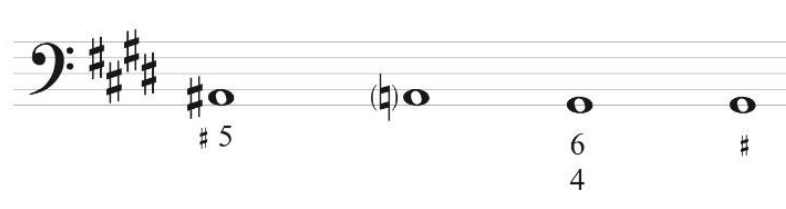

Ex. 3.6 Tonicizing progression in "Echoes"

The significance of this tonicization is that it is heard multiple times throughout "Echoes" and is one of the last things heard on the entire album of Meddle. This progression makes it clear that the ongoing dialectic between modality and tonality is still active and attempts to offer some sort of conclusion.
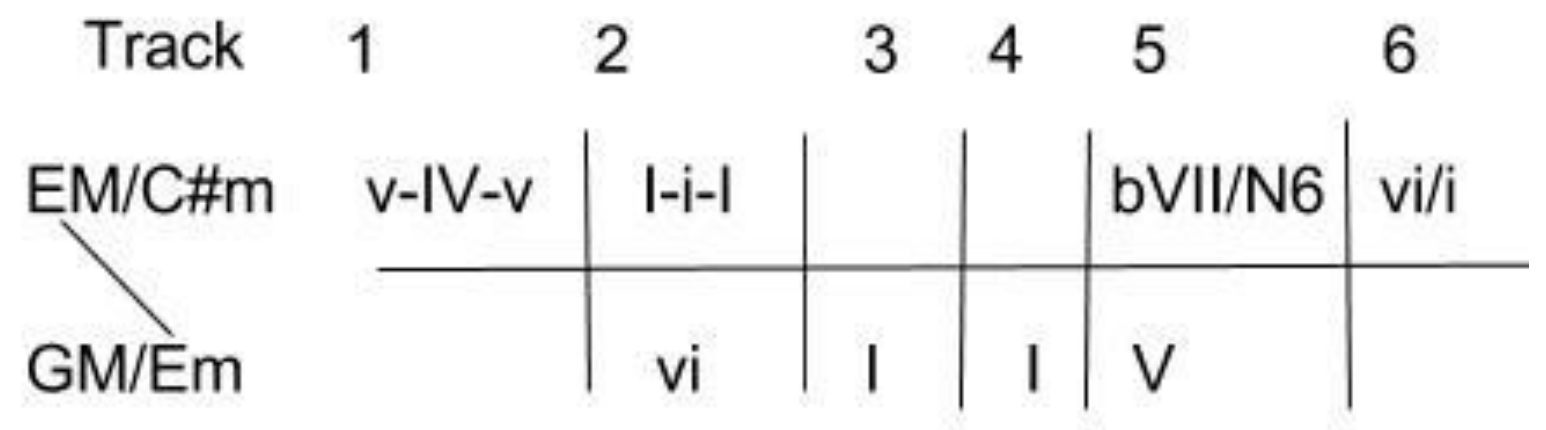

Ex. 3.7 Harmonic design of Meddle

The diagram in Example 3.7 shows how the analysis of each individual song fits together to form a long-form harmonic dialectic. Every song on Meddle can be seen as operating in either $\mathrm{E}$ major/C\# minor or $\mathrm{G}$ major/E minor. The different tonal areas are not so thoroughly integrated that a double tonic complex label is necessary, but the concept is similar. When all tracks are viewed not as individual songs, but as pieces of a 
larger work that form a single argument, the movement between the two diatonic areas is clear.

Track 1 tonicizes the arrival at $\mathrm{E}$ major in track 2. Within track 2 , there is an internal conflict between $\mathrm{E}$ major and minor. The bridge to $\mathrm{E}$ minor presented in track 2 is expanded in tracks 3 and 4 as it leads to $G$ major. Track 5 presents a key area that could be seen as a dominant before a final resolution to $\mathrm{G}$ major, but ultimately can be reinterpreted as an extended Neapolitan predominant substitution that is preparing the last tonicization in C\# minor in track 6.

This large-scale harmonic design that presents a conflict between two distinctly tonal areas, as well as the localized conflicts between modality and tonality are operating simultaneously. This gives a depth to the dialectic that is often reserved for long-form works of art-music. Whether or not these layers of harmonic argument were intentional is not relevant. What is relevant is that the uncovering of these factors influences the way in which this album can be perceived and the way in which the internal continuity can be processed. As later albums are discussed, the ideas presented in the analysis of Meddle will continue to become more crystalline, clear, and perhaps most importantly, necessary to understand each album as a whole. 


\section{Chapter 4}

\section{The Dark Side of the Moon (1973)}

The Dark Side of the Moon presents a harmonic design that is both typical of the art music tradition and the popular music tradition. On the global level-meaning the entire album — the harmonic layout presents a functional tonality that is based upon a traditional dominant tonic axis. If each individual song is analyzed though, the harmonic design is often modal. This presents an interesting case in which localized modality contributes to overall tonality.

The sense of conflict that drives the album (from the harmonic perspective) is the dichotomous juxtaposition of two contrasting ideas-tonality and modality-that undergo development in the same way that classical tonality juxtaposes contrasting themes or tonal areas as a means of generating conflict, and therefore, interest in the listener. ${ }^{36}$

The first step in understanding the harmonic rhetoric that underlies Dark Side of the Moon is to look at a chart detailing the arrangement of the album as a whole.

Dark Side of the Moon is divided into a total of eleven different songs. Each song ends with a transition of some kind into the next (with one notable exception that will be addressed shortly). The transition between each song varies in technique. The transition between "Breathe" and "On the Run" is a cadence that concludes a phrase in the former and begins a phrase in the latter. The transition between "On the Run" and "Time" consists of sounds (from the Musique Concrete idiom) that blend seamlessly

${ }^{36}$ Charles Rosen, "The Coherence of Musical Language." The Classical Style. Norton \& Company. New York. 1972. Pg. 68. 
from the sound of running footsteps to the sounds of clocks ticking. The techniques of transitions between songs, therefore, can be either harmonic or inharmonic in nature. The transitions, on the whole, lead to the sense of one continuous work.

The exception to the continuity on Dark Side of the Moon is the point at which the vinyl version (and tape cassette version) had to be turned over to begin the second side of the album. This division occurs between "Great Gig in the Sky" and "Money."

The first track, "Speak to Me," is a collection of sounds in a sonic collage in the Musique Concrete idiom. The sonic components of this introduction are derived from elsewhere in the album, including sounds of a kick drum emulating a heartbeat, the sounds of a cash register from "Money," isolated vocal tracks from "The Great Gig in the Sky," sound effects from "On the Run," and spoken words like those found in "The Great Gig in the Sky," "Us and Them," and after the final cadence in "Eclipse." The density of the layering and volume increases to a point of maximal tension and a kind of inharmonicity that the ear interprets as highly dissonant. This point of tension (track 1; 1:12) resolves into the beginning of "Breathe." The primary harmonic idiom of "Breathe" is modal.

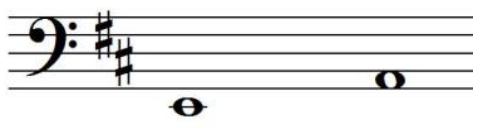

\section{Ex. 4.1 Primary root progression of "Breathe"}

Example 4.1 presents the root progression of the chords during the majority of the song "Breathe." The pitch center is E minor, but it is never tonicized by a dominant. Instead, the E minor chord is juxtaposed with an A major chord. This harmonic idea, while centered on E minor, is modal rather than tonal. The key signature that is 
appropriate for this instance is two sharps (see Ex. 4.1). Because it is presented as centered on E minor, the mode presented throughout the majority of "Breathe" is Dorian.

"Breathe" reaches a final cadence, the final chord of which marks the beginning of "On the Run," the primary focus of which is largely non-pitch-centric. "On the Run" presents a collage of sounds similar to "Speak to Me."

"On the Run" elides with the next song, "Time." The beginning of "Time" presents sounds in the vein of the Musique Concrete style. What appears to be the ticking of several clocks begins at the opening of the song (track 3; beginning) and is quickly followed by a cacophony of a multitude of chiming bells (track $3 ; 0: 18$ ). When this subsides, a single sound, evocative of a single clock ticking, sets the tempo for the rest of the song. This introduction to the song "Time" is a perspective of acute awareness of the way in which time passes, akin to the awareness of the self in time during a psychedelic experience. ${ }^{37}$ Harmonically, "Time" is centered on F\#. The idiom in which this song is presented merits breaking the song into smaller components. The song is comprised of two primary sub-sections that repeat, an A section (first occurrence track $3 ; 2: 28$ ) and a B section (first occurrence track $3 ; 2: 58$ ).

The A-section of "Time" is a modal expression of F\#. It gives the impression of

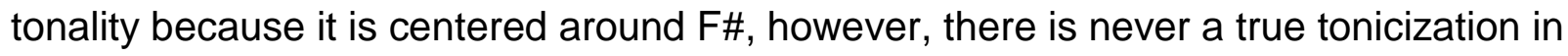
this song. That is to say, there is never a root progression moving from $V-i$ in the key of F\# minor, which, according to the tonal idiom of western art music, is the requirement

${ }^{37}$ Russell Reising, 2009. "Melting Clocks and the Hallways of Always: Time in Psychedelic Music." Popular Music \& Society 32, no. 4: 523-547. Academic Search Complete, EBSCOhost (accessed November 16, 2014). 
for a true tonicization. The mode presented in the A-section of "Time" is Aeolian. It presents the following root progression:

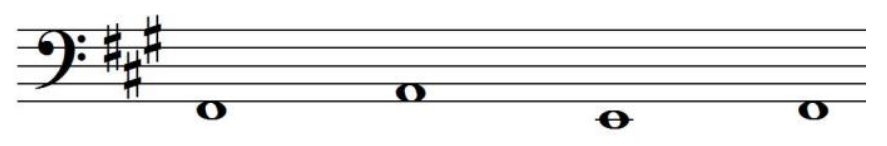

Ex. 4.2 Primary root progression of "Time"

It is pitch centric around F\# but lacks the dominant-tonic relationship necessary for labeling it as tonal.

The reason for separating "Time" into smaller formal divisions is the conflict created by different harmonic idioms between the $A$ and $B$ sections. The $B$ sections present the following root progression:

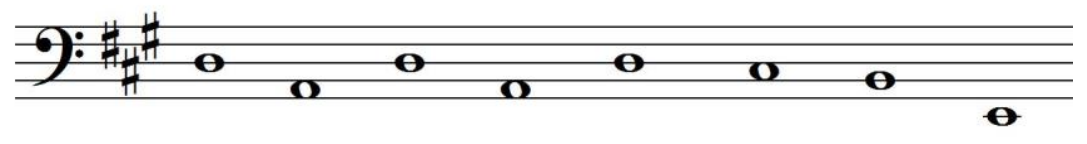

Ex. 4.3 Secondary root progression of "Time"

The first four notes, D-A-D-A, are indicative of a Plagal gesture insinuating, yet not overtly stating, a tonic. This is further reinforced in the last four notes descending from $D$ to $B$, then down a perfect fifth to an $E$. This harmonic motion, especially the final $B-E$, suggests a tonal reference in the relative major key of A major, a half cadence from ii-V. This, however, goes unfulfilled because the $E$ does not resolve as a dominant as the ear may expect, but it resolves back to F\# Aeolian. By the time at which "Time" develops into the reprise of "Breathe" (track $3 ; 5: 54$ ) the basic harmonic conflict has been made evident. The primary harmonic conflict of Dark Side of the Moon is one between tonality and modality. 
At the conclusion of the reprise of "Breathe" the transition to "The Great Gig in the Sky" occurs via a Phrygian motion of a root progression of a C resolving to a B minor harmony by descent of a half step. The initial two chordal ideas of "Great Gig in the Sky" present tertian harmonies in a way that is maximally removed from a traditional tonal hierarchy and modality. A B-minor chord leads to an F-major chord. These two harmonies are as distantly related as possible in tonal harmony: they are qualitative opposites of each other (minor and major) and the roots of each are separated by a symmetrical division of the octave (a tritone).

At 1:07 during "Great Gig in the Sky" (track 4) a repeating harmonic progression between G-minor and C-major begins. This Dorian progression is functionally the same as the primary harmonic progression from "Breathe." It is modal (Dorian) and not tonally functional. The conclusion of "Great Gig in the Sky" marks the end of the first half of the album.

The second half of the album begins with the song "Money." This song begins with inharmonic sounds, most notable the sounds of a mechanical cash register (obviously in reflection of the poetic material of the song). The sounds are presented in rhythm with what is ultimately revealed as the primary pulse of the song. What becomes most interesting about the pulse of the song is that it is metrically organized into an uneven meter. The cycle of repeating strong and weak beats repeats every seven pulses. Harmonically, "Money" is decidedly tonal. The song is centered around B and harmonized in a minor framework. The harmonic motion of the song includes the iteration of a dominant $(\mathrm{F \#})$ which, for the first time in the entire album, truly tonicizes a single note. The metric dissonance here is significant because, even though there is a 
tonal center, there is still a sense of dissonance that stems from the uneven and complex meter. ${ }^{38}$ Even though there is a sense of harmonic resolution, the music, overall, remains dissonant in some way.

The basic form of "Money" can be divided into three sections (see Figure 10). Each A-section is decidedly tonal, but metrically dissonant. At 3:00 (track 5) the metric dissonance is resolved and the meter develops into a regular quadruple meter. However, at the resolution of the metric dissonance in the B-section, the harmony ceases to be truly tonal. The harmony, as indicated by the bass line, becomes modal. The bass line features a Phrygian-colored descent of C-B in the melodic resolution to the central pitch.

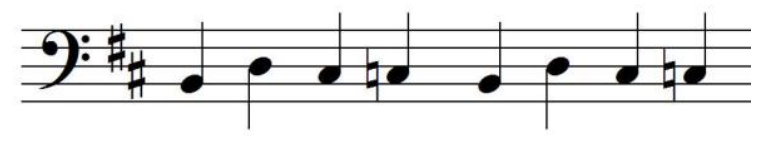

Ex. 4.4 Phrygian-colored bass line of "Money"

Therefore, there is no true resolution of the ongoing conflict between tonality and modality, but "Money" does represent a significant development of this argument in that it is the first occurrence of localized true tonality.

The next song in the album, "Us and Them," develops from "Money" with elements of Musique Concrete. The sounds fade out and are supplanted by stable pitches in the organ. The pitches are ambiguous; the sense of harmony is obscured because of the contrapuntally morphing linear motion of each individual note in the chord. The best estimate of the harmony suggests that it is a G major chord with

\footnotetext{
38 Nicole Biamonte, 2014. "Formal Functions of Metric Dissonance in Rock Music." Music Theory Online 20, no. 2: 119. Academic Search Complete, EBSCOhost (accessed November 16, 2014).
} 
extended harmonies $\left(7^{\text {th }} / 9^{\text {th }} / 13^{\text {th }}\right)$. With the extended harmonies, the chord is essentially a diatonic cluster (with the notable absence of an $11^{\text {th }}$ ) due to the very tight spacing of the extended harmonies. The B in the chord resolves down by a whole step to an $A$ and the cluster resolves to a $D$ major harmony in a Plagal motion, revealing $D$ as the pitch center for the song.

"Us and Them" can be divided into two alternating sections. The A-section is centered around the pitch $\mathrm{D}$ and sounds major, but lacks any clear tonicization with a dominant. The B-section appears to have a tertian relationship with the A-section and is centered around the pitch $\mathrm{B}$. If this were in a traditional tonal setting, this movement along the tertian axis would be indicative of motion from a major key to a relative minor key, however, multiple caveats, detailed below, cause the harmony to fall short of a simple major/minor relation.

A harmonic progression is established with a $D$ held as a pedal tone at the beginning of the A-section. The harmonies that change above the bass note move from $D$ major to $B$ minor to $D$ minor with an added major $7^{\text {th }}$ to $G$ major. To the ear, this sounds evocative of tonality. It does not fit into any of the prescribed diatonic modes as most of the material in the album had prior to this song. The harmonic idiom, therefore, is incomplete as it is presented in the beginning of the song. This is mirrored in the diatonic cluster that is presented in the organ at the beginning of the song. The best way to describe the harmonic content of the A section of "Us and Them" is incomplete tonality. It is extraordinarily referential to conventional tonality and, yet, the lack of a dominant in the motion away from "tonic" impedes the establishment of a true tonal center. The only reason that the A section can be labeled as even remotely tonal is due 
to the melody. The first presentation of the voice at the beginning of a verse is on the fifth scale degree. There is, in this, a subtle juxtaposition between the melody on the A and the pedal tone on the $\mathrm{D}$. It is not as strong as a harmonic relationship but it is enough to give an aural hint at the ultimate resolution of the album.

The B-section presents a root progression that is centered on $\mathrm{B}$. The descending bass line is indicative of minor tonality, save for the lack of a dominant. In a way, this mirrors the harmonic activity in the A-section. There is one crucial difference in the functions of each the A- and B-sections: at the end of the B-section progression, there is a modal inflection.

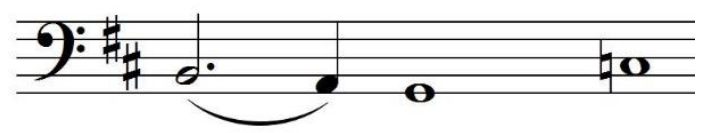

Ex. 4.5 Phrygian inflection in the bass line of "Us and Them"

Example 4.5 displays the root progression of the B-section of "Us and Them." The descending line implies a tonal motion towards a dominant (which would be $\mathrm{F \#} \mathrm{in} \mathrm{this}$ instance). The reality of what occurs at the point the ear is expecting the dominant is an aural shock—what actually occurs is a major triad on C. In a tonal setting, this could function as a Neapolitan harmony, further increasing the level of perceived dissonance leading to the dominant, but, in this instance, it does not. The function of the $\mathrm{C}$ major chord in this instance is modal. The progression shown in Example 4.5 cycles around and reiterates itself, leaving the $\mathrm{C}$ major chord to resolve down by a half step to a $\mathrm{B}$ minor chord-a motion strongly suggestive of the Phrygian mode.

The harmonic argument between tonality and modality in Dark Side of the Moon reaches a point of maximal tension in "Us and Them." The concepts of tonality and 
modality have been obscured by each other and blended together so that the difference between them is obscured by a cloud of modally-tinged tonality and tonally-tinged modality.

"Us and Them" develops directly into the song "Any Colour You Like." The recurring i-IV Dorian progression is presented with $D$ as the center pitch. This song is largely a textural exploration, given the harmony does not change for the duration of the song, or at least until the development into the last set of songs.

"Brain Damage," the penultimate song on Dark Side of the Moon can be divided into two alternating sections. The song presents a central pitch of $D$ at the beginning of the A-section. D major is suggested as a tonal center by insistent repetition. This stagnant harmony changes, however, in a move to the lower fifth, G major. While this does not directly implicate D major as a tonal center, it does mirror the i-IV Dorian progression that has been so prevalent throughout the entire album. The difference here is that both harmonies are major in this instance, whereas in the Dorian iteration of the progression, the central harmony is minor. For the first time in the entire album, true major tonality is established during the latter portion of the A-section (track 8; 1:00 for example) when there is a clear I-V/V-V7-I chord progression. This is the first time a tonic note has been juxtaposed with a harmonically complete dominant.

In the B-section of "Brain Damage," there is a similarly strong tonal progression (track $8 ; 1: 16$ for example). The harmony begins on the subdominant and moves to the dominant. This suggests an impending strong authentic cadence. However, after the move from IV-V, there is a modal turn of phrase from bVII to IV. While this harmonic 
motion is modal in nature, it lends the impression of a temporary tonicization of the subdominant tonal area.

The final song on the album, "Eclipse," develops immediately without a break from "Brain Damage." This final song is decidedly tonal. "Eclipse" presents the only instance in the entire album of a harmonic progressing whose sole purpose is to link tonic to dominant in a progression that leads from consonance to dissonance and repeats.

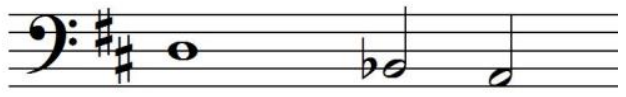

Ex. 4.6

The way the progression in Example 4.6 advances from consonance to maximal dissonance presents a final resolution of the ongoing musical conflict between modality and tonality. This progression is absolutely tonal, however, the middle chord, built on a B flat, carries modal implications. This harmony is a textbook case of modal borrowing. It is in this progression that the resolution between the two opposing ideas is made clear. The way in which the conflict is resolved is in the tonal application of modal mixture: the B flat chord is a modally borrowed chord but it exists for the purpose of contributing to the sense of tonal hierarchy. Its sole purpose, in terms of its immediate harmony, is to lead to the dominant. This represents the absolute integration of two ideas that had been, for the duration of the album, diametrically opposed.

Now that the album has been covered in terms of the progression of local harmonies, they can be put in the context of the entire album. "Breathe" immediately, in retrospect, sets up D major as tonic. This occurs by the reinterpretation of the Dorian i- 
IV progression as a ii-V progression in a major key. The reinterpreted Dorian i-IV progression sets up the expectation of an eventual resolution to D major. This chord progression is not truly fulfilled (with full tonicization of $D$ major) until the final two songs. In the time between "Breathe" and "Brain Damage"/"Eclipse," the analysis has shown an ongoing struggle between modality and tonality. The general tendency was for modality in the beginning eventually giving way to tonality by the end. The local modality that was so prevalent was actually functioning tonally on the largest level—the instances of modality were, for the most part, functioning in D major the entire time. Because, of course, a diatonic mode is simply a rotation of a diatonic set, each song that was modal can be viewed retrospectively in light of the tonal design of the album as a whole.

The global harmonic design in the first half of the album moves to the upper third (in "Time") and then the lower third (at the beginning and end of "The Great Gig in the Sky"). The conclusion of the first half of the album and beginning of the second half of the album shows a tonal motion of $\mathrm{V}-\mathrm{I}$ in the relative minor key of $\mathrm{B}$ minor. The second half of the album, after it moves away from B minor, moves directly back to the overall tonic in "Us and Them." The end of the album does not occur at this point because "Us and Them" is equal parts D major and B minor, almost reminiscent of the double tonic complex first presented by Wagner in Tristan und Isolde. In the global harmonic scheme, "Us and Them" is the point of maximal conflict between the anticipation of D major (from the modality of "Breathe") and the large-scale outline of the B minor triad (occurring in "Time" [F sharp], "Money" [B], and "Us and Them" [D]). 
"Any Colour You Like" is a deceptive resolution. The overall expectation is a strong cadence in D major. "Any Colour You Like" cadences strongly from the end of "Us and Them" on D as a central pitch, but it is modal, not tonal.

The final resolution occurs in "Brain Damage" when there is finally a strong cadence in D major. This represents the large-scale harmonic design coming to fruition as the promissory chords from "Breathe" are finally fulfilled. The i-IV from "Breathe" that was retrospectively recast as ii- $\mathrm{V}$ finally resolves to I ( $\mathrm{D}$ major). "Eclipse" is functionally a coda. Tonic has already been established in "Brain Damage" but the aforementioned modally borrowed progression (example 4.6) was still needed to bring to a close the small scale conflicts occurring on the local levels.

\begin{tabular}{|c|c|c|c|c|c|c|c|c|c|}
\hline Track & 2 & 3 & 4 & 5 & 6 & 7 & 8 & 9 & 10 \\
\hline Primary Pitch Center None & Em (modal) & Em (modal) & F\#m (modal) & Gm (modal) & | Bm (modal/blues) & DM & Dm (modal) & DM & DM (with modal borrowing) \\
\hline Secondary Pitch Center & & & AM & & & Bm (modal) & & & \\
\hline
\end{tabular}

Ex. 4.7 Harmonic design of The Dark Side of the Moon 


\section{Chapter 5}

\section{Wish You Were Here (1975)}

Wish You Were Here begins with a long track titled "Shine on You Crazy Diamond (parts 1-5)." The total play-time of this song is 13:31. The song begins with the presentation of a long $\mathrm{G}$ minor chord drone. This $\mathrm{G}$ minor chord retains a strong element of ambiguity because, at the beginning, there is little context in which it is placed. This means that, while $G$ is apparent as a pitch center, it is not clear whether it is modal or tonal, or whether it fits into any other harmonic framework. At 0:45, a loose and improvisational melody presented by the synthesizer suggests that, harmonically, the $\mathrm{G}$ minor chord is a modal center because the pitch content of the melody fits within a $\mathrm{G}$ minor blues scale. The harmony in the background continues unchanged when a solo guitar trades the synthesizer for the lead melody (2:09). The guitar melody presents pitch content that is congruent with the pitch content of the melodic material previously presented by the synthesizer. Shortly after the entrance of the solo guitar, the background chord changes to $\mathrm{D}$ minor (2:23). While this chord represents a harmonic shift to the upper fifth (if $\mathrm{G}$ minor is assumed the pitch center for the song) it does not provide a leading tone that is necessary for true tonicization. Therefore, the movement from $G$ minor to $D$ minor suggests an Aeolian modality rather than a $G$ minor tonality.

At 2:33, the chord changes from $\mathrm{D}$ minor to $\mathrm{C}$ minor. With this motion, an axis around G consisting of an upper fifth and a lower fifth is completed, lacking still, however, the true tonicization of an $\mathrm{F \#} \mathrm{(as} \mathrm{a} \mathrm{leading} \mathrm{tone).} \mathrm{This} \mathrm{chord} \mathrm{progression} \mathrm{(} \mathrm{v}-\mathrm{iv}-\mathrm{i}$ in G Aeolian) is repeated over the course of the following minute. There is no sense of 
ambiguity by the time this section comes to a close (3:50). It is clear that the modal center is $\mathrm{G}$.

At 3:53, an electric guitar presents new melodic material that changes the modal implications from Aeolian to Dorian. The pitch content of this melody is Bb-F-G-E. The inclusion of $E$ natural in this melody keeps the sense of modality, further concretizing the pitch center as a modal one, rather than tonal. The Dorian shift is confirmed when the overall harmony moves from i-IV (4:30) and cadences on G minor via the subtonic $(4: 38)$.

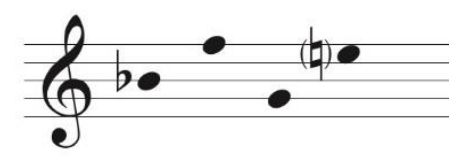

Ex. 5.1 Pitch content of motive presented at 3:53 in "Shine on You Crazy Diamond (parts 1-5)" suggestive of the Dorian mode

Until the next entry of the electric guitar as the lead melodic instrument, Shine on You Crazy Diamond (parts 1-5)" remains decidedly modal, changing gradually from G Aeolian to G Dorian. This changes, however, at 6:05 when there is a Perfect Authentic Cadence in the key of $\mathrm{G}$ minor. This is the first time during the entire album that there has been any true tonicization, representing a shift from a modally oriented harmonic framework to a tonal hierarchy. A series of Perfect Authentic Cadences follows over the course of the next two minutes (notably at 6:26, 7:32, and leading into the next section at 8:41).

The next section presents the first vocal melody of the album. The shift from modality to tonality is retained and expanded to include a brief shift from $\mathrm{G}$ minor to $\mathrm{Bb}$ 
major. This includes a Gb major chord that serves a predominant function in $\mathrm{Bb}$ major and a common-tone chord in $\mathrm{G}$ minor (Bb, the third, acts as a pivot between $\mathrm{i}-\mathrm{bVI} / \mathrm{III})$.

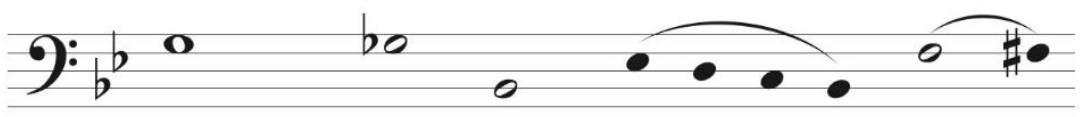

Ex. 5.2 Root progression suggesting Bb major in "Shine on You Crazy Diamond (parts1-5)"

The descending bass line this section is characteristic of conventional minor tonality, as is the open chord progression ending on a leading tone diminished seventh chord (which resolves to a reiteration of the same progression).

"Shine on You Crazy Diamond (parts 1-5)" stays in G minor for duration of the part that is defined by a vocal melody. At 11:08, at the entrance of a saxophone as the lead melodic instrument, the harmonic framework reverts back to modality (Dorian) until the conclusion of the track at which point there is a final Perfect Authentic Cadence in the key of G minor.

The next track on Wish You Were Here is "Welcome to the Machine." The first harmonic material presented in this song is an E minor chord that, similarly to the initial presentation of harmonic material in the first track on the album, is not immediately given any context. The chord progression beginning at the entrance of the vocal melody (1:03) is the first event in this track that gives any harmonic context. There is a change from i-VI-i. This harmonic motion does not immediately confirm whether it is modal or tonal, but it does suggest modality in the absence of either the upper or lower fifths. The tertian relationship between the two chords does not conventionally tonicize $\mathrm{E}$ minor. 
This ambiguity is sustained for the entire song. The only true harmonic changes for the duration of "Welcome to the Machine" are those from i-VI-i.

The following song, "Have a Cigar," also centers around E minor and, at the beginning of the track, is similar to "Welcome to the Machine" in its ambiguity. At 0:25, with the help of a melodic line in the guitar and synthesizer, there is harmonic motion to $\mathrm{VI}$ and back to i. Despite the seeming similarity to the previous song, the sense of modality is reinforced in the harmonic progression that accompanies the first presentation of a vocal melody (i-VI-VII-i). The scalar motion of $\mathrm{VI}$ ascending to $\mathrm{i}$ reinforces e minor as the modal (Aeolian) center.

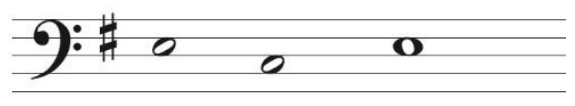

Ex. 5.3 Root progression showing tertian relationship in "Welcome to the Machine" The next song is the title track "Wish You Were Here." Another E minor chord is the first harmonic material presented in this song. In contrast to the past two tracks, there is immediately a harmonic change to the upper third, G major. This is a direct contrast between this song and the previous two songs and is immediately noticeable as a change in the harmonic direction. After several oscillations between $\mathrm{E}$ minor and $\mathrm{G}$ major, the G major chord is supplanted with an A major chord. This substitution is suggestive of $E$ as a modal center (Dorian). However, it becomes clear shortly thereafter that this A major chord did not have any long-lasting modal effects, as the harmonic progression eventually resolves to $G$ major.

The point at which the vocal melody begins presents a harmonic motion from $\mathrm{G}$ to the lower fifth of $\mathrm{C}$. This is the first reference to any tonally oriented fifth relationship 
since the end of "Shine on You Crazy Diamond (parts 1-5)." The harmonic progression that follows clearly and undeniably tonicizes $\mathrm{G}$ major.

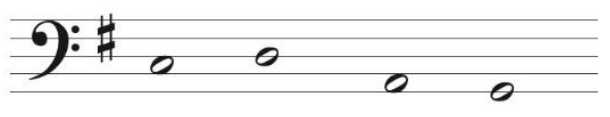

Ex. 5.4 Tonicizing harmonic progression in "Wish You Were Here"

The progression of IV-V-ii-I confirms $\mathrm{G}$ major as tonic. The motion from V-ii may be viewed as a retrogression which can be uncharacteristic of conventional tonality, but it can also be viewed as a dominant substitution. While it is true that the supertonic triad does not contain a leading tone, because it follows the dominant (containing a clear statement of a leading tone) it can be seen as a dominant substitution presenting the melodic cadences of re-do and fa-mi. This cadence, therefore, still fulfills the requisite function of a dominant resolving to tonic. The rest of "Wish You Were Here" presents a sectional form in which the two harmonic concepts discussed ( $E$ as a potential modal center, resolving to $\mathrm{G}$ as a tonal center) alternate until the end of the track.

The last track on the album Wish You Were Here is the completion of the first track on the album, titled this time "Shine on You Crazy Diamond (parts 6-9)." The harmonic content is almost identical to the first track and does therefore not need very much more discussion. One key difference, however, is the time it takes for the distinction between $G$ as a modal center and $G$ as a tonal center. The reprisal of "Shine on You Crazy Diamond" establishes G minor as a tonal center at 2:08 through a Perfect Authentic Cadence (VI-V-i). This contrasts with the first track on the album that took nearly six minutes to tonicize $G$ minor. The early confirmation of $G$ minor as a tonal 
center is congruent with the end of the song (and end of the album) at which point there is a Perfect Authentic Cadence resolving to $G$ major.

\begin{tabular}{l|l|l|l|l|l}
1 & 2 & 3 \\
$\mathrm{Gm} /$ modal & & & & $\mathrm{GM}$ & $\mathrm{Gm} /$ Modal--------> $\mathrm{GM}$ \\
\hline & $\mathrm{Em}$ & $\mathrm{Em}$ & $(\mathrm{Em})$ & &
\end{tabular}

Ex. 5.5 Harmonic organization of Wish You Were Here

The overall harmonic design of the album Wish You Were Here is an exploration of different expressions of $\mathrm{G}$. The beginning of the album in track 1 presents an ambiguous pitch center of $\mathrm{G}$ that moves back and forth between modality and tonality. The dialectic that is established between different expressions of $G$ as a center of some kind is continued in tracks 2,3 , and the beginning of 4 . Those tracks are centered around $\mathrm{E}$ as a modal center (still with a minor third). This is a continued exploration of $\mathrm{G}$ as a center because of the association between $\mathrm{E}$ minor (tonicized or not) and $\mathrm{G}$ major as relative tonal areas.

The first track does not allude to $G$ major as a tonal center, only $G$ minor and $G$ Aeolian/Dorian. Therefore, the closeness to G major in "Welcome to the Machine" and "Have a Cigar" is left as a tangential reference to the overall dialectic until the title track of the album (track 4, "Wish You Were Here"). At this point, the conflict between 
different expressions of $G$ is brought into the foreground as the song is definitively in the key of $\mathrm{G}$ major. This is important because all other songs so far have either been ambiguous in their tonality/modality or they have shied away from making an obvious statement (such as in "Shine on You Crazy Diamond" which alternates between two distinct expressions of $G$ as a pitch center).

The final track on the album resolves the conflict between the three expressions of $\mathrm{G}$. While the harmonic content is almost identical to that of the first track, the song (and therefore the album as well) is closed with a Perfect Authentic Cadence in the key of $\mathrm{G}$ major. This also serves as a definitive conclusion to the title track and gives insight regarding the function of such an important track existing in a key that was not directly stated until after the beginning of the song (the beginning of "Wish You Were Here"). 


\section{Chapter 6}

\section{The Wall (1979)}

The final album to be covered in this discussion of long-form harmonic design is Pink Floyd's 1979 release The Wall. This album is a double album, and therefore is more complex and nuanced than the preceding three albums that have been examined so far. The cohesion of The Wall does not rely solely on a clear harmonic argument, but also on recurring motivic ideas, as well as a very concrete and linear story (as a Rock Opera). The reliance on a long-form harmonic dialectic is, therefore, not as singularly critical as it was in the previous three albums that have been covered in this chapter.

The beginning of The Wall, "In the Flesh," presents a barely audible instrumental melody and accompaniment which is then disrupted by a loud E minor chord. A melodic line rises from $E$ in a scale up to $G$, and then returns to $E$ while $E$ remains in the bass as a pedal point. This introductory material never tonicizes $E$ minor, instead moving to an $A$ major chord (0:55). At the arrival of the A major chord, another melody (voiced by the guitar) clearly tonicizes A major. This melodic tonicization is clear because there is a prevalent leading tone. In addition to the melodic tonicization, there is a clear Perfect Authentic Cadence (1:31) that confirms A major as a true tonal center. In the first minute and a half of The Wall, there is already a harmonic dialectic that is congruent with the technique that was clear in the past three albums covered in this discussion. The $\mathrm{E}$ minor-ish material that

is modal, followed by the A major material that is tonal (as seen in ex. 6.1).

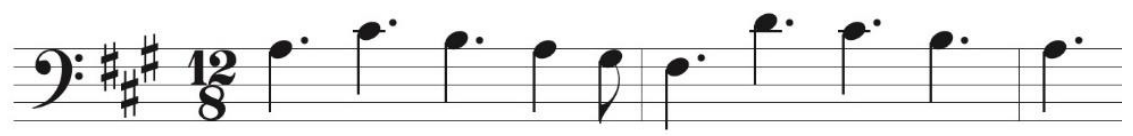




\section{Ex. 6.1 Melody from "In the Flesh?" (0:54)}

The next song on the album, "The Thin Ice," begins in C major. The tonality is established by a harmonic progression in descending thirds that ultimately resolves to the dominant (I-vi-IV-V). This progression repeats several times throughout the course of the track and resolves to either $\mathrm{C}$ major or an unconfirmed $\mathrm{A}$ minor. The instances in which it resolves to $A$ as a pitch center reinforce the tonal versus modal argumentwhen the chord progression described above, a very harmonically teleological progression, resolves deceptively to $A$, the pitch center shifts to $A$ minor, but a modal form of A minor that is referential to the first part of the first track on the album.

The next track, "Another Brick in the Wall, Pt. 1" presents D as a pitch center. It is suggestive of $D$ minor but is never confirmed with a dominant. A G major chord in this context confirms that it is not D minor, but a Dorian expression of D. "Another Brick in the Wall, Pt. 1" presents a motivic idea that recurs throughout the entire album. In the context of this song, the motive begins on the pitch center and rises in stepwise motion to a third above and then descends. This melodic content presents itself multiple times throughout the album at various points and in various forms and iterations.

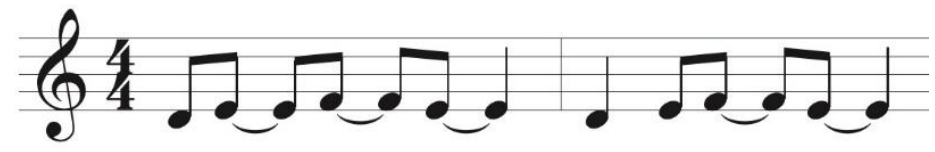

Ex. 6.2 The "Wall" motive as presented in "Another Brick in the Wall, Pt. 1"

"Another Brick in the Wall, Pt. 1" leads seamlessly into "The Happiest Days of our Lives." This track still presents D as a pitch center and almost establishes D minor as tonic with a iv-v-i harmonic progression, but still lacks the requisite leading tone to fully confirm $\mathrm{D}$ as a tonal center, rather than a modal center. Soon thereafter, a prominent 
cadence in $\mathrm{F}$ major (1:33) shifts the pitch center to the upper third, a movement characteristic of a true minor tonal center. A sustained dominant in $\mathrm{F}$ major leads to the beginning of the next track ("Another Brick in the Wall, Pt. 2") in which a deceptive resolution presents, again, D as the pitch center (decidedly Dorian).

"Mother" is the next track. A stripped-down texture highlights the simple G major tonality (confirmed at $0: 46$ by a Perfect Authentic Cadence). This entire song stays firmly tonal. At 2:00 there is a modulation to the lower fifth, $\mathrm{C}$ major, that ultimately serves as a prolonged predominant resolving to $\mathrm{D}$ major as a dominant (2:30). The song ends in a movement from tonic to the lower fifth in what sounds almost like a Perfect Cadence in the secondary tonal area of $\mathrm{C}$ major. However, this plagal motion serves only to keep the final resolution from sounding too final and absolute.

"Goodbye Blue Sky," the next song on the album, presents D major as the first harmony. D major is juxtaposed immediately with an A minor chord. This furthers the ongoing dialectic between modality and tonality because the minor quality of the A triad combined with the root relation of a fifth between the two harmonies creates a cognitive dissonance in which, on one hand, there is a functional dominant (reinforced by the leading tone presented as a chromatic passing tone) while simultaneously referencing a Mixolydian expression of $\mathrm{D}$. the obfuscation of a true tonal center is furthered when the center of pitch moves to the lower third, B minor, suggesting a relative relationship between $\mathrm{D}$ major and $\mathrm{B}$ minor.

"Empty Spaces" presents several different versions of the "Wall" motive. The first melodic material is presented by a barely-audible electric guitar and is the "Wall" motive in its original form of a minor third filled in with stepwise motion ascending and 
descending. The relationship of this melodic material to the melodic ideas presented in earlier tracks is confirmed by the restatement of the motive in the vocal melody (1:28). All iterations of the "Wall" motive in this track are augmentations of the original motive presented in "Another Brick..."

"Empty Spaces" leads directly into "Young Lust." Both songs are centered around an E minor triad and "Young Lust" is modal, presenting a double-plagal chord progression that is built on a blues-like scale. Because the aesthetic of this song is blues-oriented, the variable pitches (blue notes) mean that the specific modal expression of $E$ as a pitch center is variable. There are references to both the Dorian mode (i-IV at 0:30) and the Mixolydian mode (bVII-IV at 0:56).

The first melodic material in "Young Lust" is an inverted presentation of the "Wall" motive. The motive still spans the interval of a minor third, but the starting pitch is the upper third rather than the pitch center.

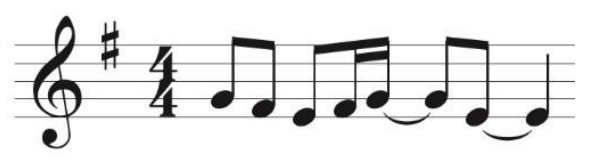

\section{Ex. 6.3 The "Wall" motive presented in inversion in "Young Lust"}

The next song, "One of My Turns," begins with a diatonic cluster presented by a keyboard instrument. Eventually, the cluster becomes clearer in its harmonic arrangement and becomes something closely resembling an $\mathrm{F}$ major chord. When the voice enters, there is a plagal resolution to $\mathrm{C}$ major. A progression from tonic to mediant to subdominant to dominant follows. This adds to the argument between the concepts of modality and tonality because of the emphasis on the mediant. The mediant is often considered a chord that is modally ambiguous, sounding more like it belongs to the 
relative minor in a major key because of its perfect fifth relationship. However, the mediant here does not function as a link between two related key areas, but as a passing chord that links tonic and subdominant. The second part of this song (2:02) presents a pitch center of $\mathrm{D}$ minor. However, the first chord in this section is an Eb major chord. This is a Phrygian expression of $D$. While it could be rationalized as a Neapolitan substitute for a predominant in D minor, the bll never resolves to a true dominant. At most, there is a brief reference to the tangentially related tonal area of $\mathrm{Bb}$ major, but the pitch center of $D$ is always reinforced at the ends of phrases.

"Don't Leave Me Now," the following song, begins with the most harmonically ambiguous content yet. The keyboard presents a sustained augmented chord while melodically, notes move in and out of whole-tone patterns. The voice enters with a melody that is suggestive of $\mathrm{Db}$ major, which furthers the harmonic ambiguity. This vocal melody, even though it contributes to the sense of harmonic instability, is another instance of the "Wall" motive. The melodic contour of the motive is preserved but the exact intervals are altered. The original "Wall" motive presented a minor third as the prominent outlining interval and a syncopated rhythm. This new statement outlines a major third and is rhythmically consistent with the meter (not syncopated). Eventually, the voice and the keyboard converge on $\mathrm{G}$ major (2:55). The next material presented moves harmonically between $\mathrm{D}$ minor and A minor. This suggests a modal expression of $A$ (Aeolian). This is reinforced and confirmed with a harmonic cadence that progresses from VI-VII-i with A as a modal center.

The third iteration of "Another Brick in the Wall" follows. It is, again, presented in a Dorian expression of $\mathrm{D}$, and the primary melodic content is the "Wall" motive in its first 
identifiable form. The final cadence of III-VII-i elides with the beginning of "Goodbye Cruel World." "Goodbye Cruel World" is in D major and is tonicized by a harmonic progression of I-IV-I-V-I. This is the last track on the first half of the album.

At this point in the discussion, it is useful to step back and look at the dialectic that is developing. Musically, the first half of The Wall contains a well-developed dialectic that is self-contained within the first half.

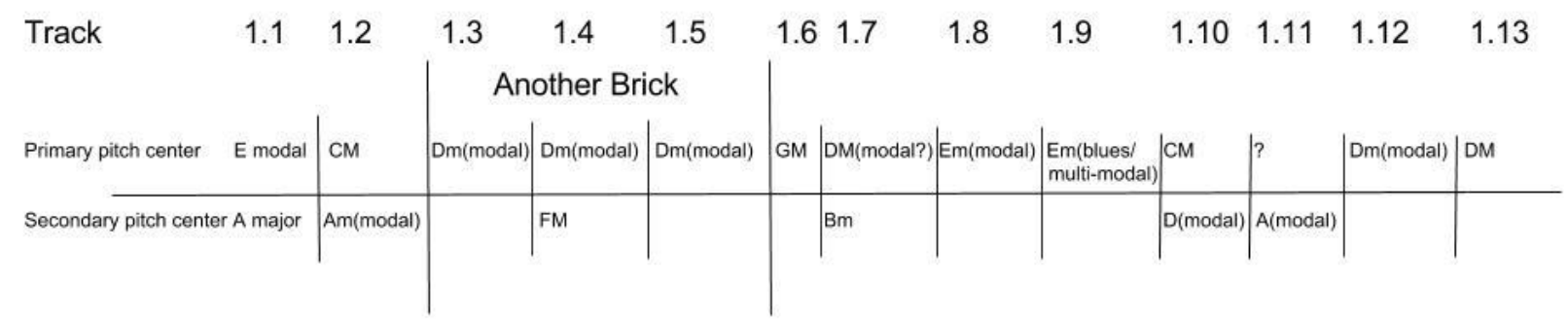

Ex. 6.4 Harmonic design of The Wall, first half

The prominence of the dialectic between modality and tonality as well as the simultaneous presentation of multiple pitch centers in individual songs creates a new harmonic dimension that was not apparent in the first three albums covered in this discussion. The overall conflicting elements join to give the impression that the overall argument is dealing with different expressions of $D$ as a pitch center. The primary and secondary pitch centers of track 1.1, similarly to The Dark Side of the Moon, seem to set up E minor as a modal predominant, A major as a long-range dominant, and then proceeds to observe different possible outcomes. Tracks 1.3-1.5 are a Dorian expression of $D$, track 1.7 is a major expression of $D$, but is interrupted by an equally important presentation of its relative minor (a precedent set by the dual presentation of C major and a modal A minor in track 1.2), tracks 1.8-1.9 are primarily a Dorian expression of $E$, which references the primary pitch center of track 1.1 and still recalls a 
modal extension of a predominant, track 1.11 is a Phrygian expression of $D$, and ultimately, 1.13 is the truest resolution yet-D major. This phenomenon may best be described as a poly-modality complex-a situation in which a central pitch is expressed in multiple modal forms that are all presented with equal importance.

The second half of The Wall begins with "Hey You." The first harmonic material presented in this song is an arpeggiated $\mathrm{E}$ minor chord. This $\mathrm{E}$ minor chord alternates with a D minor chord. This suggests a Phrygian expression of E, in that there is an emphasis on the melodic motion from E-F-E in the harmonic progression. When the voice enters with an augmented and ornamented statement of the "Wall" motive (0:33), E remains the pitch center, but is followed by a B minor chord. This is a shift of emphasis to the upper fifth but does not achieve tonicization because the $\mathrm{B}$ triad is minor and lacks the necessary leading tone to $\mathrm{E}$. The guitar solo presented at 2:00 is accompanied by motion from the pitch center (still E) to the lower fifth: A minor. This completes an Aeolian expression of E. At the conclusion of the guitar solo (2:55) there is a shift from $E$ as a modal center to $G$ as a major tonal center. This is confirmed by a chord progression of IV-V-I-V-IV. This presents $\mathrm{G}$ major as tonic in the middle of the closed progression. This acts as a continuation from the first half of The Wall of the presentation of secondary pitch centers that are frequently relative to the primary pitch centers.

The next song, "Is There Anybody Out There," presents A as a modal pitch center. Although a short track, this is reinforced by a low drone on the pitch $A$. The next track, "Nobody Home," picks up A minor as what appears to be a tonal center. Over an A minor triad, a chromatic line descends from A to G\# (giving the impression of a 
tonicization of $A$ ) but continues from $G \#$ to $G$ to $F \#$ to $F$. This ultimately leads to an arrival at $\mathrm{C}$ major as a tonal center. At the entrance of the vocal melody, the piano presents a chord progression that moves from I-V/vi-IV-iv-I. The tertian motion of the harmony from tonic to V/vi recalls the beginning of the track in A minor, but shows that ultimately the purpose of the leading tone to A was in the service of a tonal hierarchy built around C. This is confirmed when the subdominant is replaced by a modally borrowed substitution in which the third is lowered-this downward-leading leading tone $(\mathrm{Ab})$ is both a reexamination of the secondary dominant that resolved deceptively (the $\mathrm{V} / \mathrm{vi}$ ) and an explanation of the descending chromatic melody that begins the song.

"Vera," the next track, operates simultaneously in G major and a modal expression of $E$ (Aeolian). The chord progression begins on $G$ as a suggested tonic, and moves from tonic to predominant to dominant but resolves deceptively. This presents a tonal hierarchy around G, including both the upper and lower fifths, but because of the harmonic rhythm, points equally to $E$ as a modal center. "Vera" elides with the next track titled "Bring the Boys Back Home." The significance of this is that the conflict between the two pitch centers in "Vera" is amplified in the next track because the entirety of the song is a series of two cadences: the first cadences are Perfect Authentic Cadences in the key of $\mathrm{G}$ major that are prepared by a subdominant. The last cadence, however, is a Deceptive Cadence in the key of $G$ which gives the two pitch centers ( $G$ Major and a modal expression of $E$ ) equal importance. The arrival at an $E$ minor chord is the last harmonic content of the song (other than an extremely short sound sample from "Is There Anybody Out There" that acts as a transition to the next song). 
"Comfortably Numb" follows with an immediate presentation of a modal expression of $B$ minor that features a diatonic descending bass line. There is, however, no formal confirmation of B minor via a dominant. Each of the first two phrases cadences with a minor plagal progression. A shift to the upper third occurs at 0:52 at which point there is a tonicization of $D$ major through repeated alternations between $D$ major and A major as tonic and dominant. This progression is followed by a modally borrowed subtonic chord resolving to a subdominant chord in a double-plagal motion. This double-plagal progression obscures the expression of $D$ as a tonal center when (at 1:53) the two previous harmonic progressions undergo a process of synthesis into one harmonic progression in which the dissonance of the dominant is diffused by an unexpected pseudo-resolution to subtonic and then subdominant. The rest of the "Comfortably Numb" is a sectional presentation of alternating instances of B as a modal pitch center and D as an obfuscated pseudo-tonic.

"Comfortably Numb" is followed by "The Show Must Go On." A G major harmony alternates with a $\mathrm{C}$ major harmony at the beginning of the song. This serves to imply $\mathrm{G}$ major as a tonal center but does not yet go so far as to confirm $\mathrm{G}$ major as a true tonic via the presentation of a dominant. Eventually, there is an arrival at $D$ major which sounds like a dominant but resolves in a retrogressive progression from V-IV-I. The final cadence presented in the song is a Plagal Cadence.

A reprisal of the first song on The Wall follows. Harmonically, the content of this iteration of "In the Flesh" is functionally identical to the first one. This restatement of "In the Flesh" presents a modal expression of E as the primary pitch center and then A major as the secondary pitch center. Upon second hearing of this song, because of the 
prominence of the "Wall" motive throughout the album so far, it is clear that the melody presented in the electric guitar (at the very beginning of the track) is something of a preparation of this motive in which both the major form of the motive and the minor form of the motive overlap. This song, much like its first iteration on the first half of the album, leads into the following track in an elision. The pitch content of "Run Like Hell" begins similarly to "Another Brick in the Wall" but at 0:22, a series of chords presented in the guitar give a $\mathrm{D}$ major context to the pitch content at the beginning of the song (via a I-VIV-I retrogression). When the voice melody enters, there is a harmonic shift up a whole step to a pitch center of $E$, which, still in the context of $D$ major, gives the impression of a Dorian expression of $\mathrm{E}$ as a pitch center. The harmony moves up in parallel motion again, but this time by a half-step to an $\mathrm{F}$ major chord. This changes the apparent expression of $E$ from a Dorian expression (as indicated by the original context of $D$ major) to a Phrygian expression (as evidenced by the distinct half-step motion between $\mathrm{E}$ and $\mathrm{F})$. These two modal expressions are another example of multiple modes existing simultaneously and with equal emphasis (i.e. the poly-modality complex).

"Waiting for the Worms" implies G major as a tonal center. The first harmonic progression in this track is reminiscent of the harmonic content of "The Show Must Go On"-the G major chord alternates with a C major chord as an emphasis on the lower fifth of $G$ followed by a weak retrogression (0:28) from V-IV-I. The implied tonality of $G$ major is questioned when, in the next section of the song, $C$ major is temporarily tonicized $(0: 34)$ via the transformation of $\mathrm{G}$ major into a dominant. This casts doubt on the tonal identity of the song because this temporary tonicization is the only direct tonicization and it is in direct conflict with what the ear interprets as tonic. This conflict is 
intensified when in the next section (1:24) there is a modal expression of $A$ (Aeolian) that is followed by a reiteration of the harmonic progression that tonicizes $\mathrm{C}$. A shift to the lower third (E minor) of the perceived tonic with a return to the primary motivic material for a brief moment presents a method of dialectic intensification that is typically unique to art music and is reminiscent of the developmental techniques prevalent in long-form art music.

"Waiting for the Worms" presents the most detailed and multifaceted argument yet in The Wall. There is a direct conflict between tonality and modality which is amplified through the ambiguous tonal state of $\mathrm{G}$ major. There is a direct conflict between $\mathrm{G}$ major and $\mathrm{C}$ major as equal tonal centers. There is a direct conflict between a modal expression of $A$ and a modal expression of $E$. And finally, there is a direct conflict between the apparent beginning key of G major and the ending key of the song (an Aeolian modal expression of E).

The final cadence of "Waiting for the Worms" resolves into the beginning of "Stop," in which there is a pedal point on E. The vocal melody centers around an E and a G. This intervallic relationship suggests that this song is in some form of $E$ minor (albeit a modal form). The piano presents a descending melody in counterpoint to the vocal melody from E-D-C\#-C. The function of multiple modes increases the dialectic that has been intensifying in which multiple expressions of a single pitch center are simultaneously presented. In this instance, both Aeolian and Dorian expressions of $E$ are presented (per the variable $\mathrm{C} / \mathrm{C \# )}$. The dialectic between tonality and modality is also intensified through this melodic material because a descending melodic line in a minor context has the tonal tendency to want to resolve all the way down to the 
dominant (if the melody were to follow $\mathrm{C}$ as a downward-leading leading tone and resolve to $\mathrm{B}$, the dominant). The final furthering element of the multi-level harmonic argument in this track is in the last iteration of the descending piano melody-in its last statement, the melody is altered slightly and the C\# is replaced by a D\#, which has tonal implications for $\mathrm{E}$ as a pitch center.

The next track, "The Trial," has a distinct sonic identity in The Wall; it is one of only two songs that features a fully orchestrated accompaniment (the other being "Bring the Boys Back Home"). Of these two songs that presents a fully orchestrated accompaniment, "The Trial" is the longest and the most reliant on the orchestration. The first material presented in "The Trial" is a bass line that alternates between E and B. This is filled in by the orchestra by a melody that centers around B and its chromatic neighbor tones ( $A \#$ and $C)(0: 18)$. The prominent interval of a fifth in the bass line suggests a minor tonal expression of $\mathrm{E}$. However, there is a harmonic shift to an $\mathrm{F}$ major chord which suggests a Phrygian expression of $E$ as a pitch center. The F major chord is not a functional Neapolitan predominant substitute because it does not resolve to a dominant. The bll chord connects iterations of E minor. This introduction to "The Trial" reinforces the conflict between tonality and modality by simultaneously referencing both a tonal expression of $E$ (in the bass line and melody) and a Phrygian expression of $E$ (in the harmonic accompaniment).

The Phrygian Half Cadence (from VI-V) around 0:55 in "The Trial" is the first time in the track when there is a harmonic and melodic agreement. This cadence resolves to E minor, as would be expected. The Phrygian motion at the Half Cadence (0:55) mirrors the Phrygian expression of $E$ that came before and shows a parallel between the modal 
and tonal expressions of the same pitch. The following phrase presents a harmonic progression that is modified from the previous section in which the bll is replaced by a V/V which subsequently temporarily tonicizes $B$ minor (1:04). The B minor harmony leads to a $\mathrm{G}$ major chord that is treated as a functional predominant in D major, the relative of $B$ minor. This brief venture into the tonal area of $B$ minor/D major leads back to $E$ as a pitch center. This time, however, $E$ minor as a tonal center is more overtly suggested by juxtaposition with its dominant (1:29). The reason that $E$ minor is not yet fully confirmed as a true tonal center despite the presentation of a B major chord is the resolution of the dominant. The harmony that immediately follows the B major chord is an F\# minor chord followed by a D major chord; this progression subverts the attempted tonicization by the $\mathrm{B}$ major chord and reverts $\mathrm{E}$ back to a modal center rather than a tonicized tonal center. It is not until the end of the next phrase $(1: 58)$ that $B$ major, as a dominant, resolves clearly and concisely to E minor. After this Perfect Authentic Cadence in $E$ minor, the minor expression of $E$ reverts to a melodic minor expression and a Phrygian harmonic expression as in the beginning of "The Trial."

The musical material detailed above repeats a total of two times. The last iteration of this section ends with a Half Cadence in $E$ minor, the resolution of which (to e minor) overlaps with the beginning of the next phrase. This phrase presents the primary motivic idea from the entire album (the "Wall" motive) synthesized with the Phrygian harmonic content from the beginning of "The Trial" (3:26). Harmonically this is a Phrygian expression of E, but melodically intact, the "Wall" motive retains an Aeolian identity. The alternation of an $\mathrm{E}$ minor chord and an $\mathrm{F}$ major chord cross-fades into the sound of a wall being torn down and segues into the next and final track on The Wall. 
"Outside the Wall" presents a harmonic progression that decidedly tonicizes C major. It ends with the presentation of a Perfect Authentic Cadence in C major.

\begin{tabular}{|c|c|c|c|c|c|c|c|c|c|c|c|c|c|}
\hline Track & 2.1 & 2.2 & 2.3 & 2.4 & 2.5 & 2.6 & 2.7 & 2.8 & 2.9 & 2.10 & 2.11 & 2.12 & 2.13 \\
\hline Primary pitch center & Em (modal) & Am (modal) & (Am) & GM & GM & $\mid \mathrm{Bm}$ (modal) & GM & Em (modal) & DM & $\left|\begin{array}{c}\mathrm{GM} /(\mathrm{Em} \\
\text { modal })\end{array}\right|$ & Em (modal) & $\begin{array}{l}\text { Em (modal)/ } \\
\mathrm{Em} \text { (tonal) }\end{array}$ & CM \\
\hline Secondary pitch center & GM & & $\mathrm{CM}$ & Em(modal & 1) $(\mathrm{Em})$ & DM & & AM & Em (modal) & ) $\mid$ Am (modal) $\mid$ & & (GM) & \\
\hline
\end{tabular}

Ex. 6.5 Harmonic design of The Wall, second half

The second half of The Wall, like the first half, is harmonically driven by an ongoing dialectic between the concepts of modality and tonality. The second half is less reliant on global varying expressions of a single central pitch and is more dependent on the departure from $D$ as a central pitch in the first half of the album. The second half of The Wall presents an intensification of local poly-modality which peaks in track 2.12 , in which there are simultaneous statements of different ideas in different tonalities/modalities. This point of maximal conflict (and especially the Phrygian expression of $E$ in track 2.12 and the modal/minor expressions of $A$ in 2.2-2.4) is effectively resolved in track 2.13 with the presentation of $C$ major as a true tonal center confirmed by a Perfect Authentic Cadence. 


\section{Chapter 7}

\section{Compositional Relationships and Trends}

Here we will summarize the changes in the compositional approaches to musical form in Pink Floyd's music between 1971 and 1979 as evidenced by the four albums discussed in the analytical case studies of the previous chapters. The methods by which they will be compared are the densities of the harmonic discourse over the course of each individual album and the motivic development and reliance on textual and poetic devices.

The general trend that occurred in the progression of Pink Floyd's compositional style between 1971 and 1979 is one of increasing complexity and increased attention to large-scale formal elements. The previous chapters examined the harmonic layout of Meddle, The Dark Side of the Moon, Wish You Were Here, and The Wall in depth. The findings show that in each album there is a cohesive harmonic narrative occurring. In Meddle, the global harmonic dialectic was a musical exploration of $\mathrm{G}$ major and $\mathrm{E}$ minor/major. On the local level, Meddle tends to be primarily modal. The conflict between modality and tonality is present but the strength of the dialectic is not remarkably profound. This argument between local modality and global tonality is clearer in The Dark Side of the Moon. The harmonic design shows a clear global motion towards a well-defined end goal. The second track in The Dark Side of the Moon sets up the anticipation of a resolution (the alternation between $\mathrm{E}$ minor and $\mathrm{A}$ major) in the global sense while remaining largely modal in the local sense. 
The change that occurred between Meddle and The Dark Side of the Moon was one that showed an increased sensibility to the nuance of form and the effect it can have on the way an entire album is perceived. On the surface, Meddle can be viewed as a collection of unrelated songs and it is only through an in-depth analytical process that the underlying dialectic is revealed. The Dark Side of the Moon presents a harmonic dialectic that is more cohesive. Between the promissory progression in "Breathe" and its ultimate resolution in "Eclipse," each song has a well-defined place in relation to both the beginning and the end.

Wish You Were Here presents a harmonic dialectic that is as clear as The Dark Side of the Moon. The harmonic argument is one that deals with different sides and expressions of $\mathrm{G}$ as a central pitch. Wish You Were Here also is notably more aware of form because it is book-ended by a single song that is split into multiple parts. "Shine On You Crazy Diamond" begins the album and ends the album. While there was a reprisal of one song ("Breathe") in The Dark Side of the Moon, this instance of material reprisal is more formally significant because of its placement in the album -it is both the first and last idea heard. Wish You Were Here also presents a prominent motivic idea, the first time in any of the albums examined in the previous chapter (see Ex. 3.13). While this motivic idea is not developed to a significant degree, it is still presented as a formal marker and reinforces the multiple parts of "Shine On You Crazy Diamond" as being very formally important.

An important notion in the concept album, that of textual and poetic cohesion, is also brought to a new level in Wish You Were Here. The textual content of the album almost follows an autobiographical story of the band. "Shine On You Crazy Diamond" is 
all referential to founding member Syd Barrett, and "Welcome to the Machine" and "Have a Cigar" are referential to their induction to mainstream success in the music industry ("Come in here dear boy, have a cigar/You're going to go far."). This is an element that is new to Wish You Were Here (in terms of the four selected albums feature in chapters 3-6). The Dark Side of the Moon is poetically coherent, but is more a loose association than a linear storyline. It is bound together by concepts that address larger philosophical concepts and questions (e.g. "Time," "The Great Gig in the Sky" as an examination of death and grief, "Money," "Us and Them" as an examination of conflict).

The Wall is a synthesis of all of these concepts: harmonic design, motivic development, and textual cohesion. The Wall has an intensely layered harmonic dialectic that presents simultaneous expressions of multiple modal expressions of the same pitch (as a natural outgrowth of the oppositional concepts of tonality and modality) similarly to how the Prelude to Richard Wagner's Tristan und Isolde presents multiple tonics as equally important. Motivic development is clear and important (the prevalence of the "Wall" motive). Finally, The Wall is concise and clear as a linear story. This is a large leap from the content of Meddle, but one that can be traced through the progression of albums.

This analysis is not intended to be exhaustive or all-inclusive. There are elements that deserve more attention (for example a spectral analysis of all albums to document fluctuating levels of harmonicity). The purpose of this document is to give one perspective on the ways that large-form coherence in the work of Pink Floyd is achieved. This is demonstrable through the previous examination of long-range 
harmonic dialectics and the role of modality in a tonal framework. Because this document is not exhaustive of all potential analytical techniques, it is this author's hope that, ultimately, the result of this analysis is one of a deeper appreciation and understanding of the music of Pink Floyd and the ways in which their music operates and, hopefully, one that helps to define the allure of one of Rock music's most iconic figures. 


\section{Bibliography}

"Dark Side of the Moon." Library Journal 110, no. 19 (11/15, 1985):

44, http://search.ebscohost.com/login.aspx?direct=true\&db=a9h\&AN=7423994\&s ite=ehost-live.

Ahlkvist, Jarl A. "What Makes Rock Music "Prog"? Fan Evaluation and the Struggle to Define Progressive Rock." Popular Music \& Society 34, no. 5 (12, 2011): 63960, http://search.ebscohost.com/login.aspx?direct=true\&db=a9h\&AN=67458169 \&site=ehost-live.

Anderton, Chris. "A Many-Headed Beast: Progressive Rock as European MetaGenre." Popular Music 29, no. 3 (10, 2010): 417-

35, http://search.ebscohost.com/login.aspx?direct=true\&db=a9h\&AN=54427677 \&site=ehost-live.

Bailey, Robert. The Genesis of Tristan Und Isolde: And a Study of Wagner's Sketches and Drafts for the First Act. UMI, 1969.

Biamonte, Nicole. "Formal Functions of Metric Dissonance in Rock Music." Music Theory Online 20, no. $2(06,2014): 1$ 19, http://search.ebscohost.com/login.aspx?direct=true\&db=a9h\&AN=96909374 \&site=ehost-live.

Biamonte, Nicole. "Triadic modal and pentatonic patterns in rock music." Music Theory Spectrum, 32, 95-110, 2010.

David Buckley. "Single." Grove Music Online. Oxford Music Online. Oxford University Press.

Carter, Dale. "The vegetables turned: Sifting the Psychedelic Subsoil of Brian Wilson and Syd Barrett." Popular Music History 4, no. 1: 57-75, 2009.

Carpenter, Alexander and Jérôme Melançon. "Is progressive rock progressive? Yes and Pink Floyd as counterpoint to Adorno." Rock Music Studies 2, no. 2: 125-147, 2015.

Chandler, David. "Roger Waters and British Opera." Journal of Popular Culture 43, no. $1(02,2010): 26-$

44, http://search.ebscohost.com/login.aspx?direct=true\&db=a9h\&AN=47829585 \&site=ehost-live.

Cohen, Gilad. "Expansive Form in Pink Floyd's "Dogs." Music Theory Online 21, no. 2: 1-13, 2015.

Cone, Edward T. "Schubert's Promissory Note: An Exercise in Musical Hermeneutics." 19th-Century Music, Vol. 5, No. 3 (Spring, 1982), pp. 233-241.

Decker, Todd. "Fancy Meeting You here: Pioneers of the Concept Album." Daedalus 142, no. 4 (Fall2013, 2013): 98108, http://search.ebscohost.com/login.aspx?direct=true\&db=a9h\&AN=90623543 \&site=ehost-live.

Etheridge, Melissa. "The Dark Side of the Moon." Rolling Stone, no. 937 (12/11, 2003): $156-$

, http://search.ebscohost.com/login.aspx?direct=true\&db=a9h\&AN=11579851\&sit e=ehost-live. 
Fricke, David. "The Dark Side of the Moon." Rolling Stone, no. 1142 (10/27, 2011): 83, http://search.ebscohost.com/login.aspx?direct=true\&db=a9h\&AN=67058575\&sit e=ehost-live.

Gilmore, Mikal. "THE MADNESS \& MAJESTY OF PINK FLOYD. (Cover Story)." Rolling Stone, no. 1023 (04/05, 2007): 54-

79, http://search.ebscohost.com/login.aspx?direct=true\&db=a9h\&AN=24518991 \&site=ehost-live.

Harbison, John. "Facing Rock Reality (1988)." Contemporary Music Review 18, no. 4 (09, 1999): 5-

11, http://search.ebscohost.com/login.aspx?direct=true\&db=a9h\&AN=24876199 \&site=ehost-live.

Harris, John. "Thirty Years of Darkness." Rolling Stone, no. 922 (05/15, 2003):

45, http://search.ebscohost.com/login.aspx?direct=true\&db=a9h\&AN=9796005\&s ite $=$ ehost-live.

Hiatt, Brian. "Pink Floyd's Journey to the Dark Side." Rolling Stone, no. 1141 (10/13, 2011): 44-

72, http://search.ebscohost.com/login.aspx?direct=true\&db=a9h\&AN=66426239 \&site=ehost-live.

Hung, Eric. "Hearing Emerson, Lake, and Palmer Anew: Progressive Rock as "Music of Attractions."." Current Musicology, no. 79 (Spring, 2005): 245-

59, http://search.ebscohost.com/login.aspx?direct=true\&db=a9h\&AN=22366865 \&site=ehost-live.

Itzkoff, Dave. "All in all, it's just A Tour of 'the Wall'." New York Times 159, no. 55 $(04 / 13,2010)$ :

2, http://search.ebscohost.com/login.aspx?direct=true\&db=a9h\&AN=49078412\&s ite=ehost-live.

Keightley, Keir. "Part II the Industry: 16. Recording: Concept Album." Continuum Encyclopedia of Popular Music of the World 1 (01, 2003): 614-

, http://search.ebscohost.com/login.aspx?direct=true\&db=a9h\&AN=27360943\&sit e=ehost-live.

Lundberg, Mattias. "'to Let it be without Pretense": Canon, Fugue, and Imitation in Progressive Rock 1968-1979." Music Theory Online 20, no. 3 (09, 2014): 36 51, http://search.ebscohost.com/login.aspx?direct=true\&db=a9h\&AN=98591251 \&site=ehost-live.

Lyotard, Jean-François. 2009. "Music and Postmodernity." New Formations no. 66: 37 45. Academic Search Complete, EBSCOhost.

Mettler, Mike. "14 | Pink Floyd." Sound \& Vision 73, no. 9 (11, 2008): 40-

, http://search.ebscohost.com/login.aspx?direct=true\&db=a9h\&AN=34856023\&sit e=ehost-live.

Moore, Allan F. "Pink Floyd." Grove Music Online. Oxford Music Online. Oxford University Press.

Murail, Tristan. 2005. "The Revolution of Complex Sounds." Contemporary Music Review 24, no. 2/3: 121-135. Academic Search Complete, EBSCOhost.

Randall, Annie J. "British invasion." Grove Music Online. Oxford Music Online. Oxford University Press. 
Reising, Russell. "Melting Clocks and the Hallways of always: Time in Psychedelic Music." Popular Music \& Society 32, no. 4 (10, 2009): 523-

47, http://search.ebscohost.com/login.aspx?direct=true\&db=a9h\&AN=44263701 \&site=ehost-live.

Richardson, Ken. "Tales from the Dark Side." Sound \& Vision 68, no. 5 (06, 2003): 90, http://search.ebscohost.com/login.aspx?direct=true\&db=a9h\&AN=9868802\&s ite=ehost-live.

Rolison, Jonathan J. and Judy Edworthy. 2013. "The Whole Song Is Greater Than the Sum of Its Parts: Local and Structural Features in Music

Rosen, Charles. "The Coherence of Musical Language." The Classical Style. Norton \& Company. New York. 1972. Pg. 68.

Listening. "Psychomusicology: Music, Mind \& Brain 23, no. 1: 33-48.

Schoenberg, Arnold. Fundamentals of Musical Composition, ed. G. Strang and L. Stein (London, 1967) [written 1937-48].

Simonelli, David. "BBC Rock Music Programming on Radio and Television and the Progressive Rock Audience, 1967-1973." Popular Music History 2, no. 1 (04, 2007): 95-

112, http://search.ebscohost.com/login.aspx?direct=true\&db=a9h\&AN=36029045 \&site=ehost-live.

Stimeling, Travis D. "'Phases and Stages, Circles and Cycles': Willie Nelson and the Concept Album." Popular Music 30, no. 3 (10, 2011): 389-

408, http://search.ebscohost.com/login.aspx?direct=true\&db=a9h\&AN=65931743 \&site=ehost-live.

Strunk, Steven. "Harmony (i)." The New Grove Dictionary of Jazz, 2nd ed.. Grove Music Online. Oxford Music Online. Oxford University Press.

Tscioulcas, Anastasia. "Waters' New Concept." Billboard 117, no. 35 (08/27, 2005): 45, http://search.ebscohost.com/login.aspx?direct=true\&db=a9h\&AN=18019565\&sit e=ehost-live.

Walker, Greg. "Grand Masters of Vinyl." Times Higher Education, no. 1862 (09/11, 2008): 40-

3, http://search.ebscohost.com/login.aspx?direct=true\&db=a9h\&AN=36381259\&s ite=ehost-live.

Naphtali Wagner. "“Domestication" of Blue Notes in the Beatles' Songs." Music Theory Spectrum 25, no. 2 (2003): 353-65. doi:10.1525/mts.2003.25.2.353. 


\section{Discography}

Pink Floyd (studio albums in chronological order)

Pink Floyd. Piper at the Gates of Dawn. Columbia Records SCX 6157, 1967.

Pink Floyd. A Saucerful of Secrets. Columbia Records SCX 6258, 1968.

Pink Floyd. Ummagumma. Harvest Records SHDW 1/2, 1969.

Pink Floyd. Atom Heart Mother. Harvest Records SHVL 781, 1970.

Pink Floyd. Meddle. Harvest Records SHVL 795, IE 064 o 04917, 1971.

Pink Floyd. Obscured by Clouds. Harvest Records 1C 062-05 054, 1972.

Pink Floyd. The Dark Side of the Moon. Harvest Records, SHVL 804, 1973.

Pink Floyd. Wish You Were Here. Harvest Records SHVL 814, 1975.

Pink Floyd. Animals. Harvest Records SHVL 815, 1977.

Pink Floyd. The Wall. Harvest Records SHDW 411, 1979.

Pink Floyd. The Final Cut. Harvest Records SHPF 1983, 1983.

Pink Floyd. A Momentary Lapse of Reason. EMI EMD 1003, 1987.

Pink Floyd. The Division Bell. EMI EMD 1055, 1994.

Pink Floyd. The Endless River. Columbia 88875007882, 2014.

\section{Other Referenced Recordings}

The Beatles. Meet the Beatles. Capitol Records ST-2047, 1963.

Led Zeppelin. Led Zeppelin. Atlantic 588171, 1968.

The Rolling Stones. Beggars Banquet. London Records PS-539, 1968. 


\title{
Monongahela \\ Concerto for Viola and Orchestra
}

Christopher Everett Jones

Thesis submitted

to the College of Creative Arts

at West Virginia University

in partial fulfillment of the requirements for the degree of

Doctor of Musical Arts

\author{
David Taddie, Ph.D., Chair \\ Evan MacCarthy, Ph.D. \\ Matthew Heap, Ph.D. \\ Andrea Houde, M.M. \\ Beth Royall, M.L.I.S., M.M.
}

School of Music

Morgantown, West Virginia

2017

Keywords: Music, Viola Concerto, Concerto, Viola, New Composition Copyright 2017 


\title{
Monongahela
}

Concerto for Viola and Orchestra

\author{
C. E. Jones
}

(C)2017

In partial fulfillment of the degree of D.M.A. in Composition 
Instrumentation:

2 Flutes

2 Oboes

2 Bb Clarinets

2 Bassoons

2 Horns in $\mathrm{F}$

2 Trumpets in $\mathrm{C}$

1 Trombone

1 Percussionist:

Timpani, Bass Drum, Tam-tam

1 Harp

Solo Viola

Full String Section

Violin I

Violin II

Viola

Cello

Double Bass 
Monongahela was written in the Fall of 2016 and the Spring of 2017. It was commissioned by violist and WVU faculty member Andrea Houde to be premiered at the 2017 International Viola Congress in Wellington, New Zealand. It is named for the river that flows through Appalachia, the region that lends its character to many elements of this concerto.

The score is transposed where noted. 

Score

$$
\begin{aligned}
& \text { Monongahela } \\
& \text { Concerto for Viola and Orchestra } \\
& \text { C. E. Jones }
\end{aligned}
$$
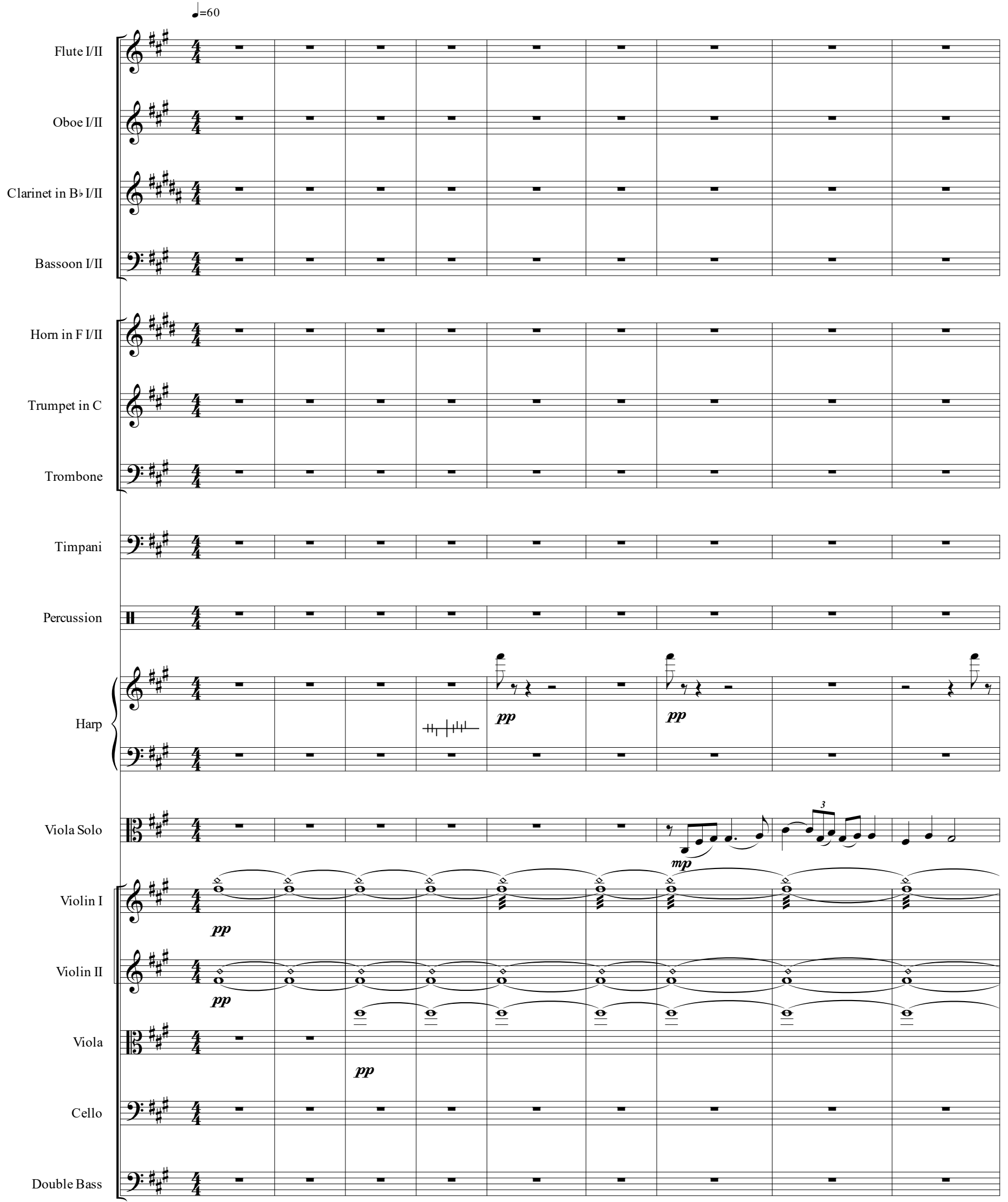
2 Monongahela

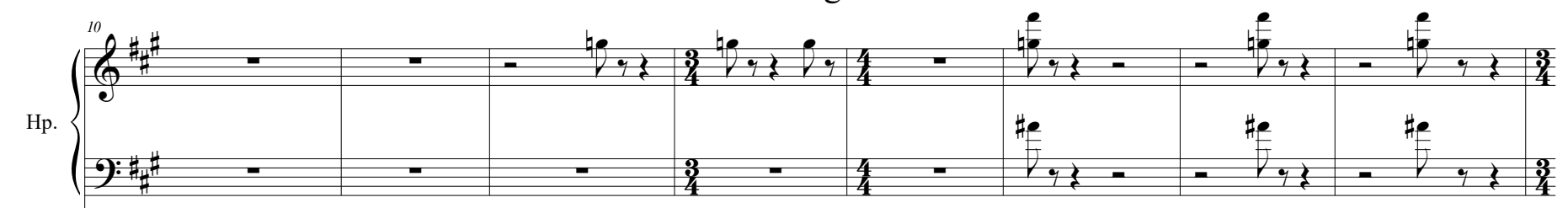

Vla. Solo ${ }^{10}$
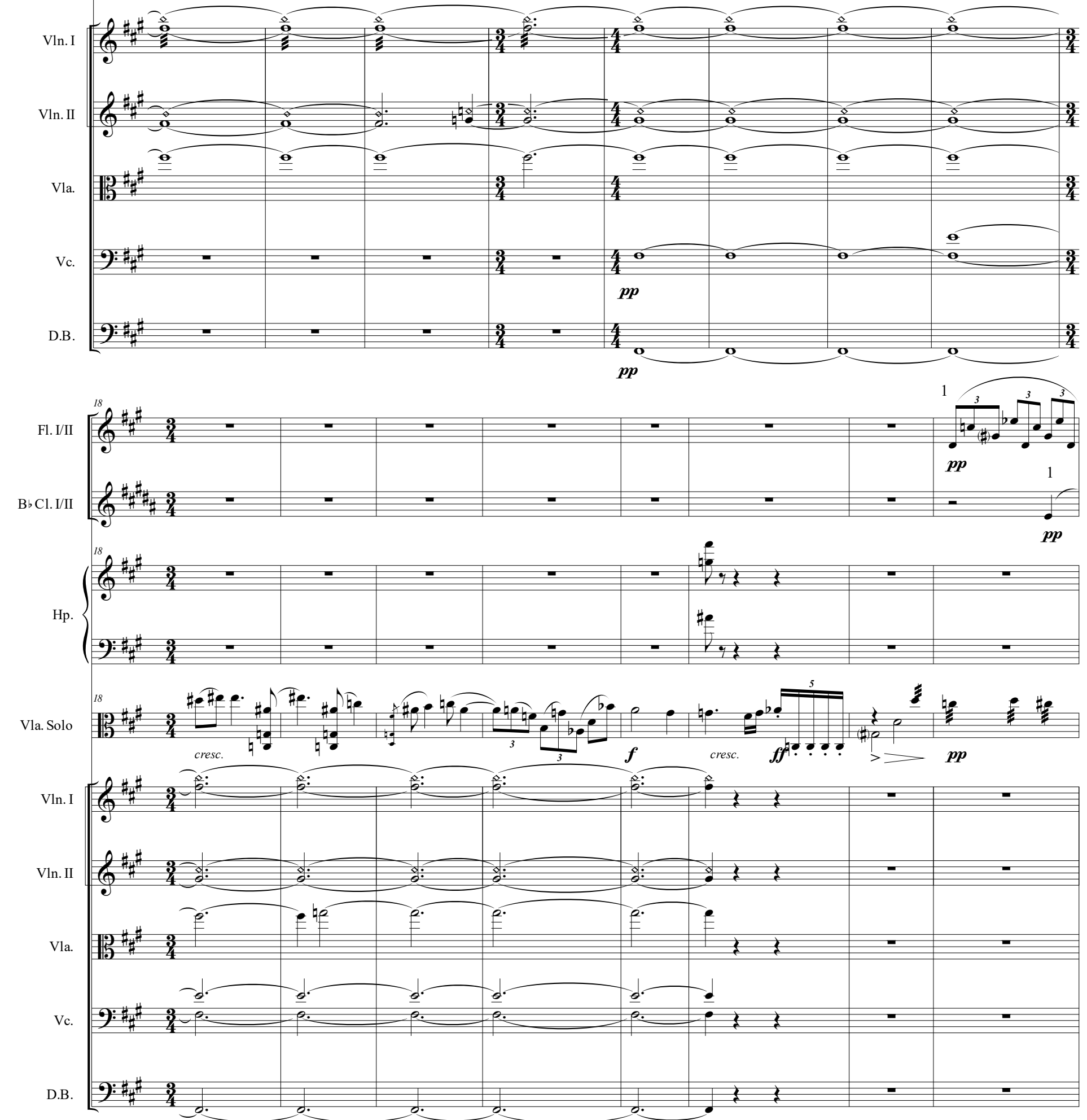


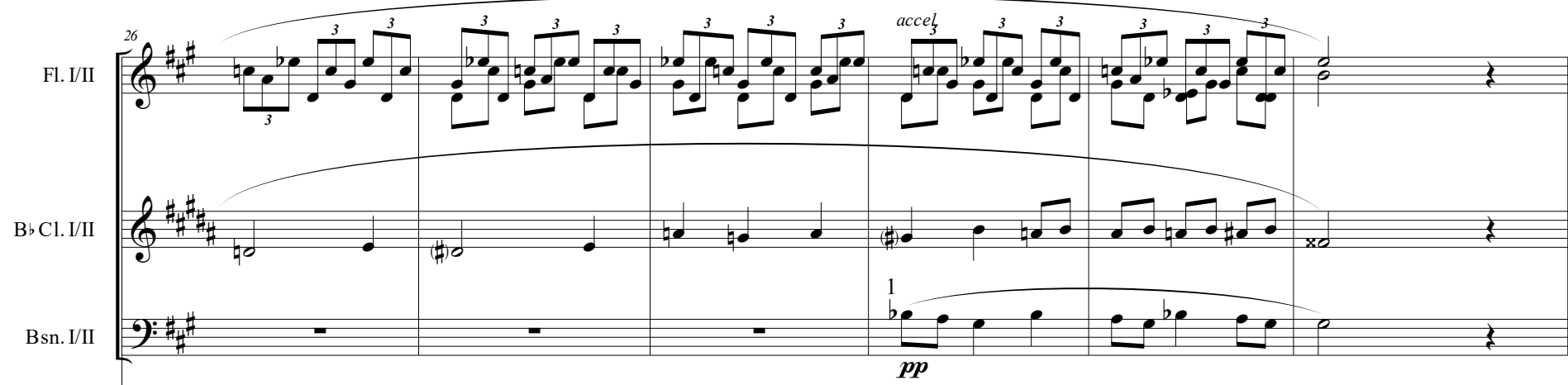

Vla. Solo

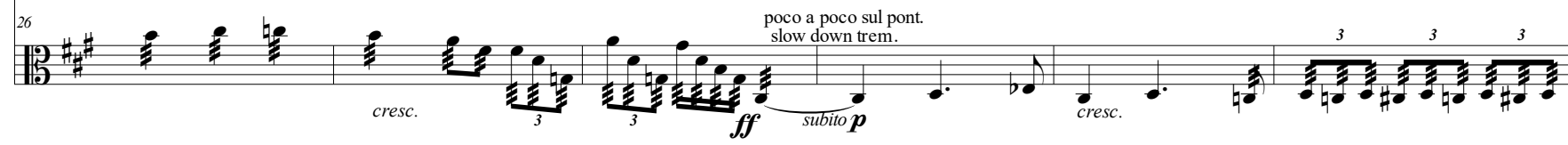

Fl. I/II

Ob. I/II

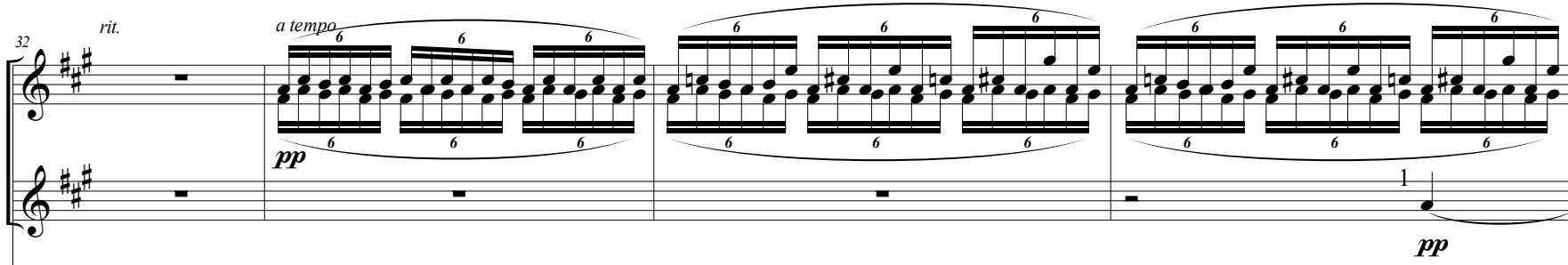

Vla. Solo

Q)

$p p$

$\equiv$

Fl. I/II
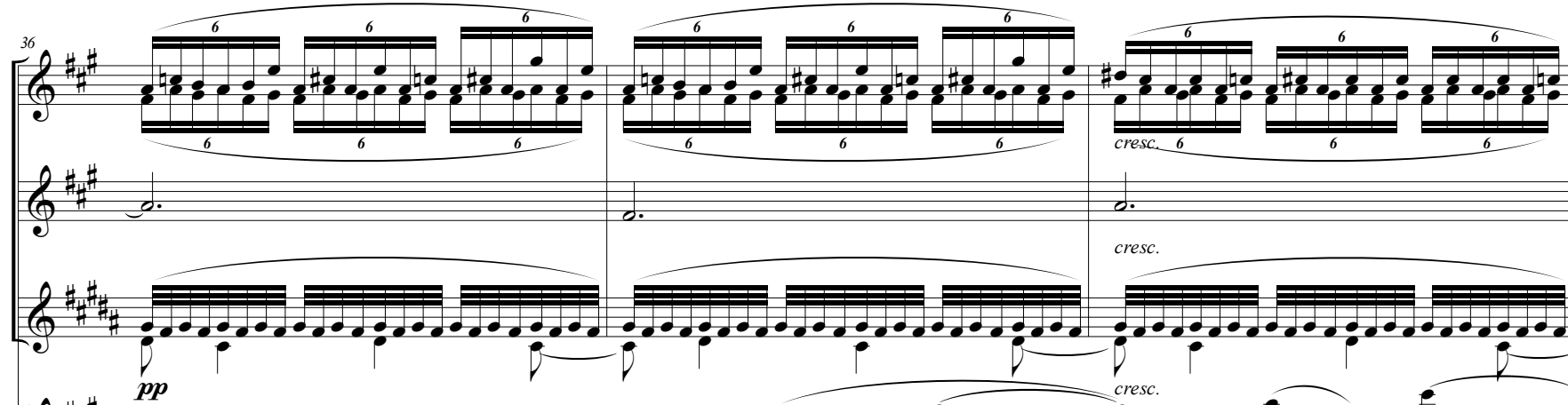

Ob. I/II

B. Cl. I/II

Vln. I
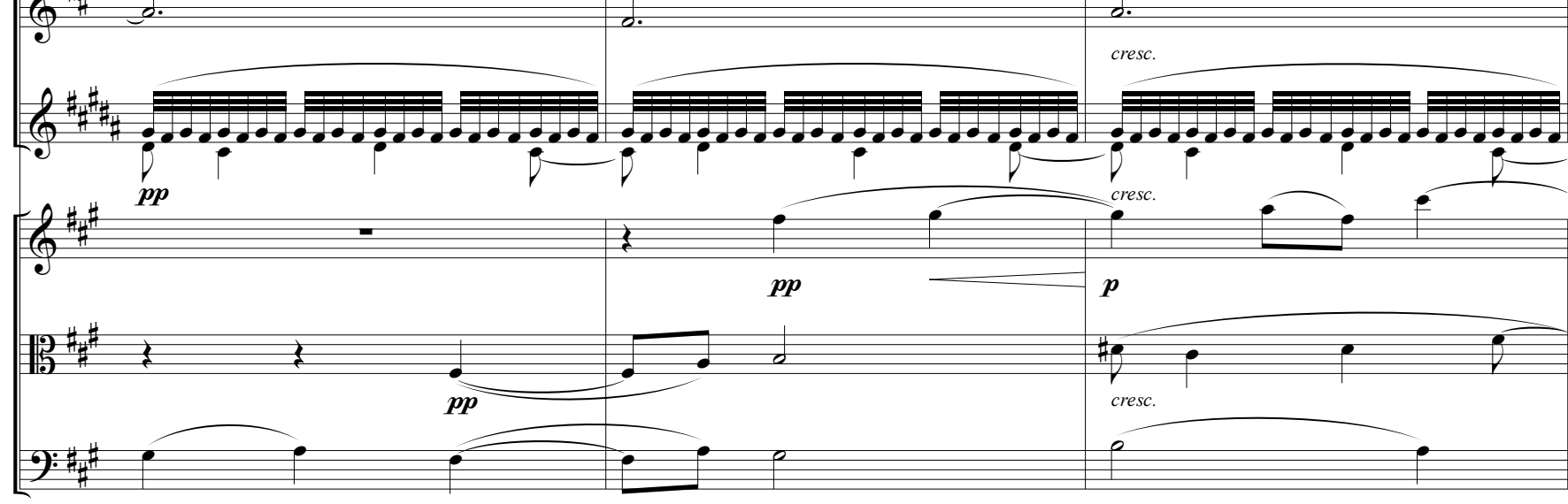

Vc.

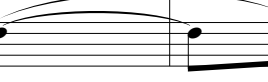




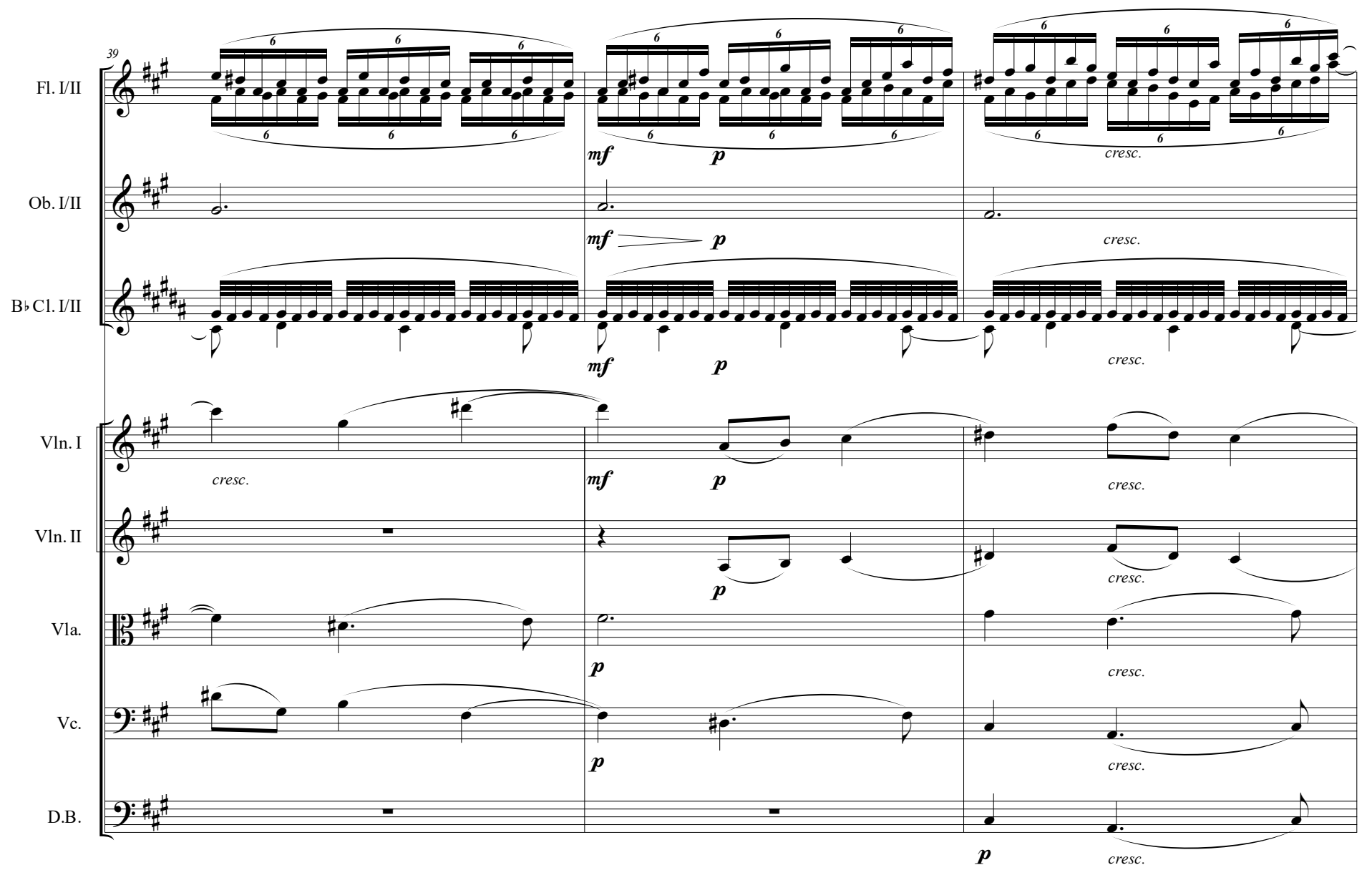




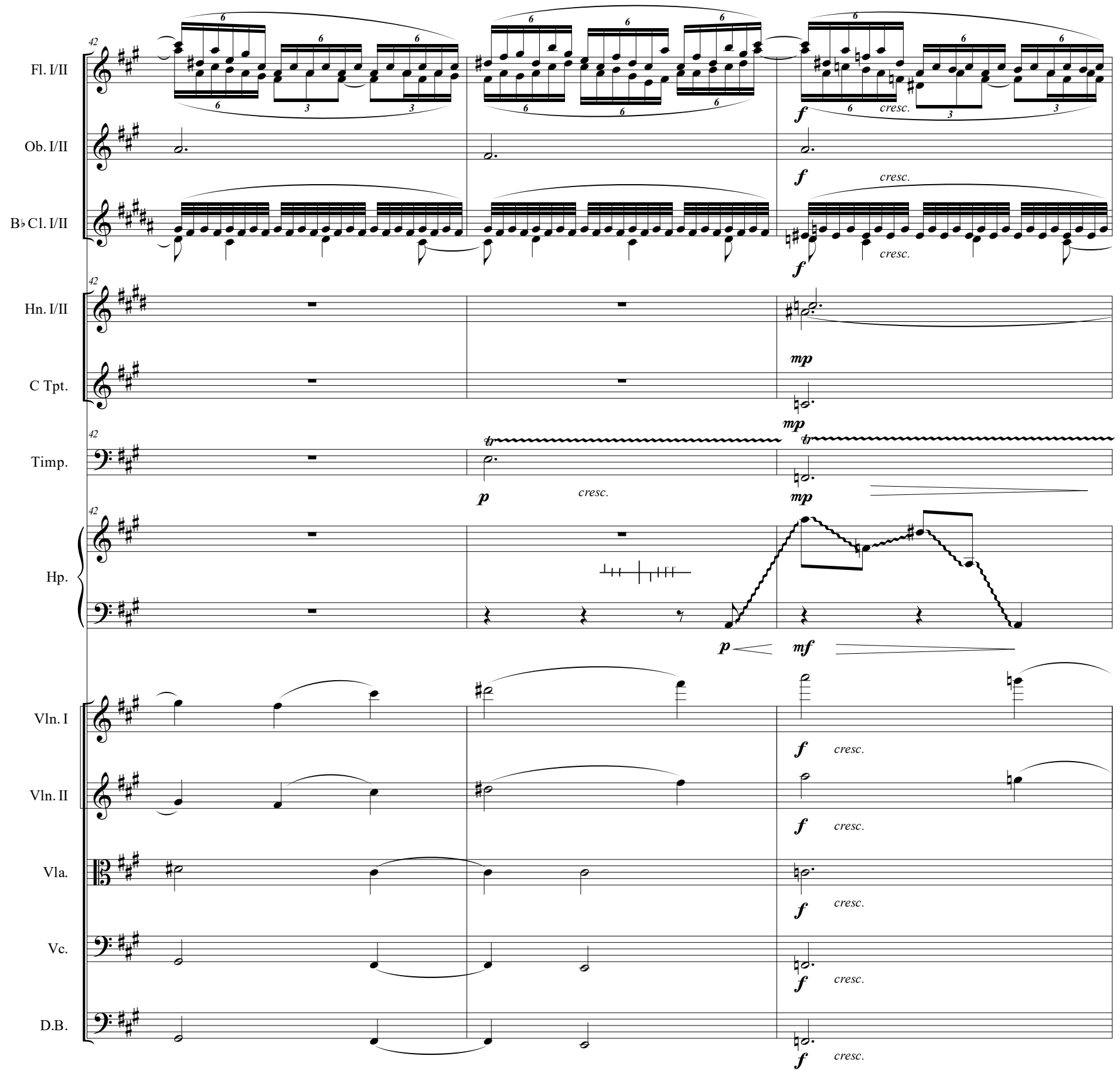


Monongahela

Fl. I/II

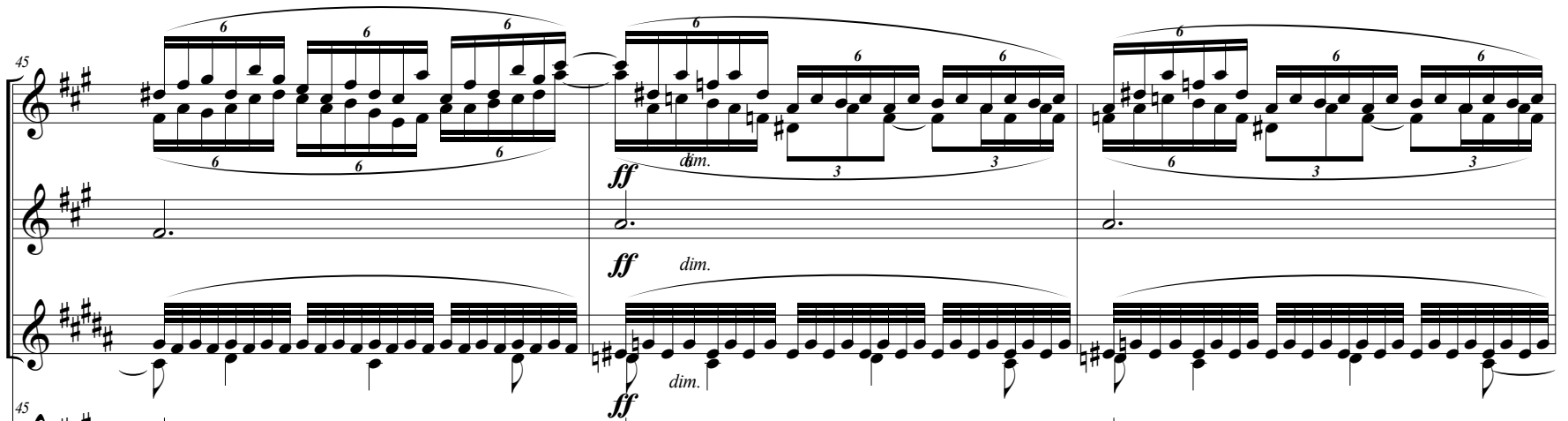

Hn. I/II
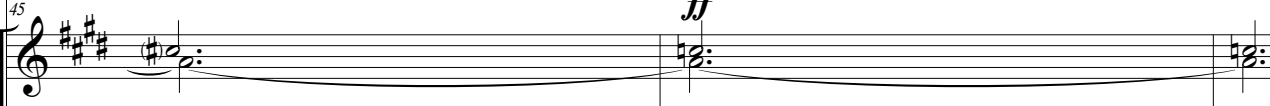

C Tpt.

0

6

Tbn.

2: \#

Vln. I

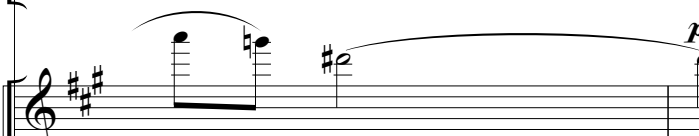

Vln. II

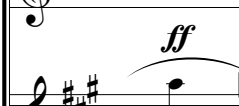

Vla.

Vc.

D.B

2:-

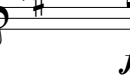

1*

$f f$

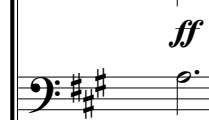

ff

\#fo.

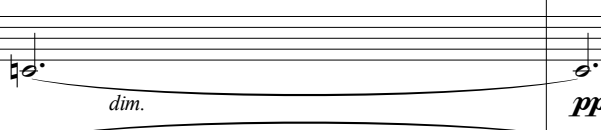

dim $p$

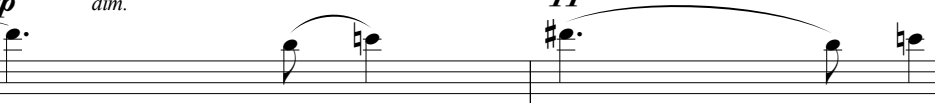



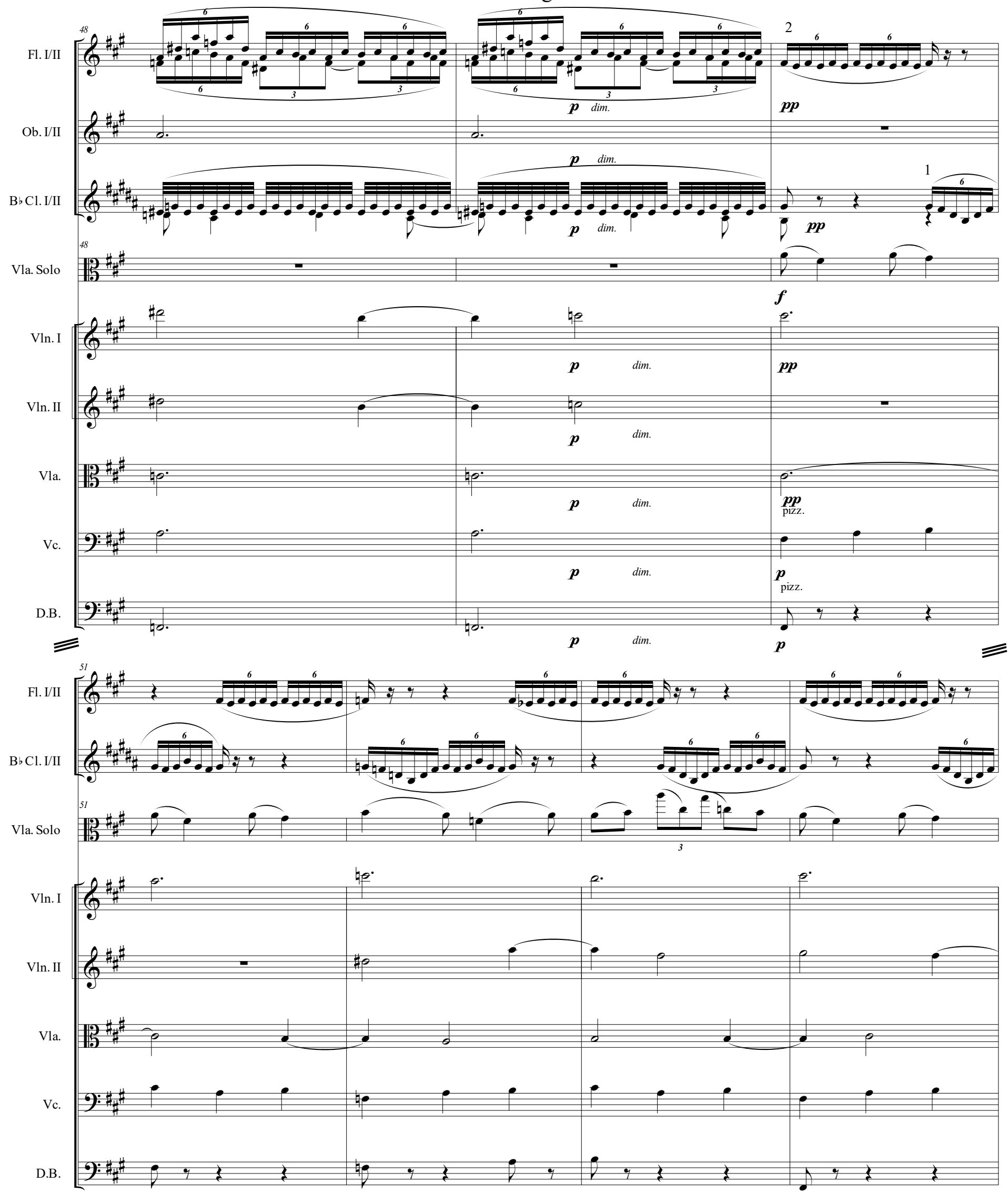


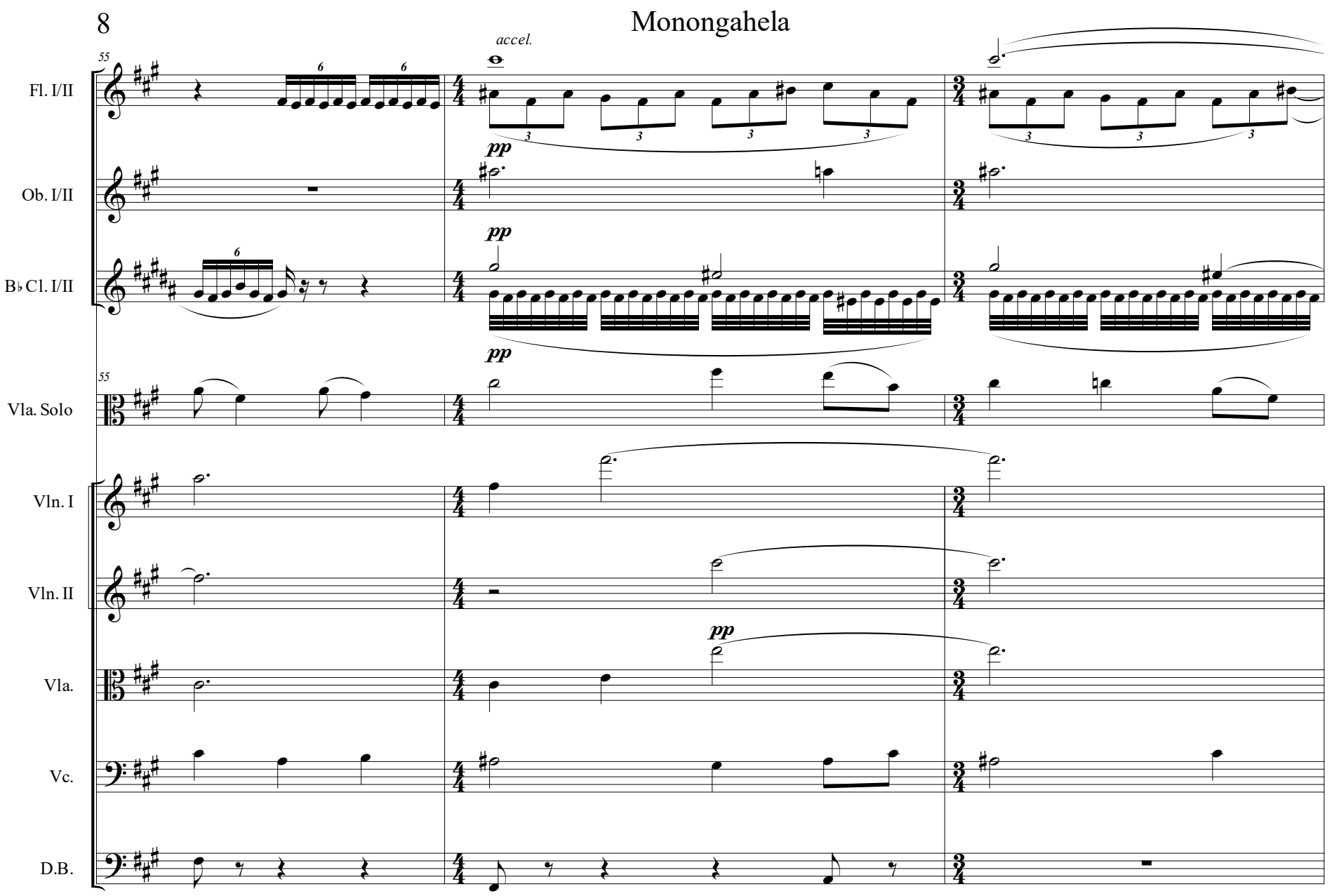

6 


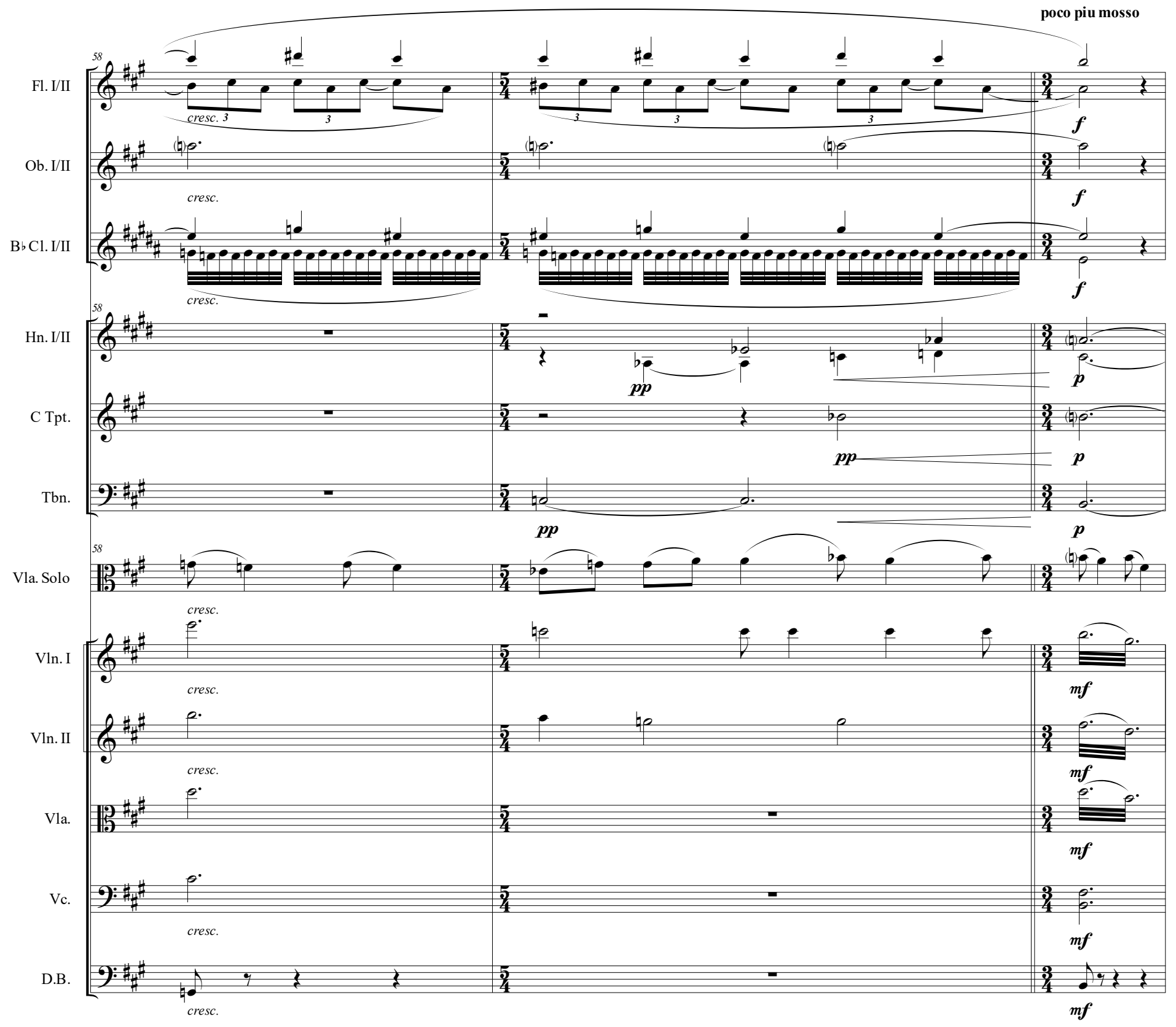


Monongahela

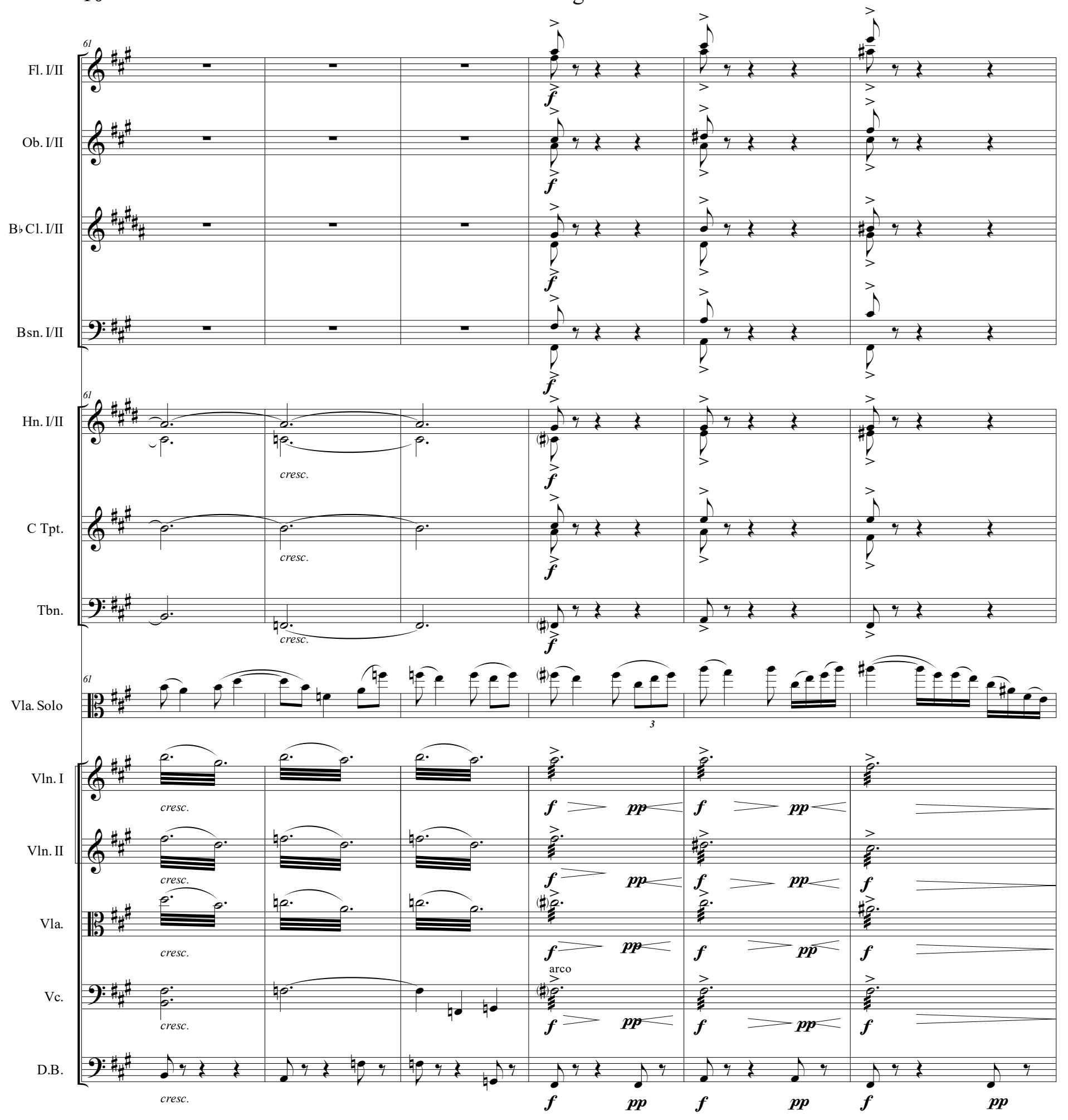


Monongahela

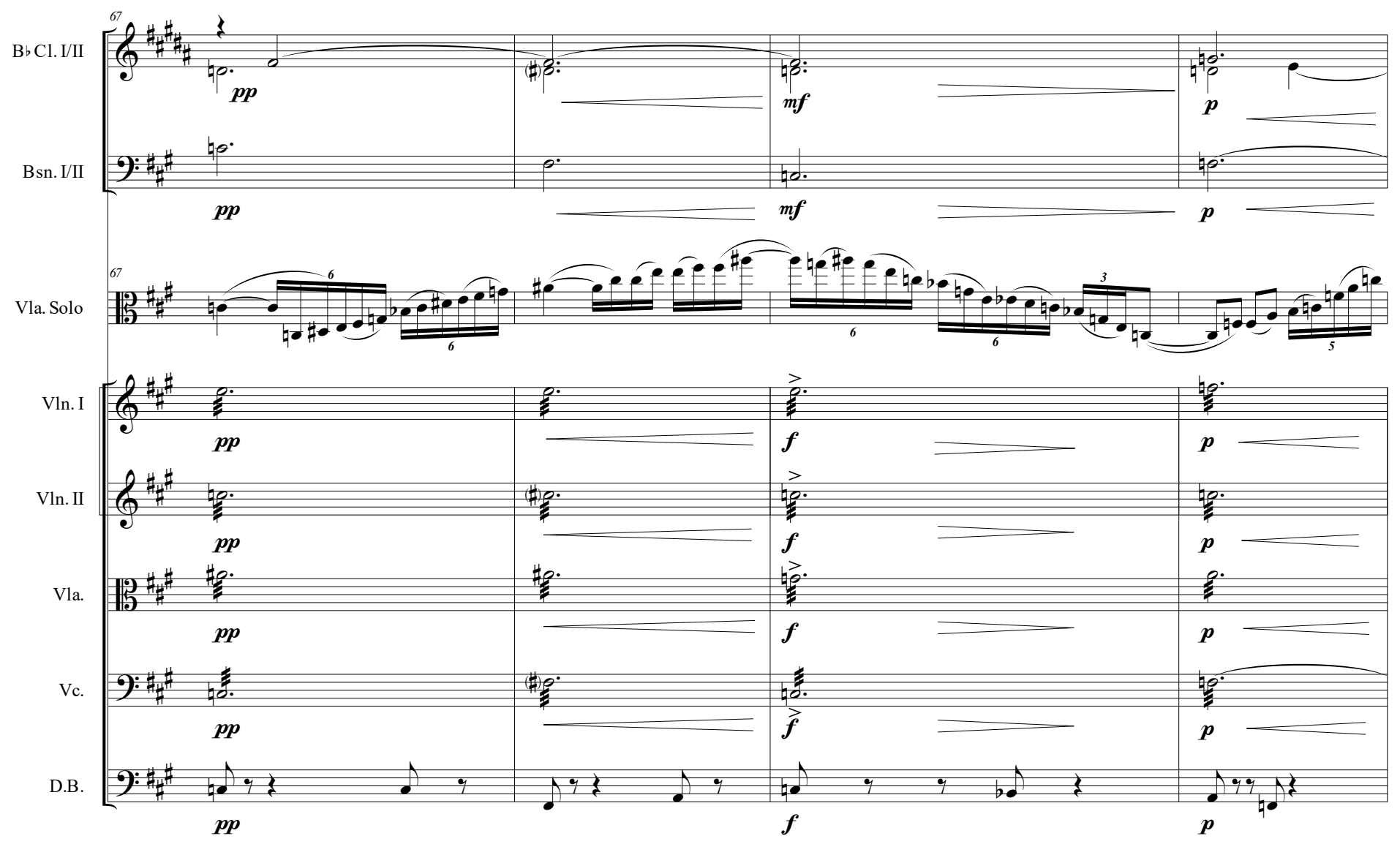



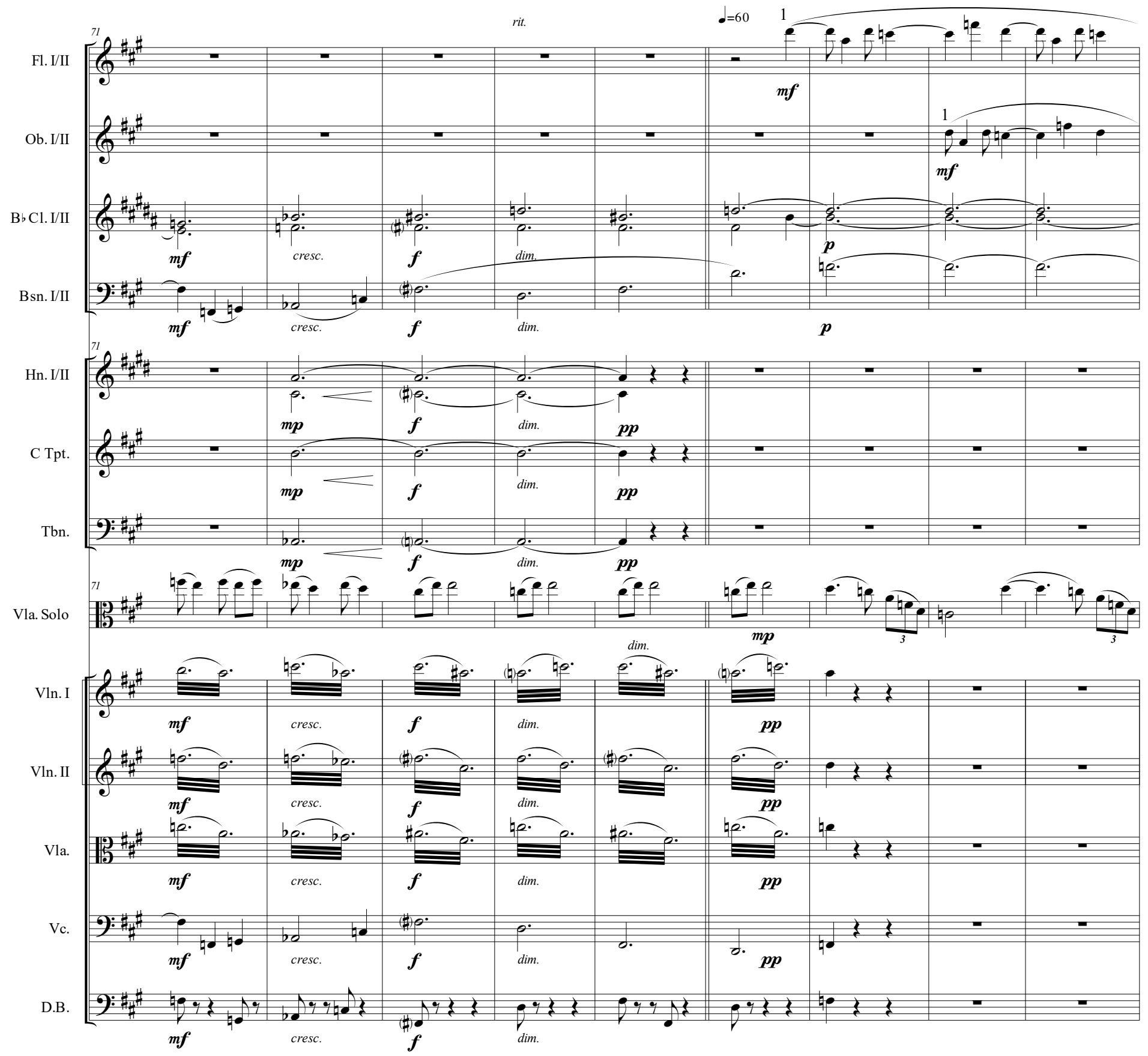

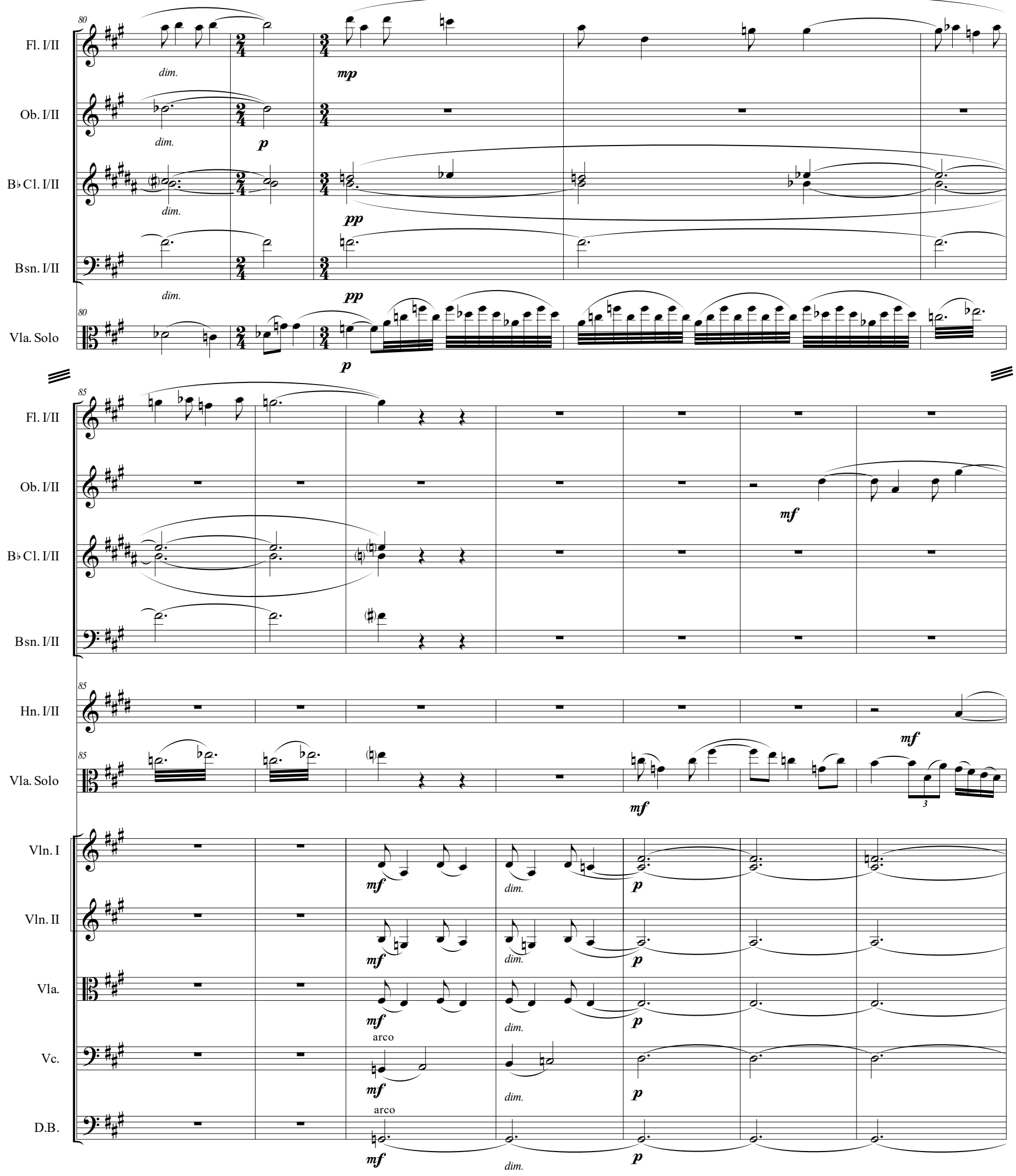
14

Monongahela
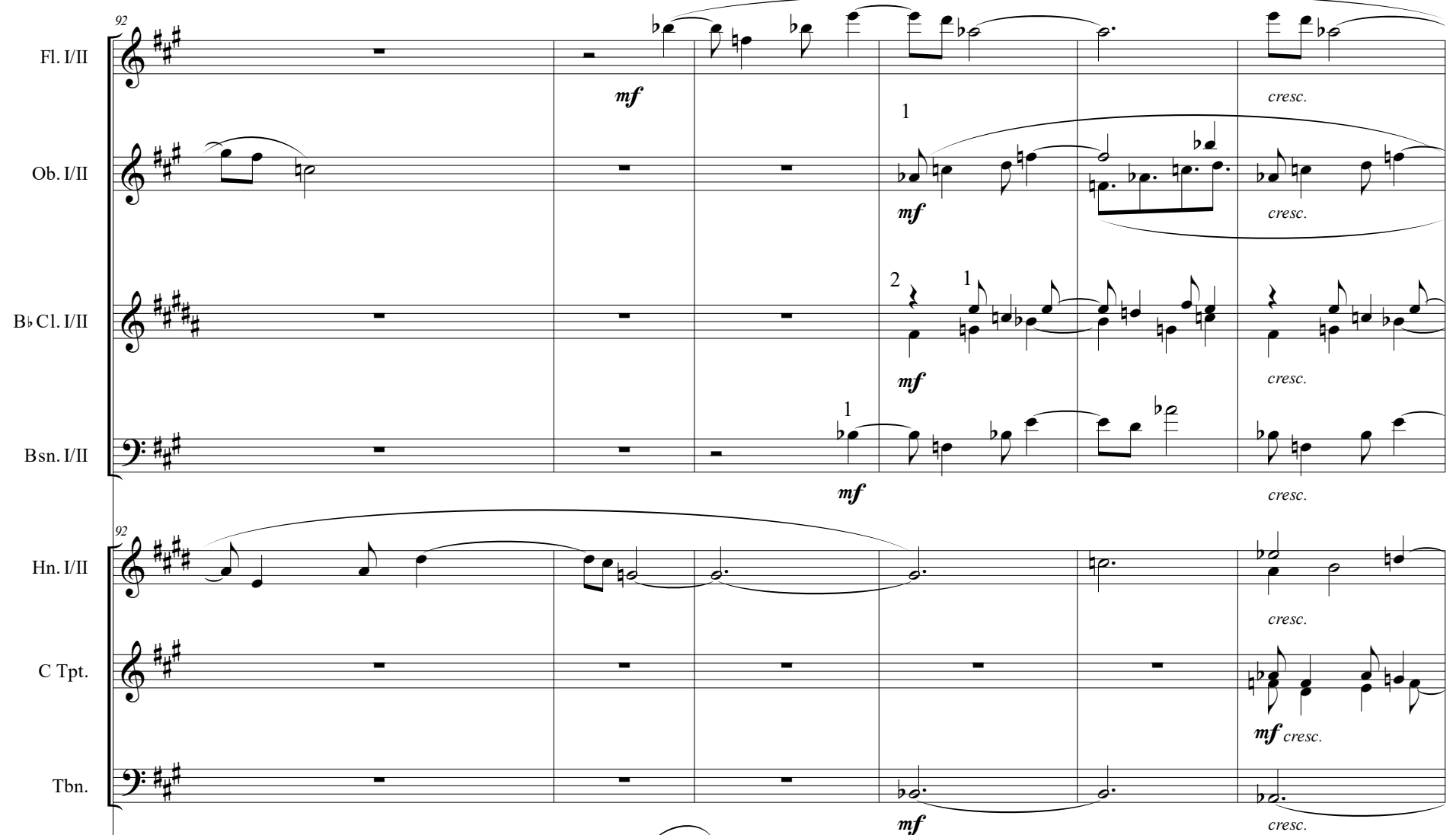

Vla. Solo

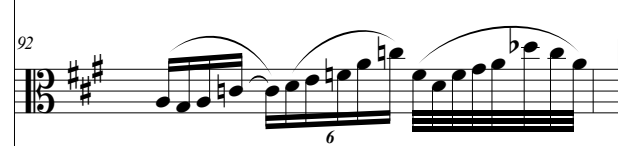

mf

cresc.

Vla. Solo

Vln. I

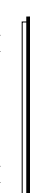

Vln. II

Vla.

$\int_{0}^{\# \text { in }}$

$6^{\# \#}$

a.

Vc.

D.B.

9

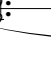

cere

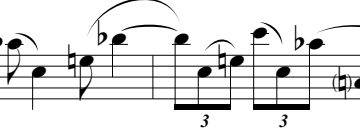

? ? ?

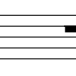



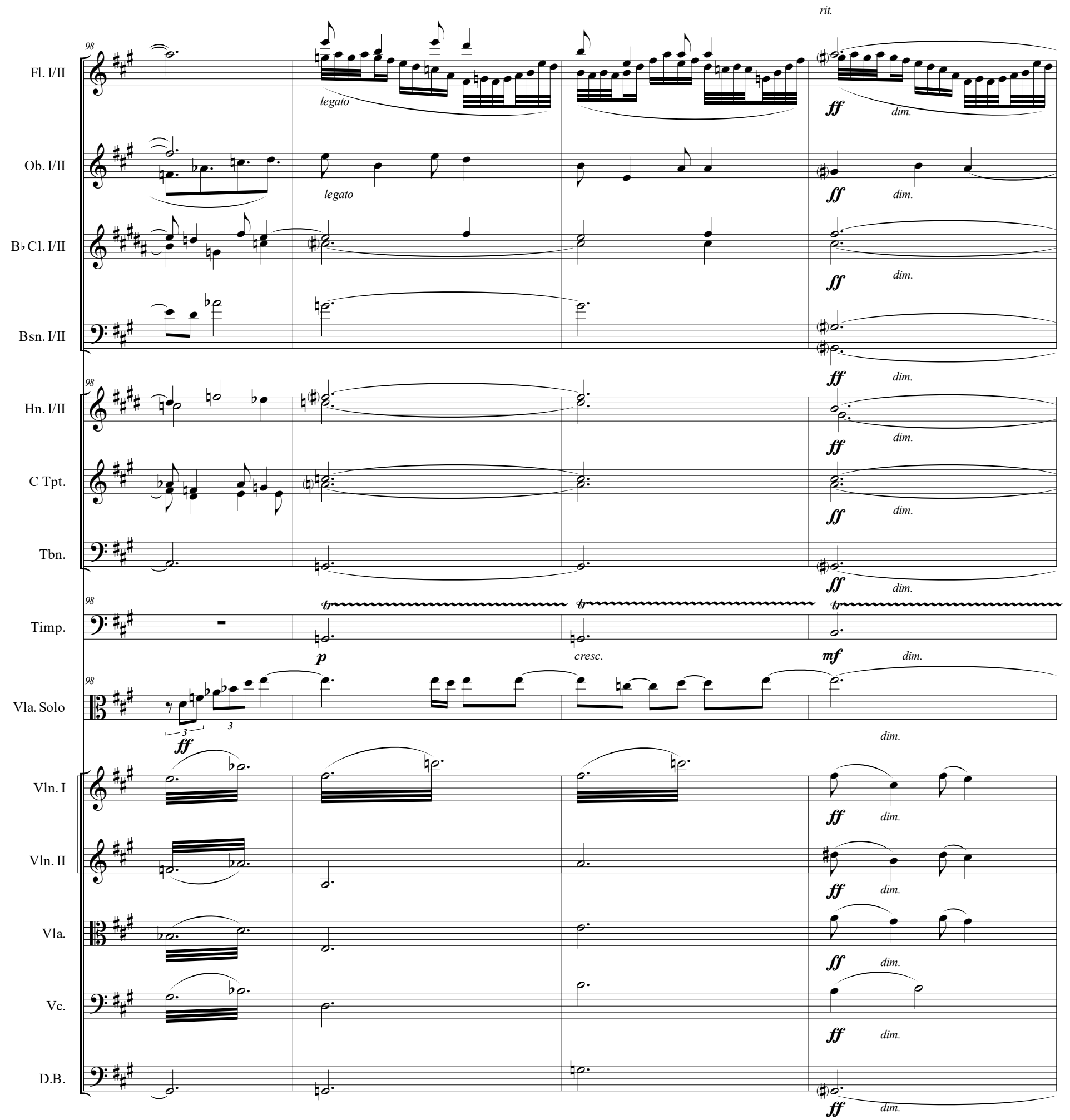


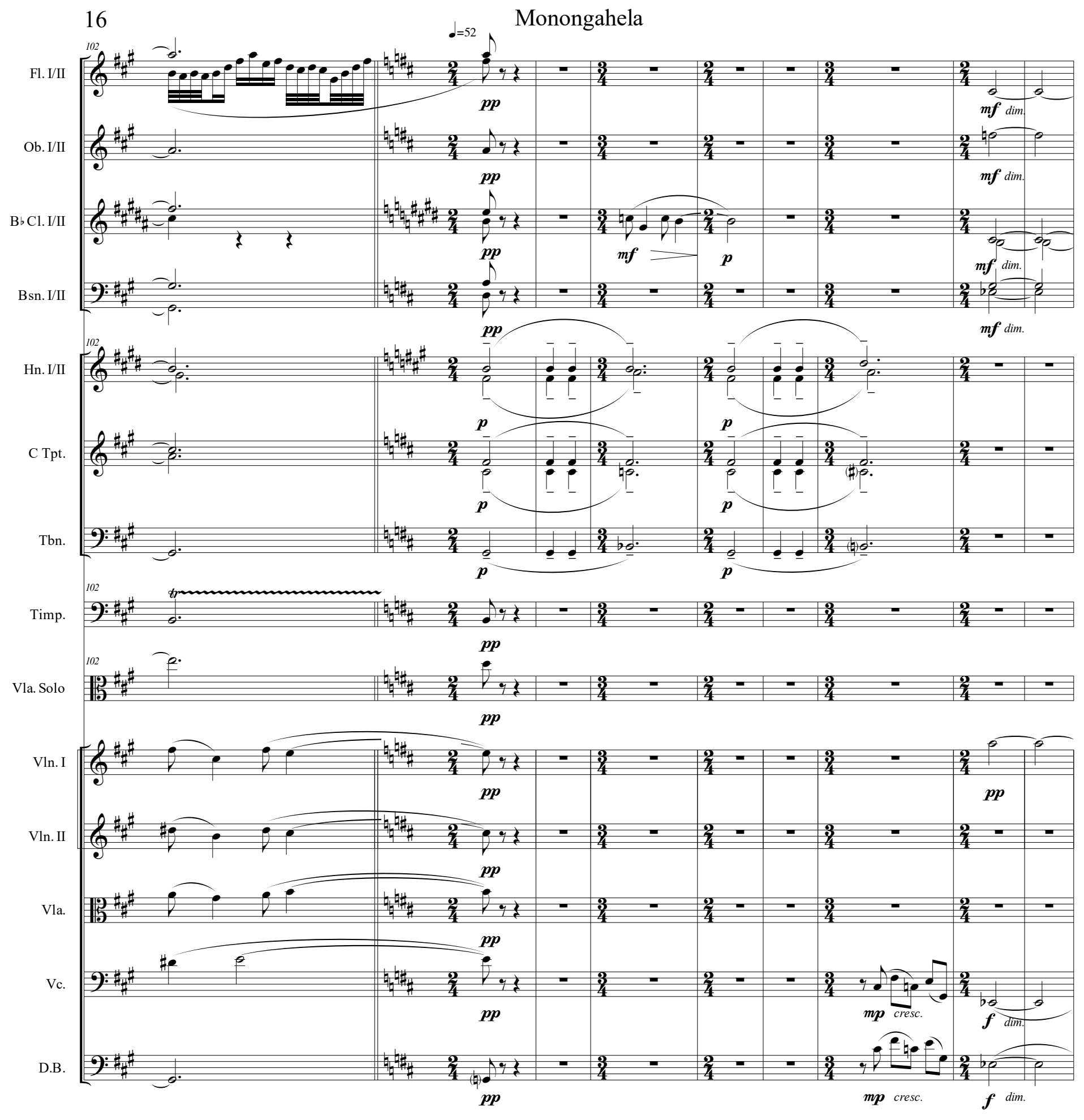


Monongahela

17

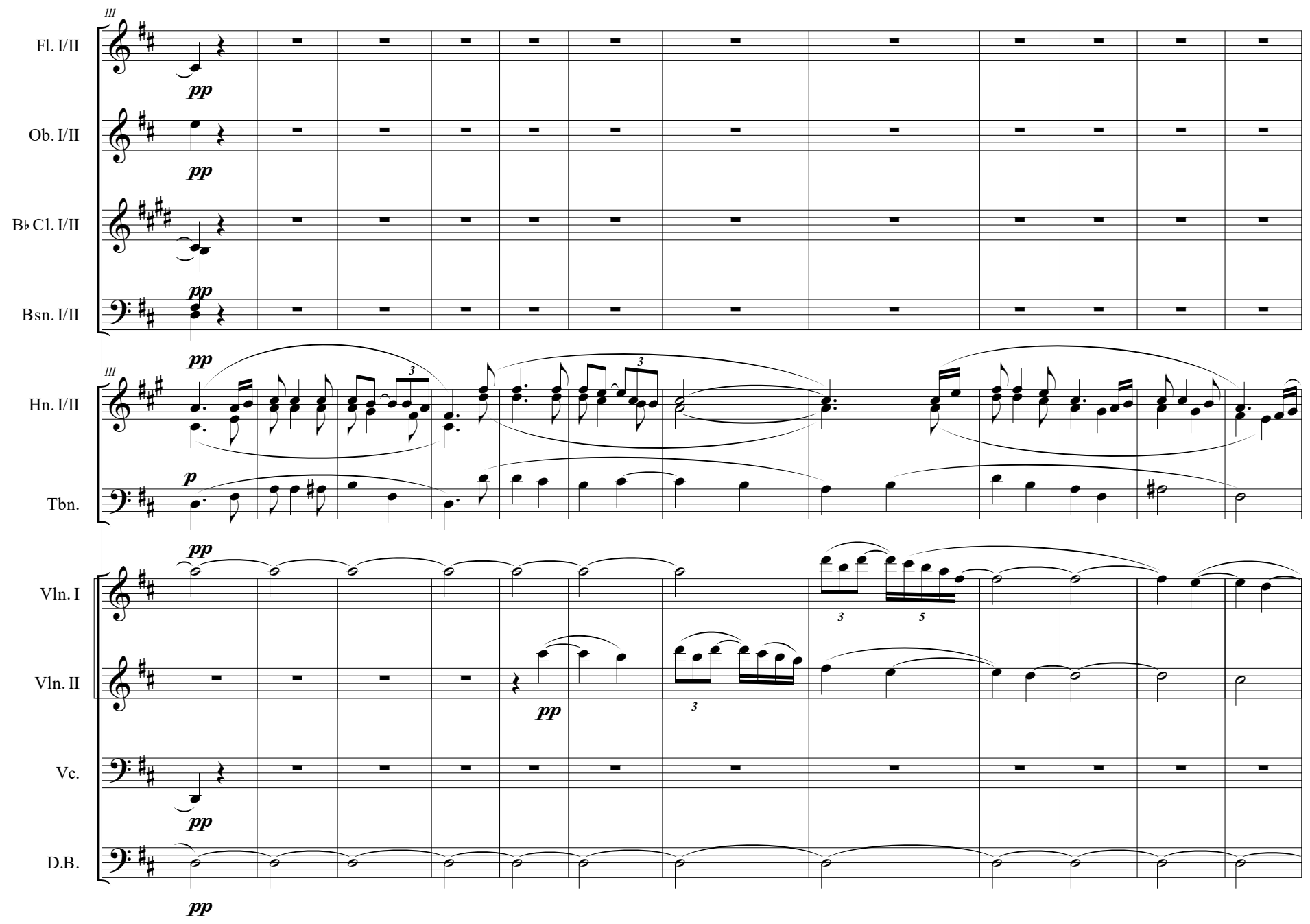

3 
Ob. I/II

8

Hn. I/II

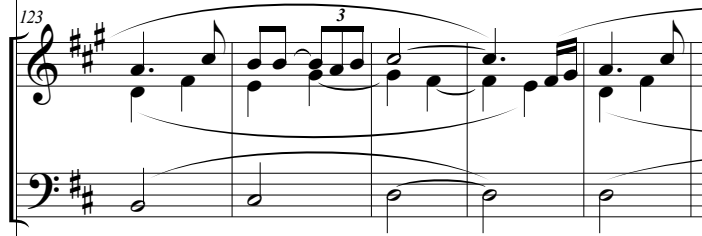

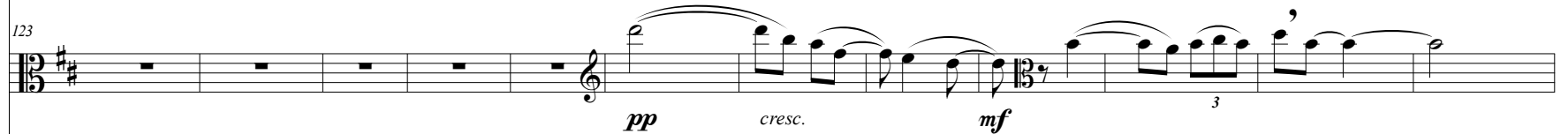

Vln. I

Vln. II

Vla.

Vc.

D.B

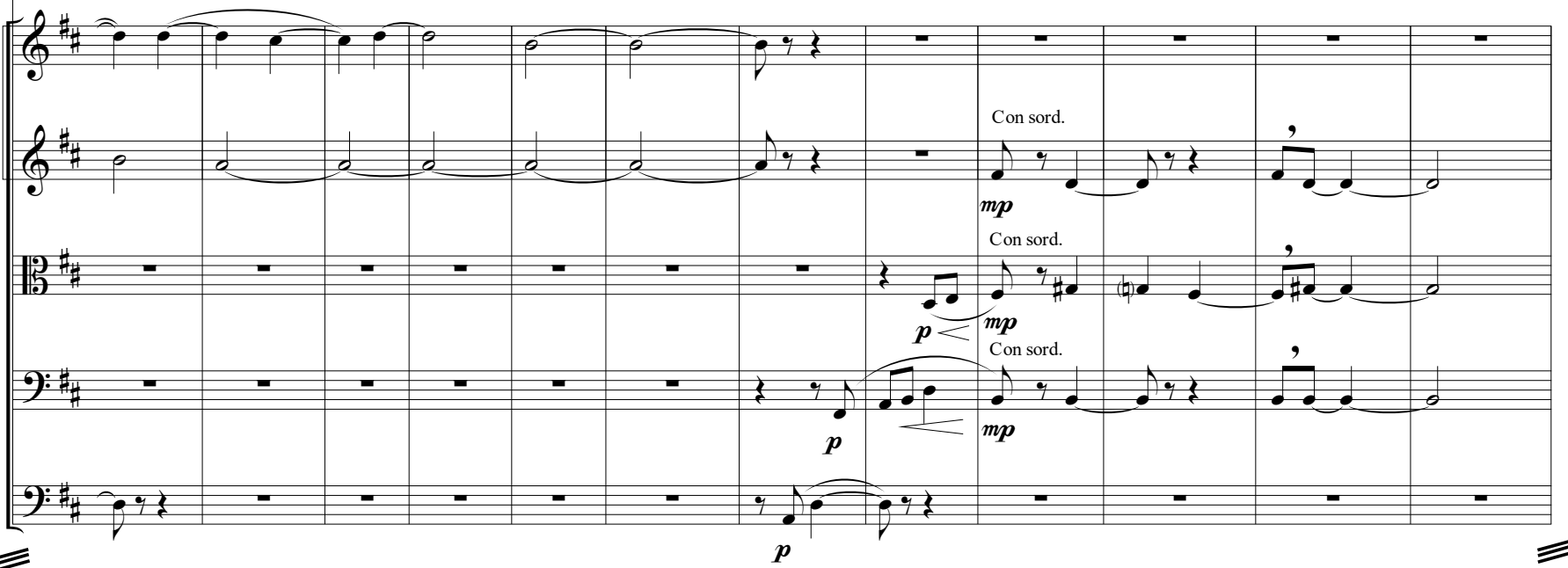

Fl. I/II

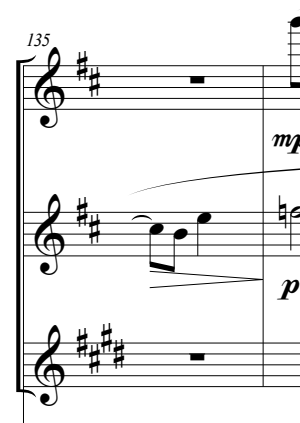

Vla. Solo

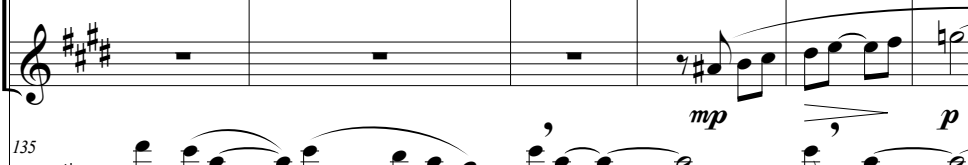

壬

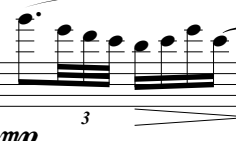

$p$

Ob. I/II

B b Cl. I/I

Vln. II

Vla.
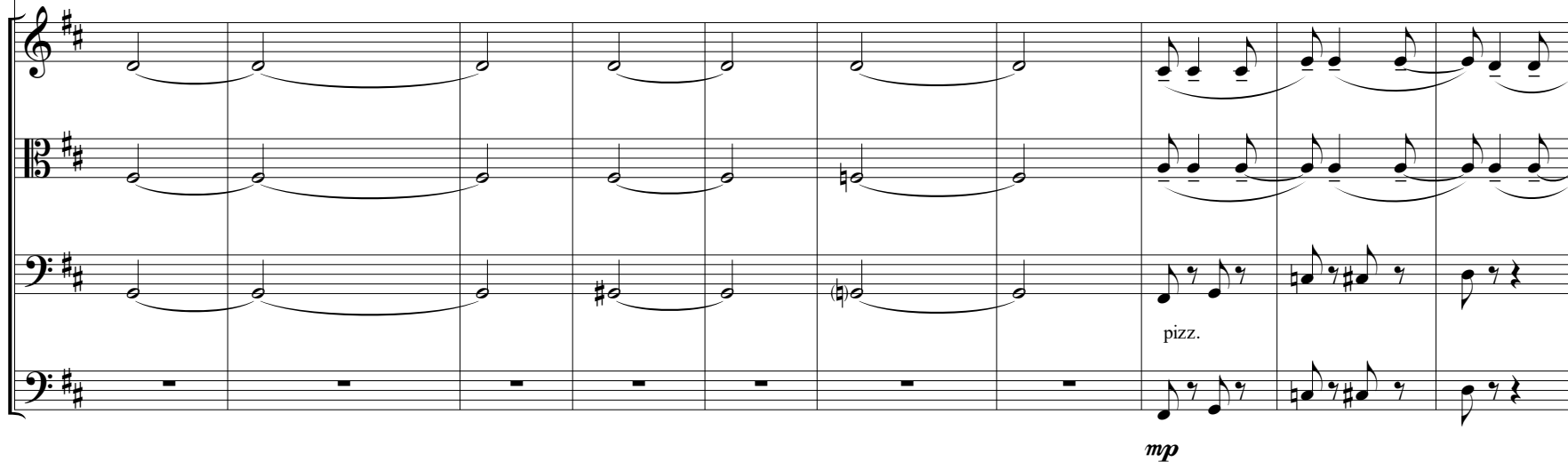


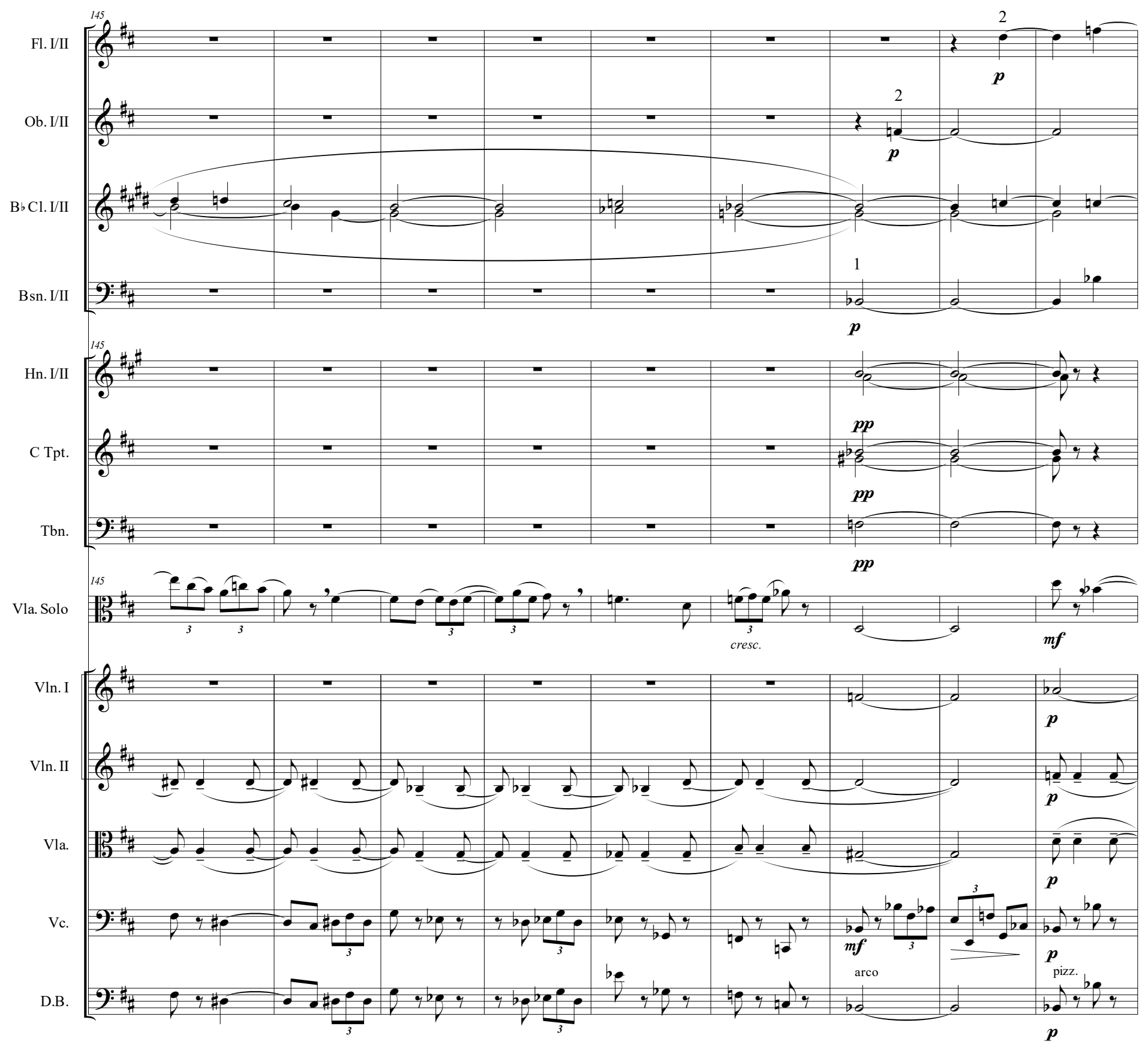


Fl. I/II

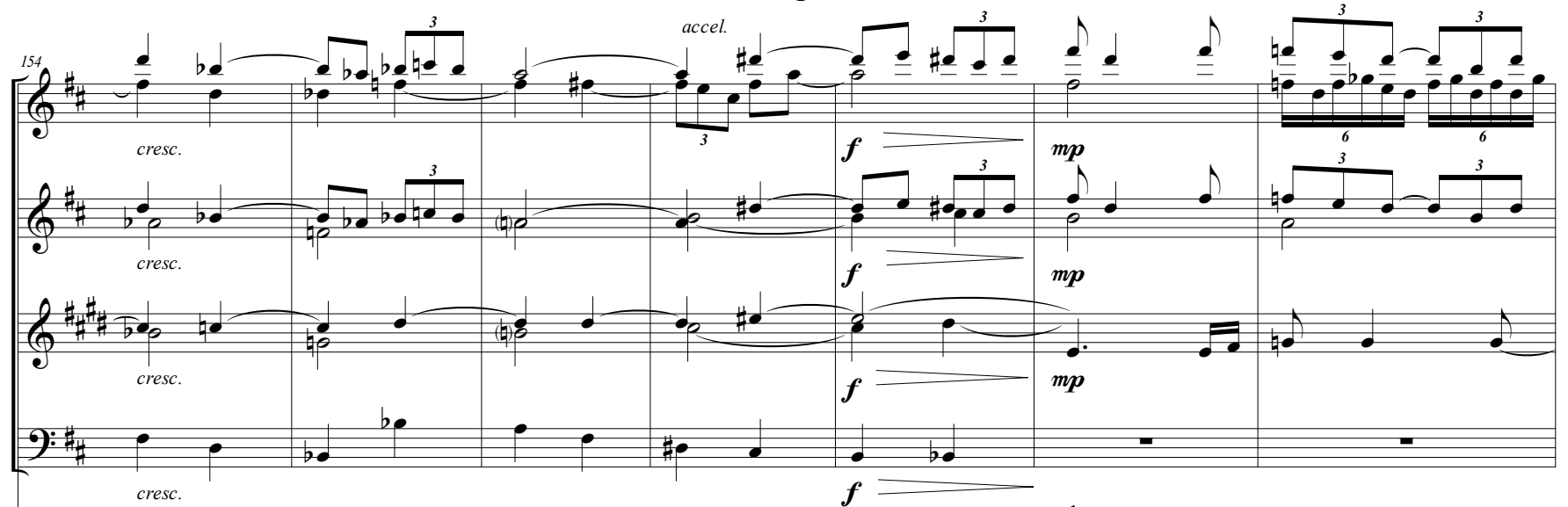

B b Cl. I/II

Bsn. I/II

Hn. I/II

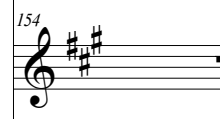

Vla. Solo
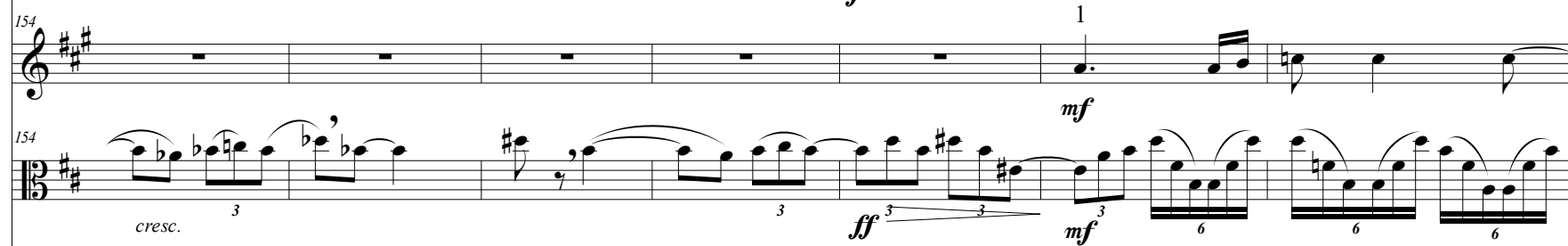

Vln. I

10
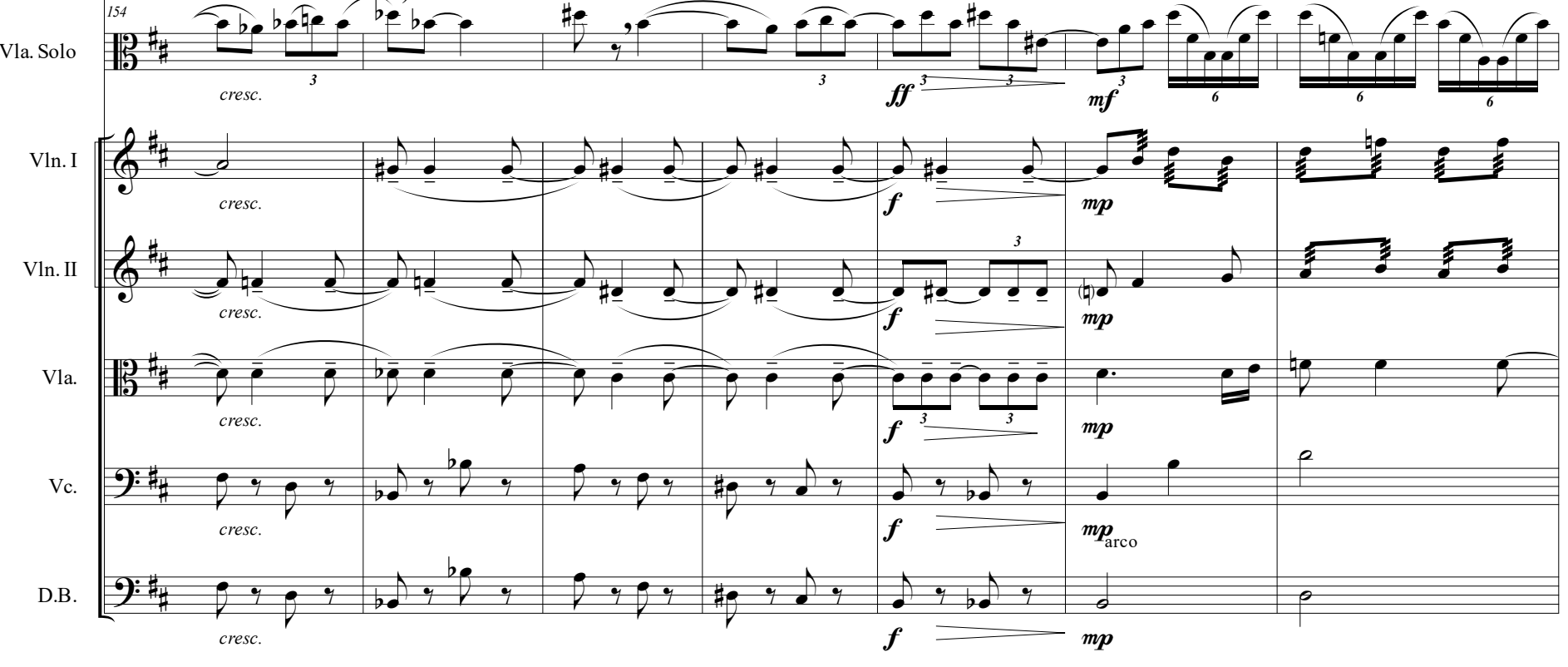
Monongahela

Fl. I/II

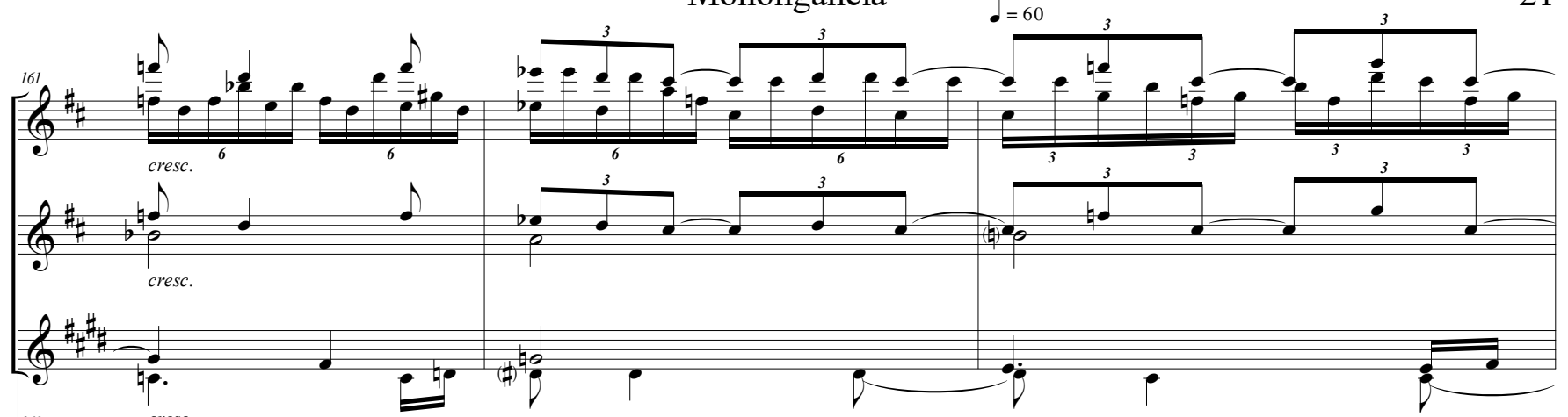

Hn. I/II

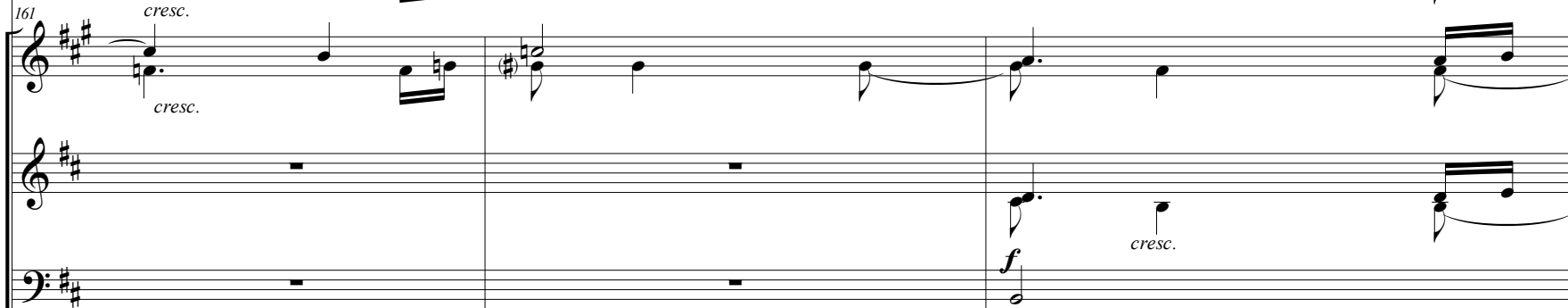

Vla. Solo

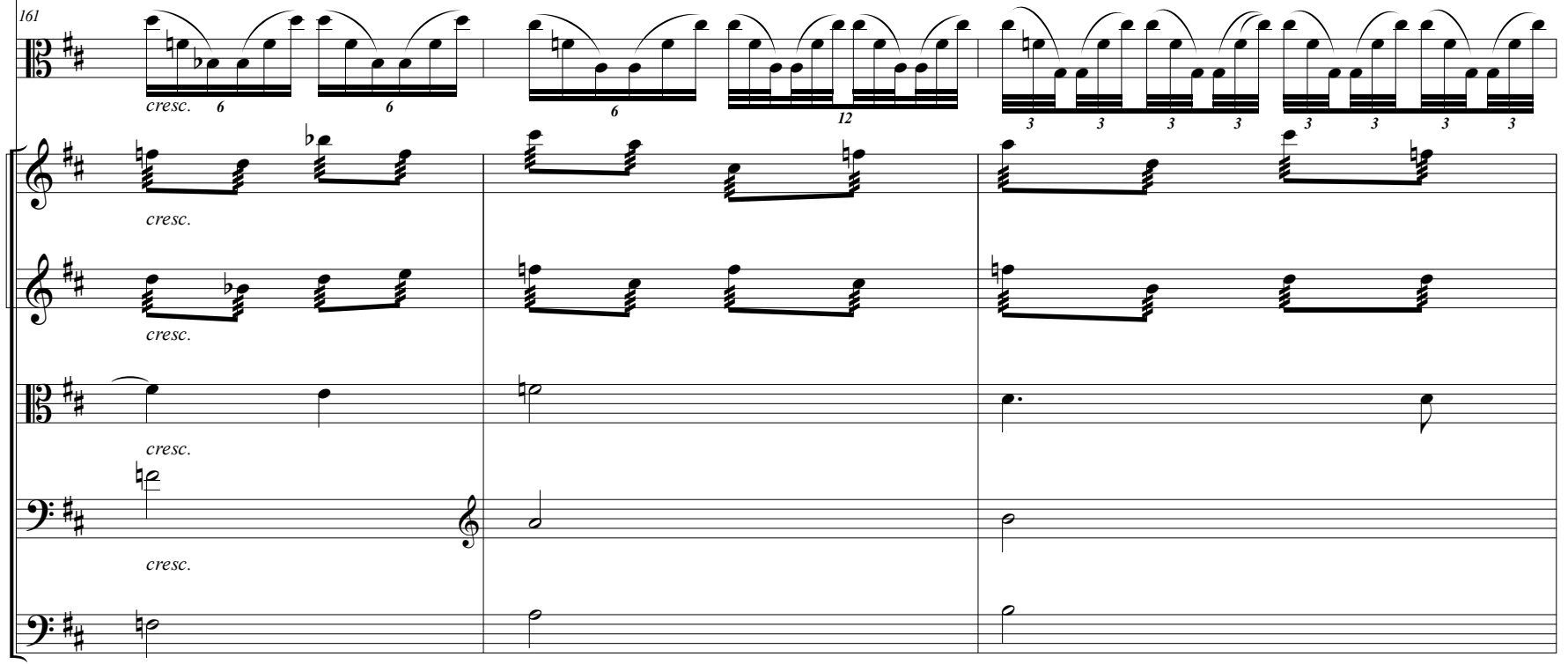

cresc. 
Monongahela

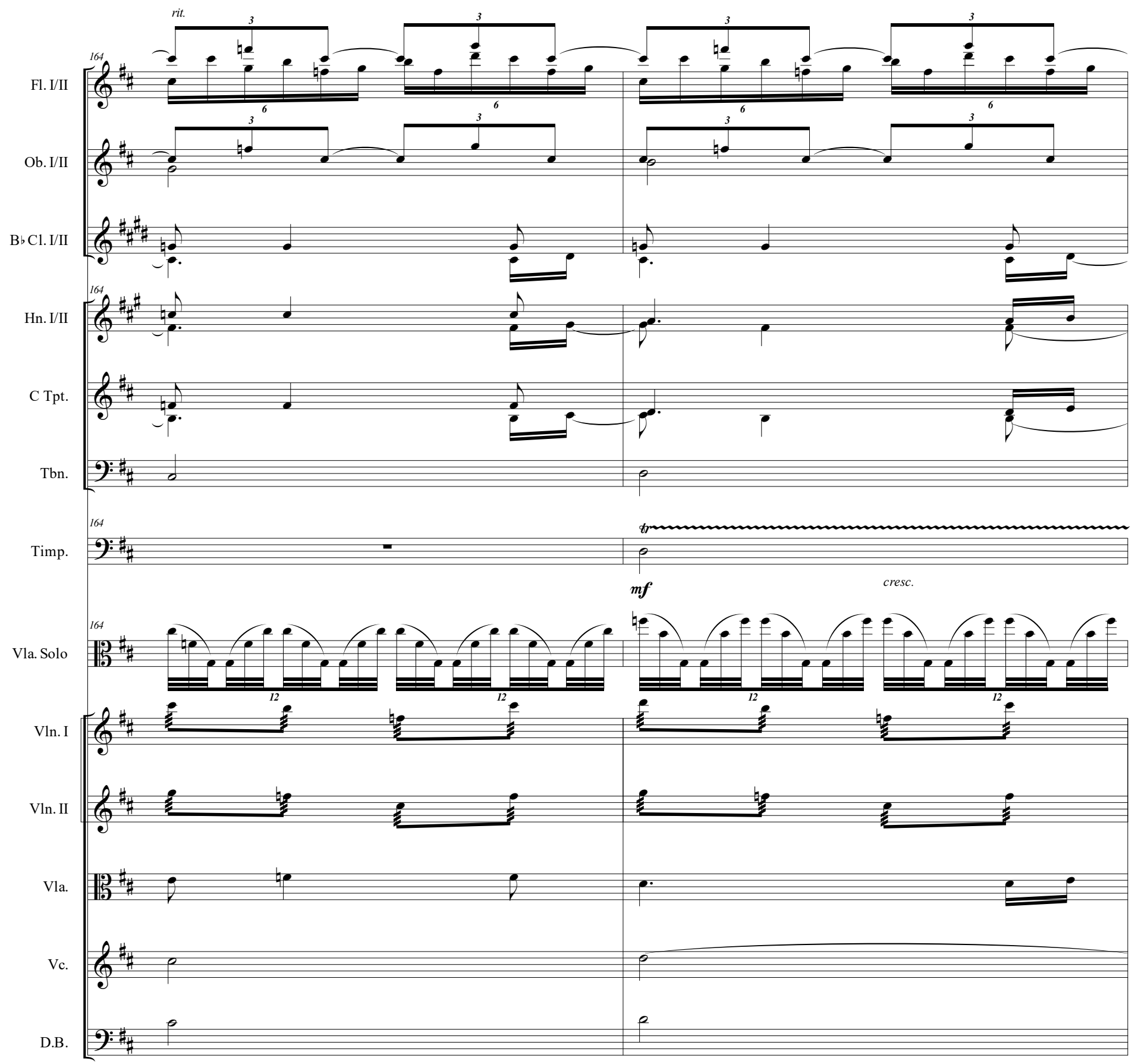


Fl. I/II
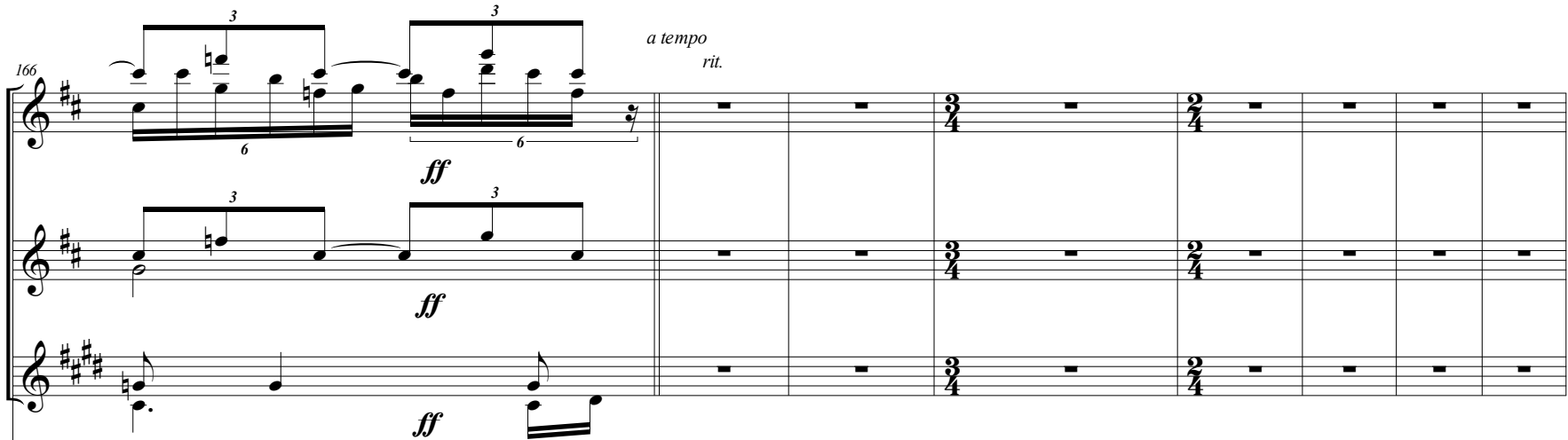

Hn. I/II

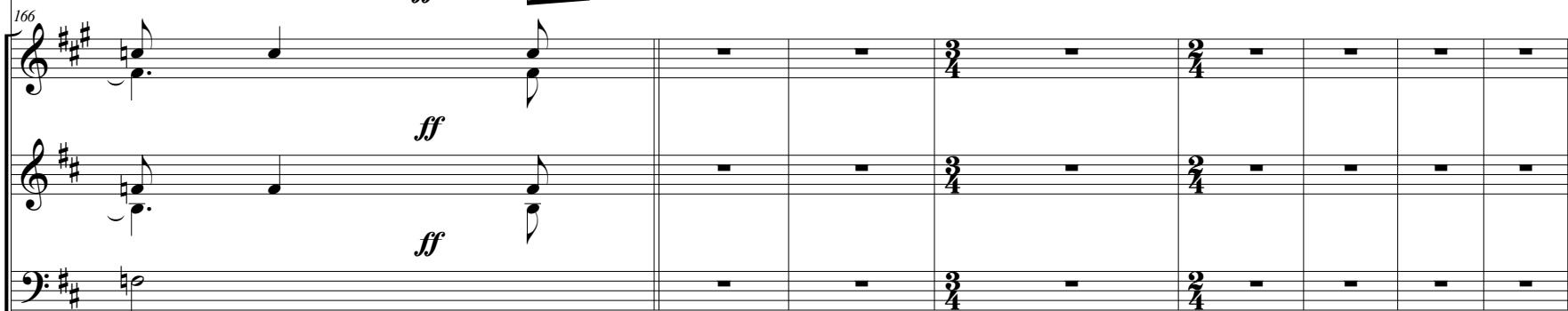

Tbn

166

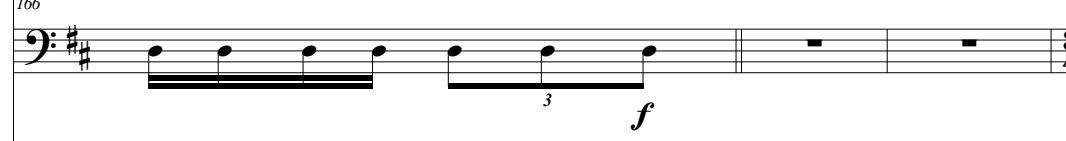

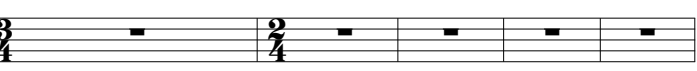

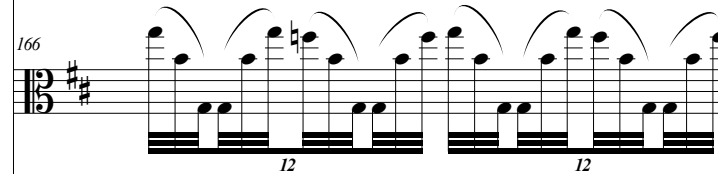

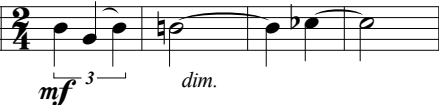

Vla. Solo

$\equiv \equiv=\underline{12} \equiv$

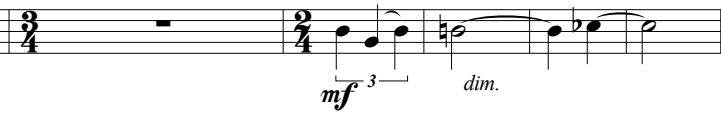

Vln. I

$0^{0}$

Vln. II

2

Vla.

陪

Vc.

0

D.B

2: 䜣

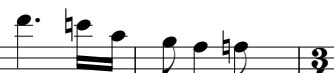

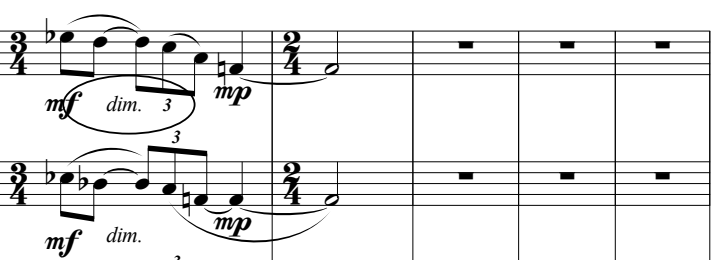

ff $\operatorname{dim} . \quad \overrightarrow{\boldsymbol{m} \boldsymbol{f}} \operatorname{dim}$.

: $=9 \cdot 9$

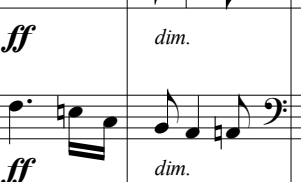

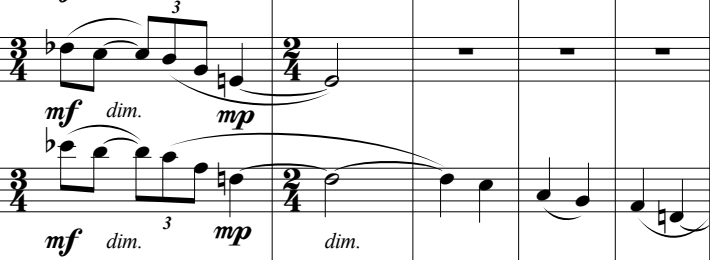

$\boldsymbol{m} \boldsymbol{f} \operatorname{dim.~}^{3} \boldsymbol{m p}$

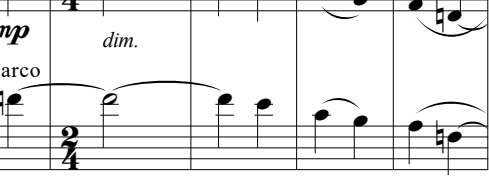

ff

$m p$ 

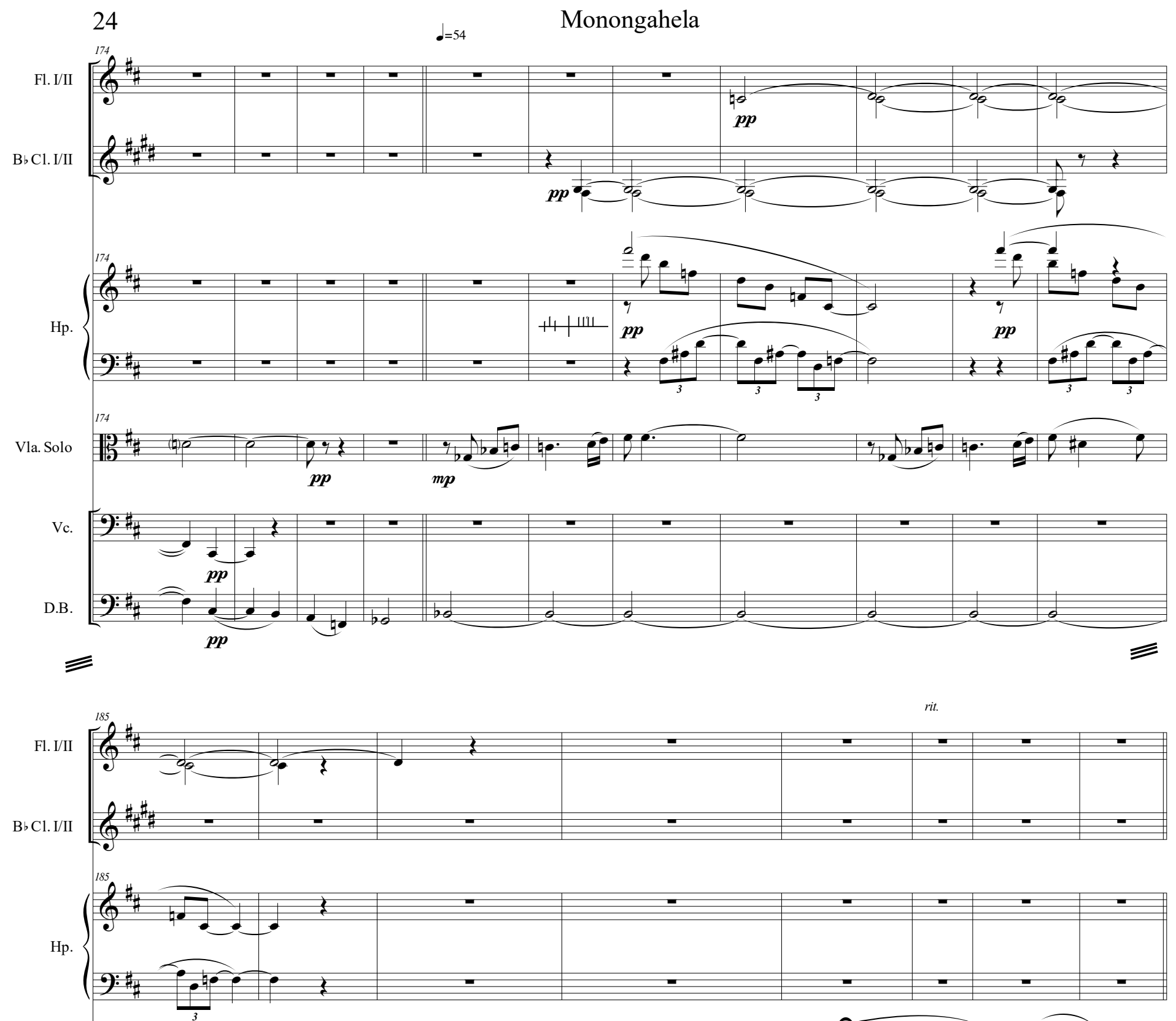

Vla. Solo

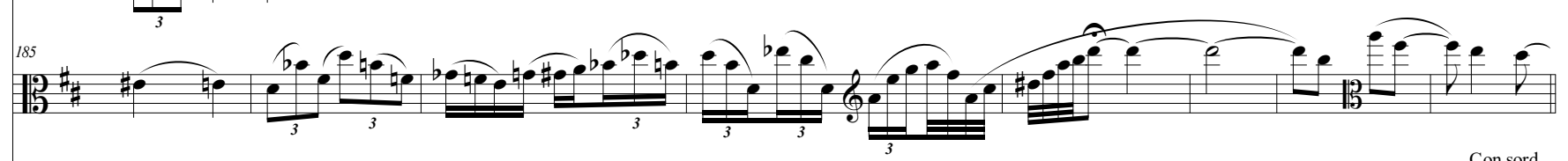

Vla.

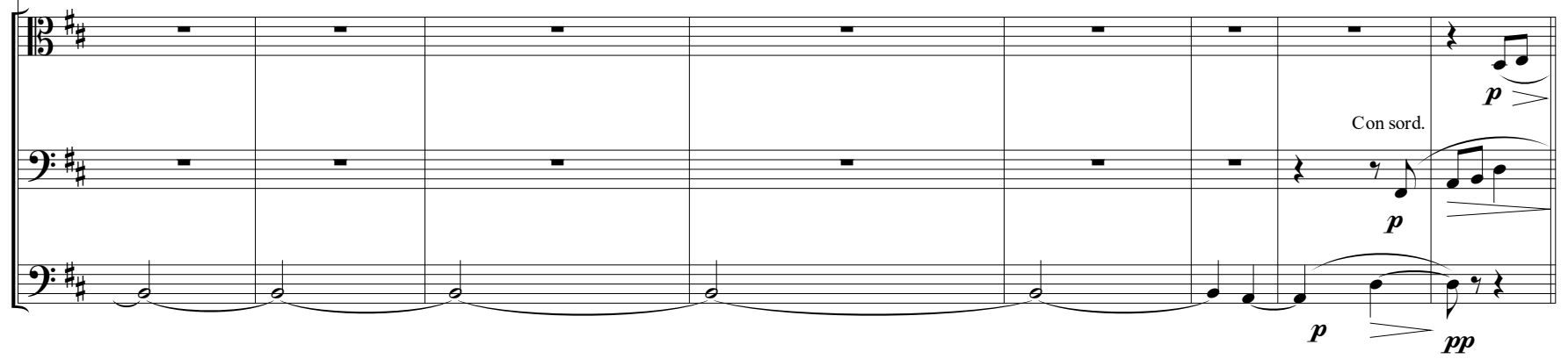



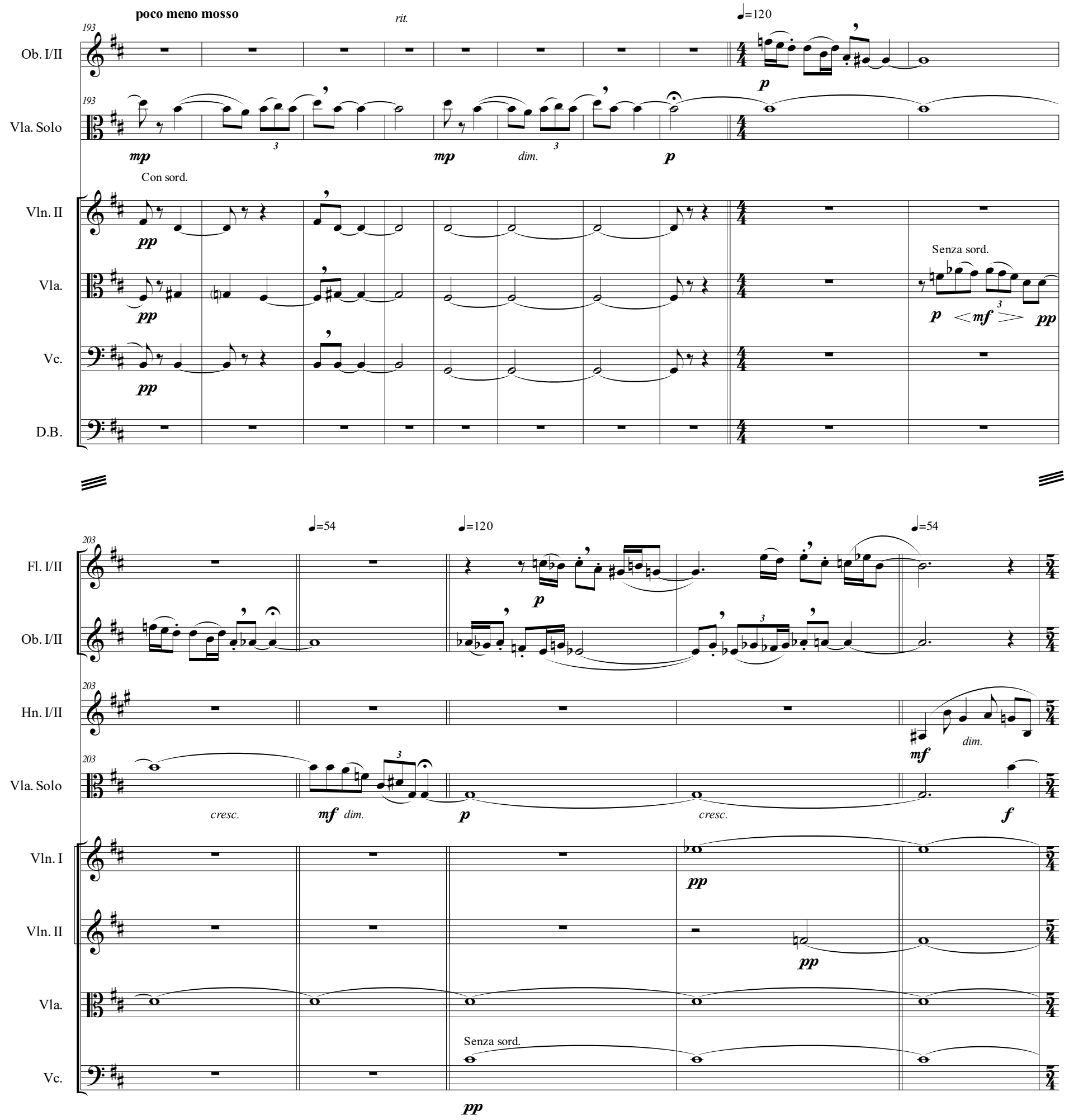

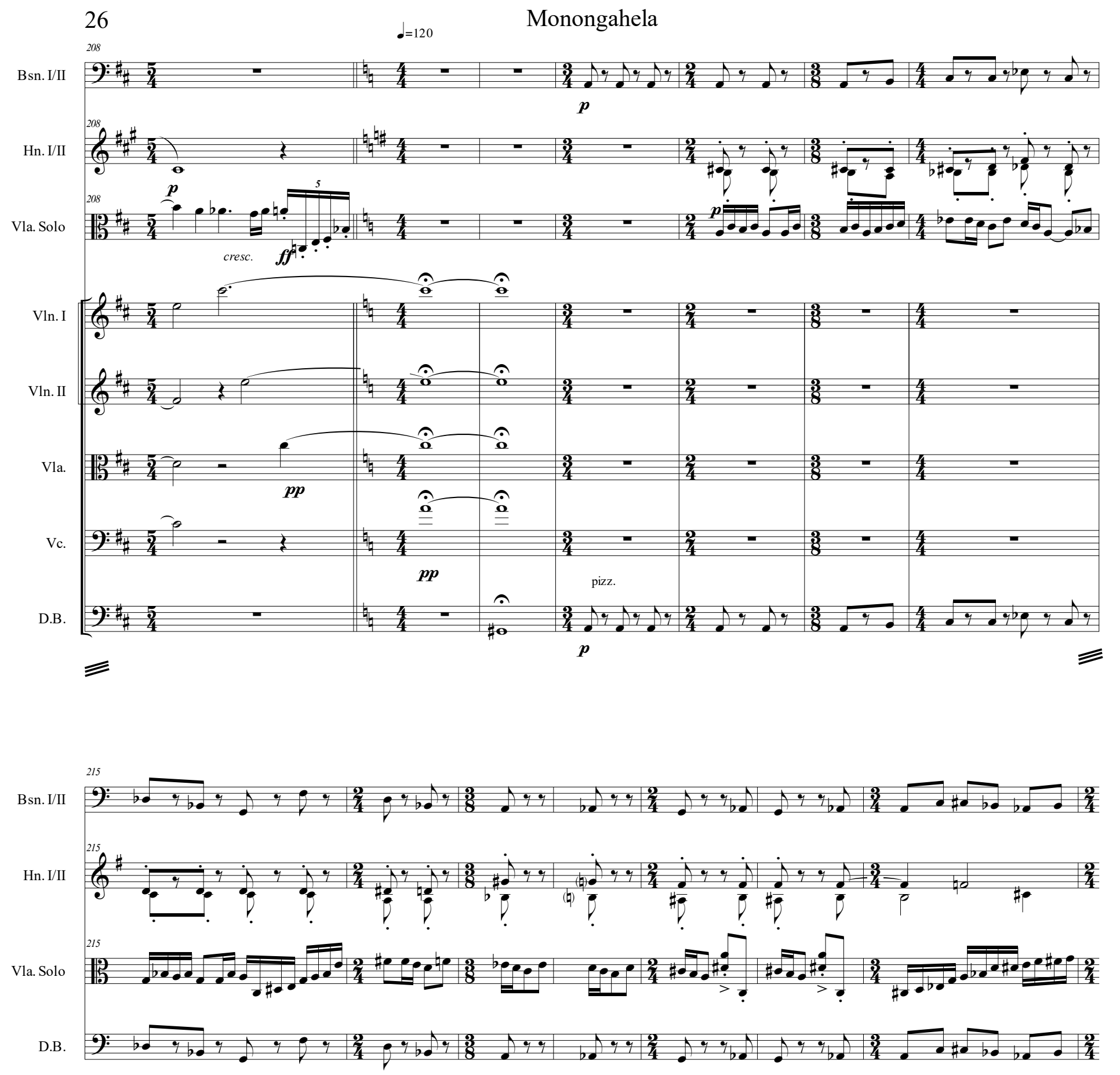


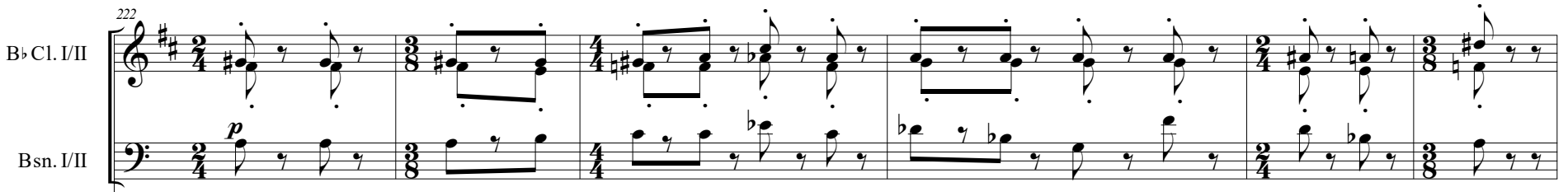

Hn. I/II

$\int^{222}$

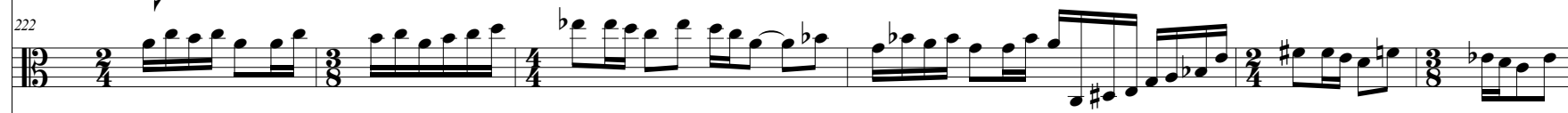

Vc.

(9):

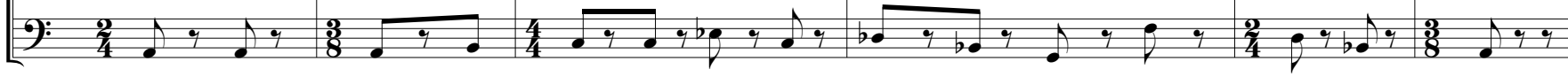
$\equiv$

$\equiv$

Fl. I/II

Ob. I/II

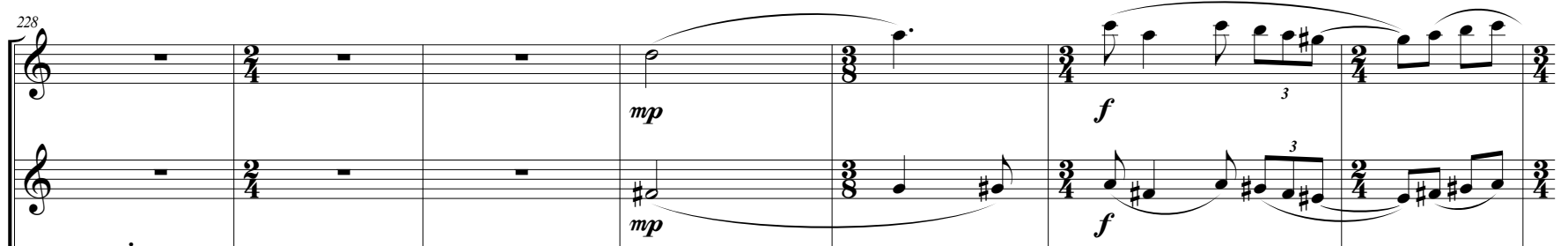

$\mathrm{B} b \mathrm{Cl}$. I/II

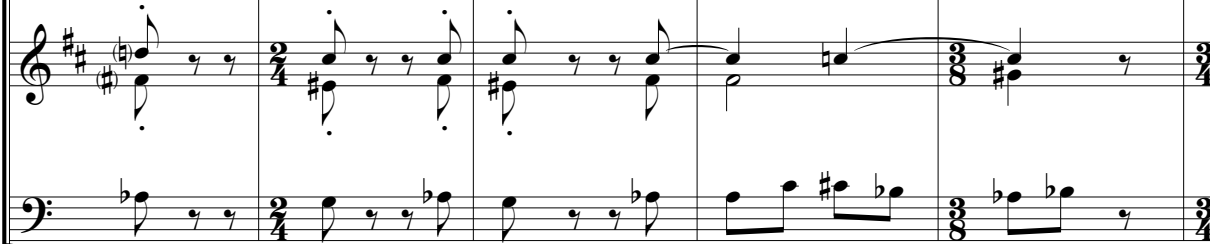

Bsn. I/II

Hn. I/II

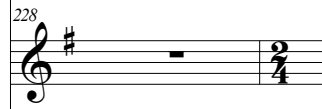

Vla. Solo

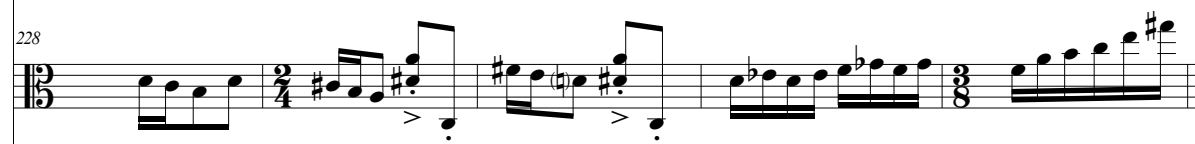

Vln. I

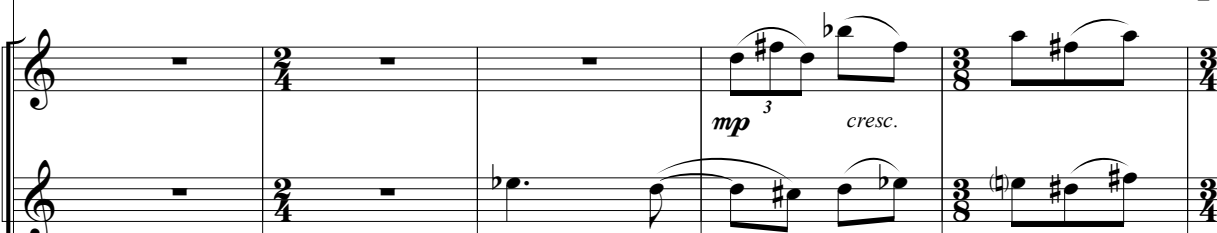

Vln. II

Vla.

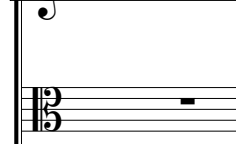

Vc.

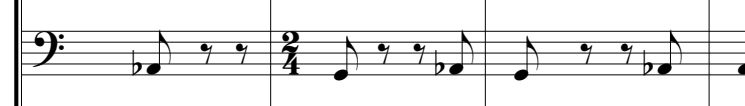

D.B.

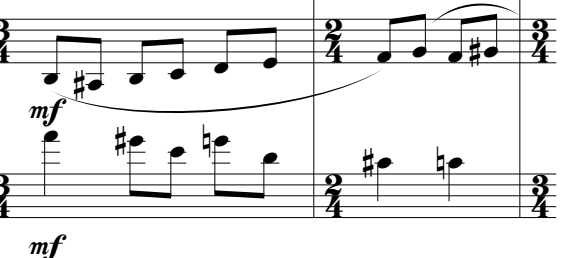

$m \boldsymbol{f}$
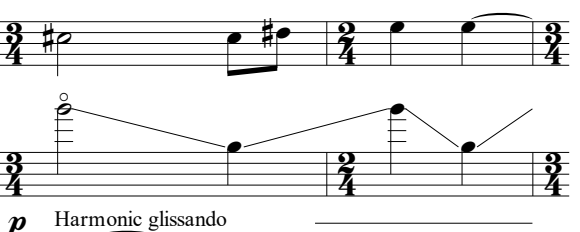

Harmonic glissand

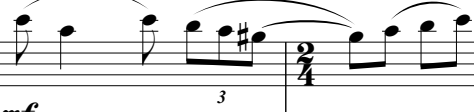

$m \boldsymbol{f}$

$\overbrace{m f}$

$m p \quad$ cresc. $\longrightarrow m \boldsymbol{f}$

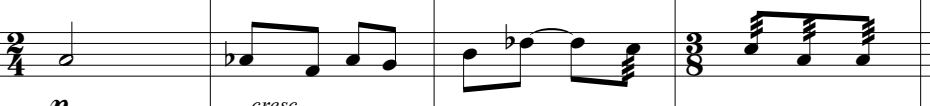

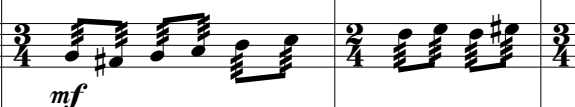

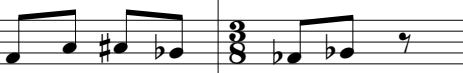

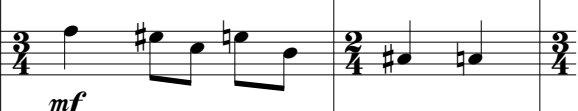

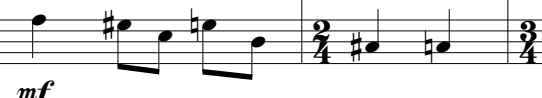




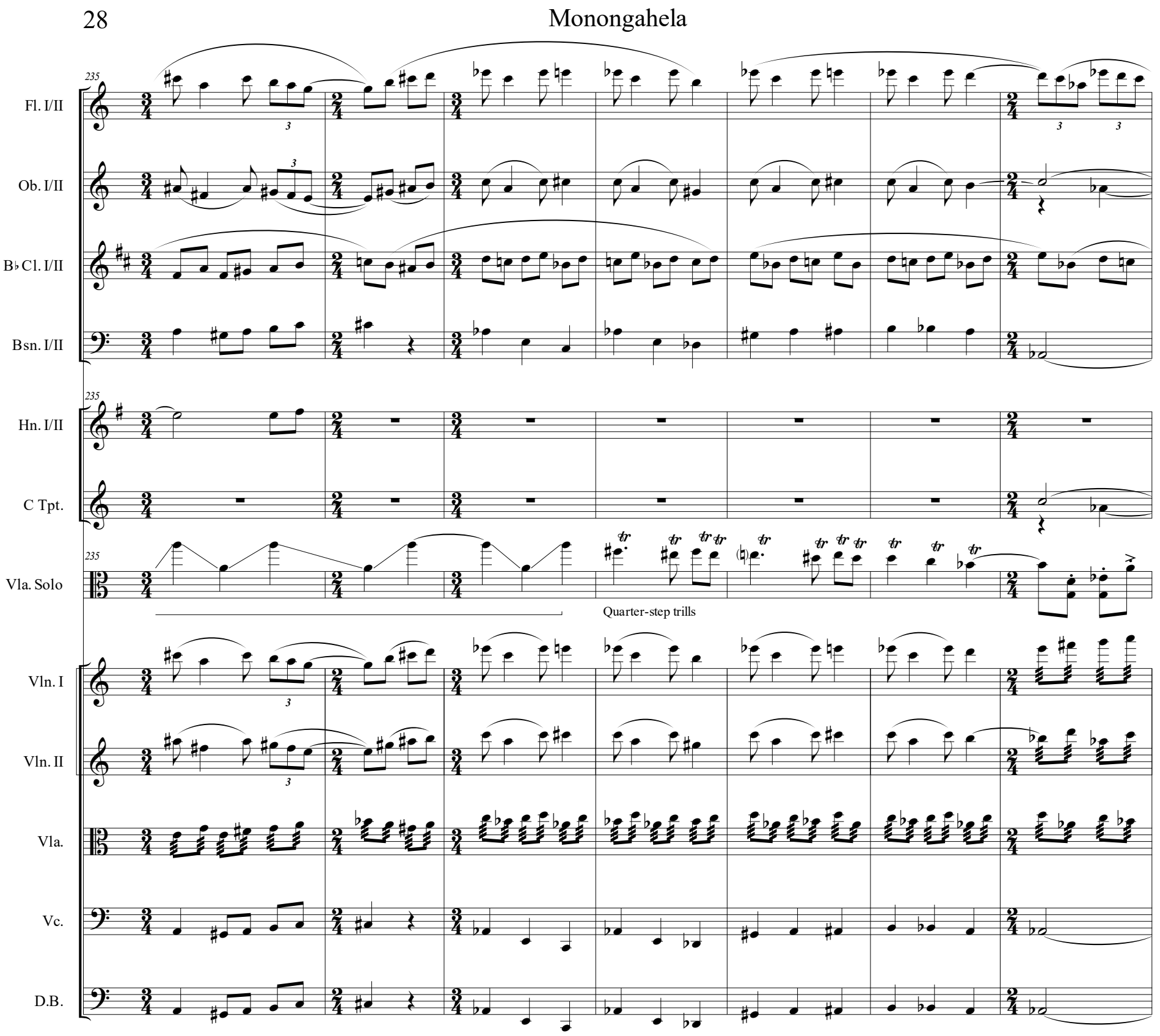


Fl. I/II

$\mathrm{B} b \mathrm{Cl}$. I/II

Ob. I/II

Bsn. I/II

6

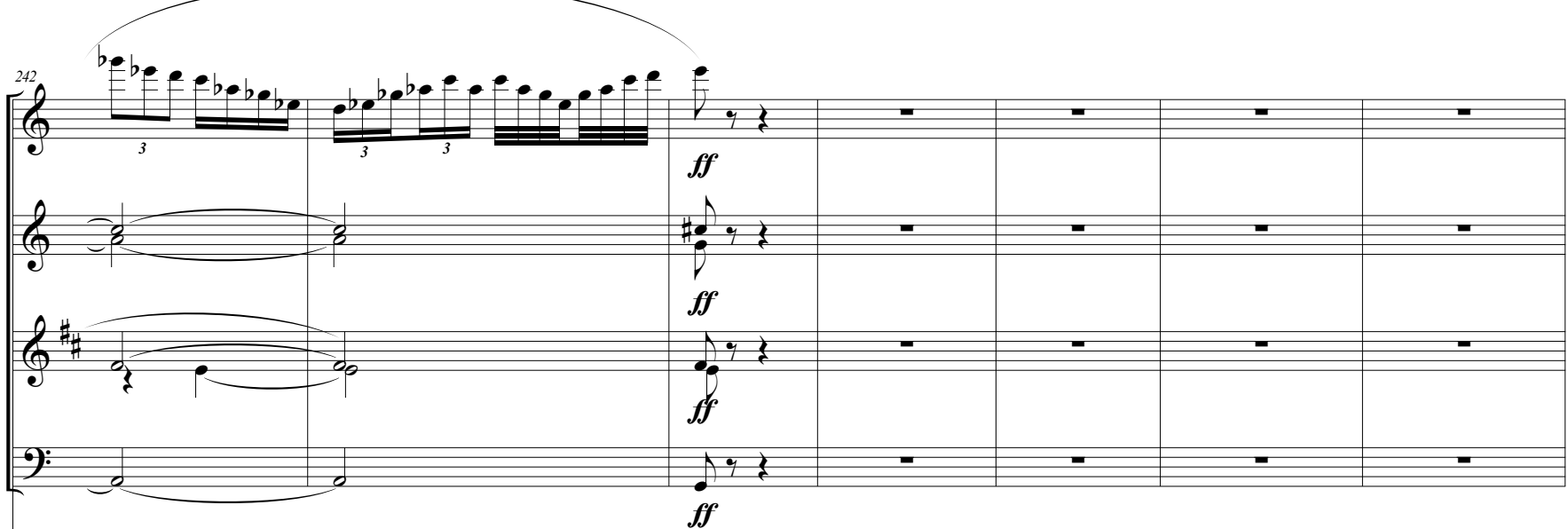

Hn. I/II

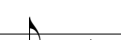

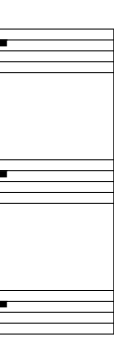

Vla. Solo

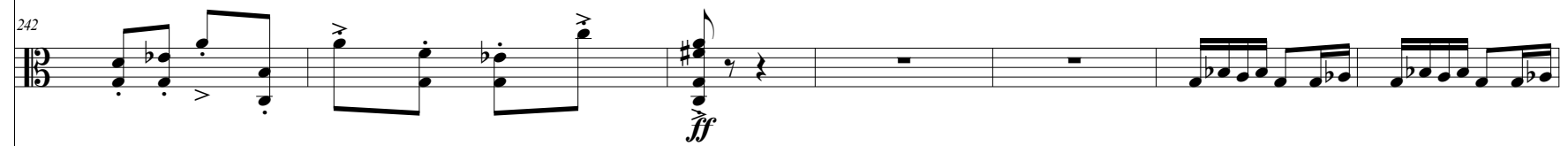

Vln. I

60

Vln. II

Vla.

Vc.

2)

D.B

2

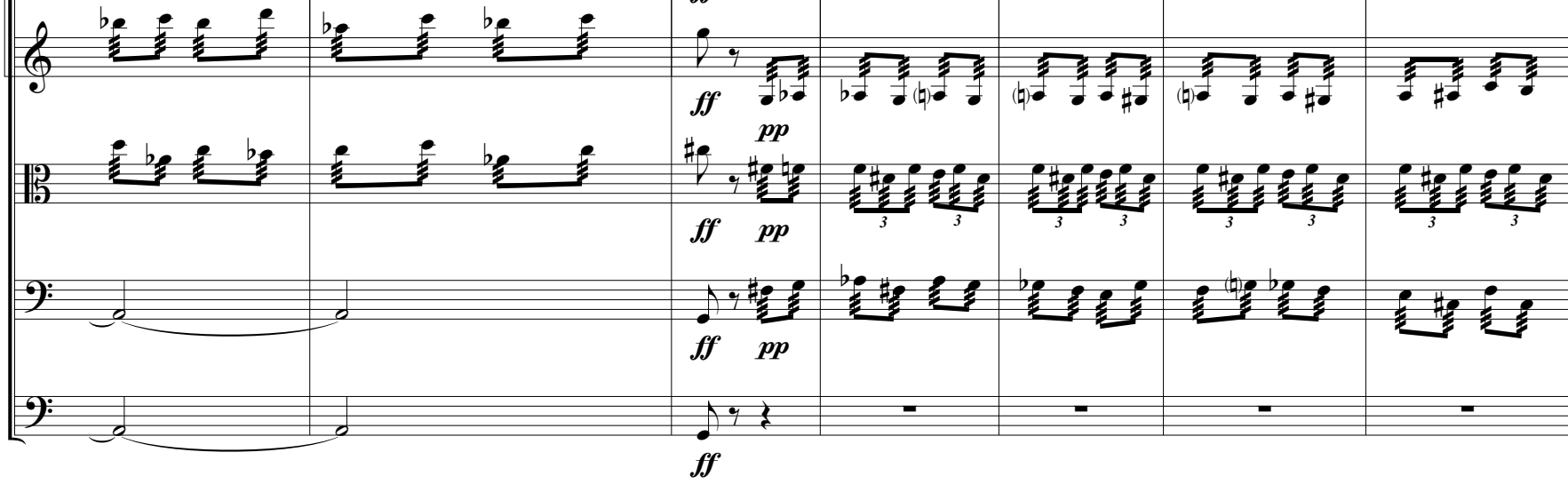


Vla. Solo

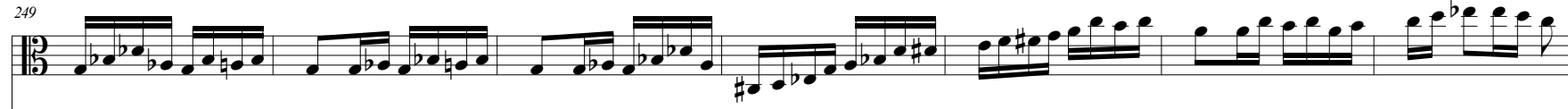

Vln. I

Vln. II

Vla.

c.

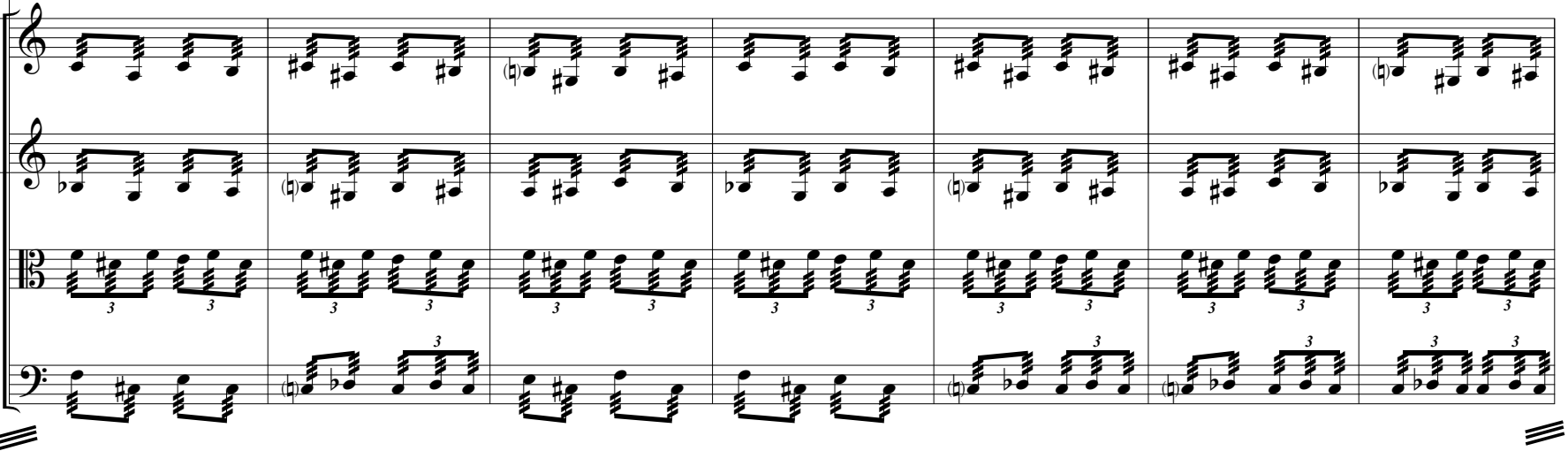

C Tpt

Tbn

Vla. Solo

8

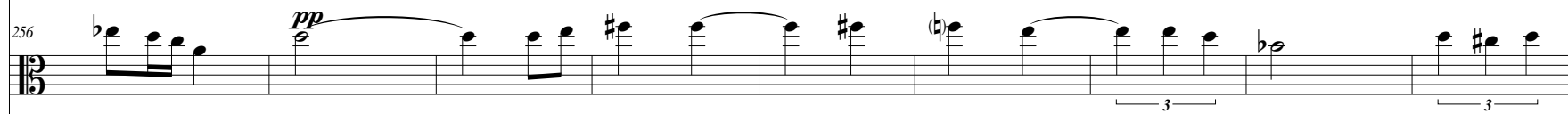

Vln. I

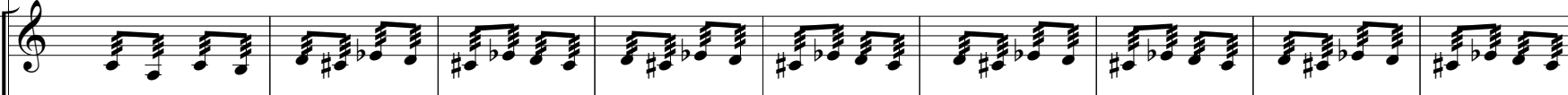

Vln. II

Vla.

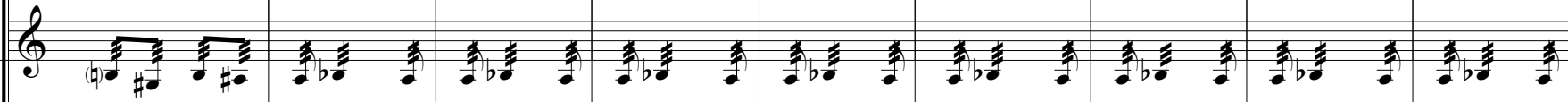

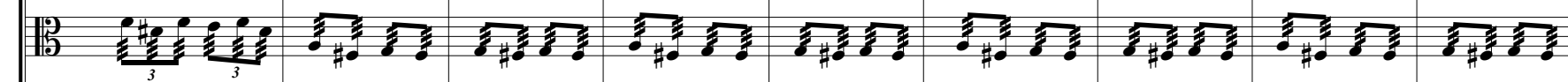

Vc.

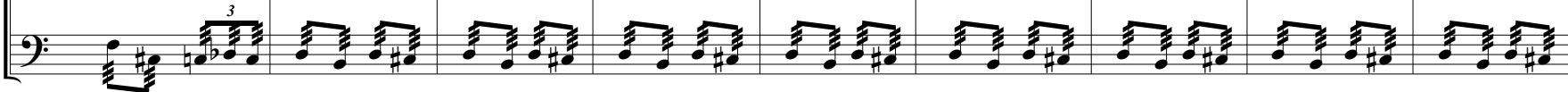




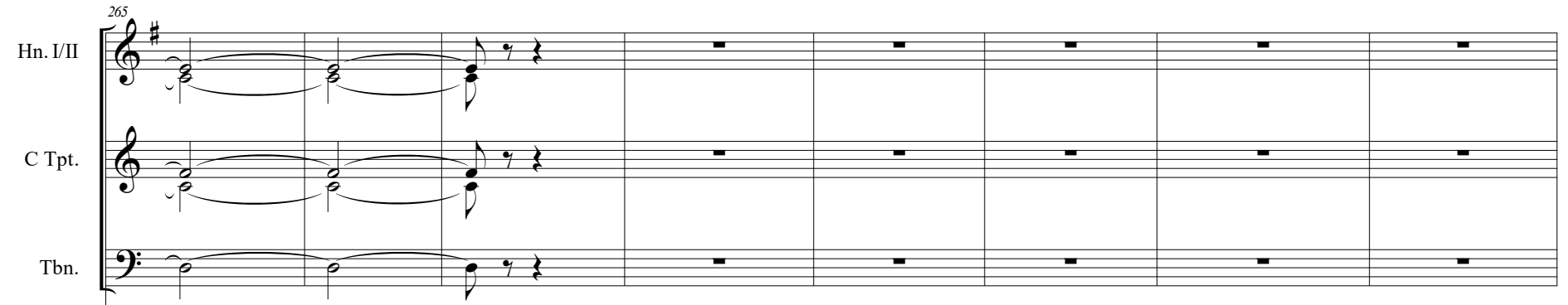

Vla. Solo

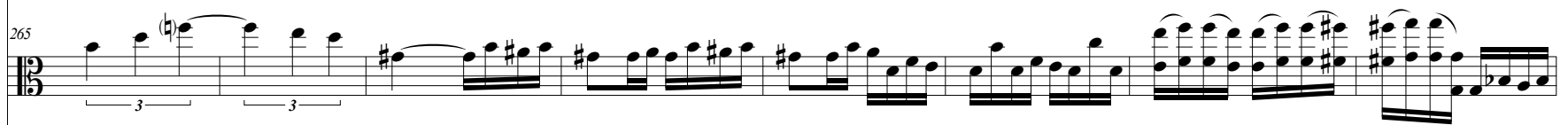

Vln. I

Vln. II

Vc.

(lesc.

$\approx$

Bsn. I/II

C Tpt.

Tbn.

la. Solo

Vln. I

Vln. II

Vla

Vc.

D.B.

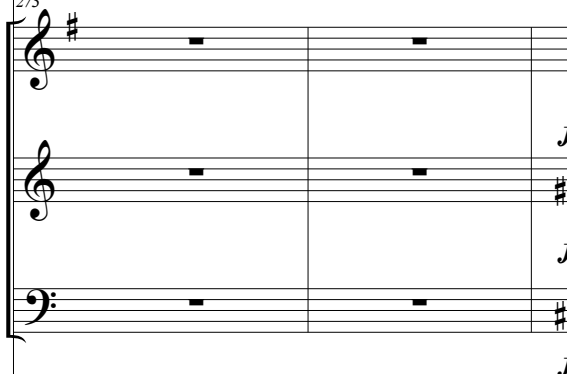

re
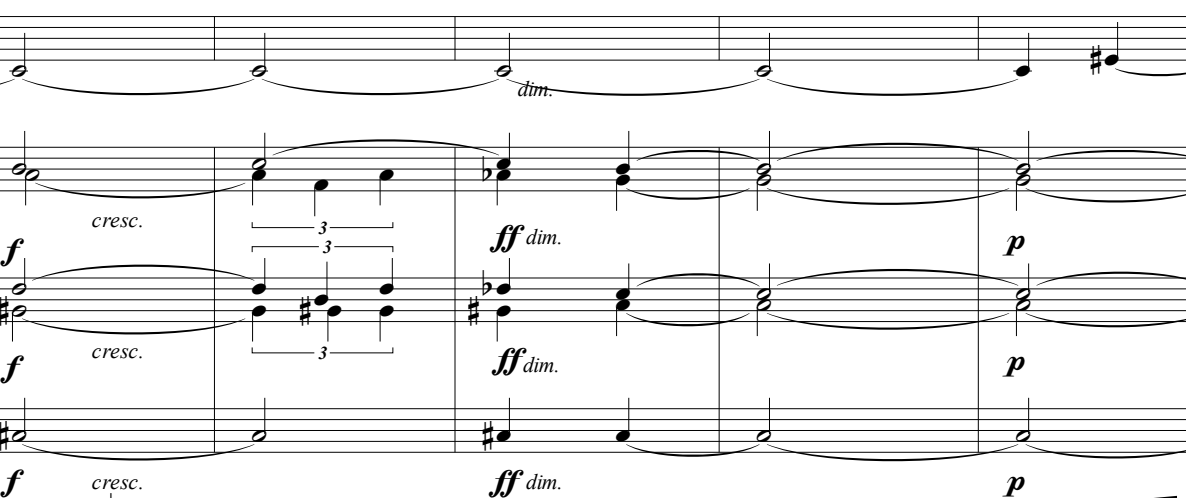

年3

0
6

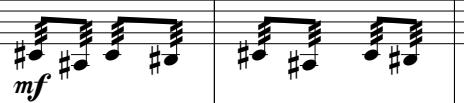

40

6

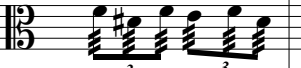

$\frac{5}{2}$

$m f$

$\frac{18}{2}$

8

$\boldsymbol{f f}$ dim.

$\boldsymbol{f f}_{\text {dim. }}$.
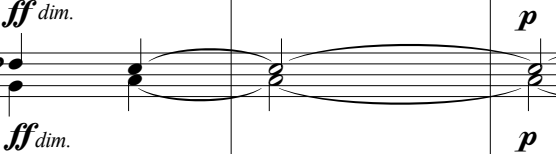


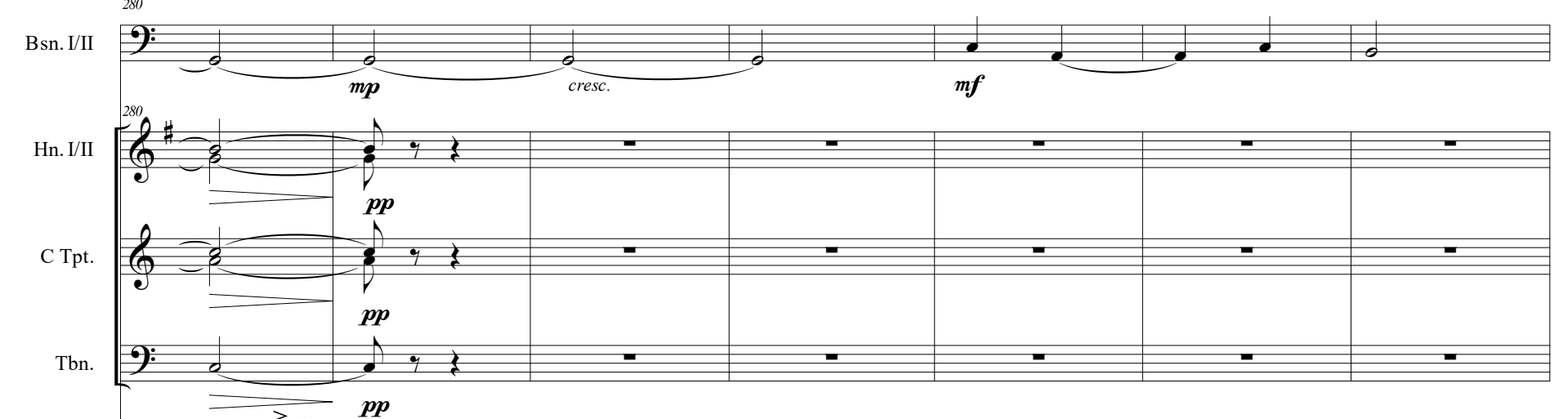

Vla. Solo $\left.\right|^{280}$

梛

Vc.

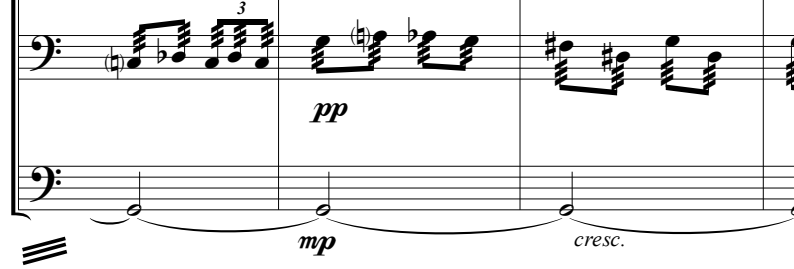

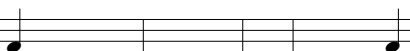

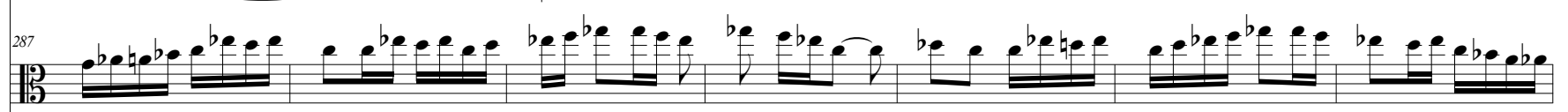

Vln. I V

Vln. II 

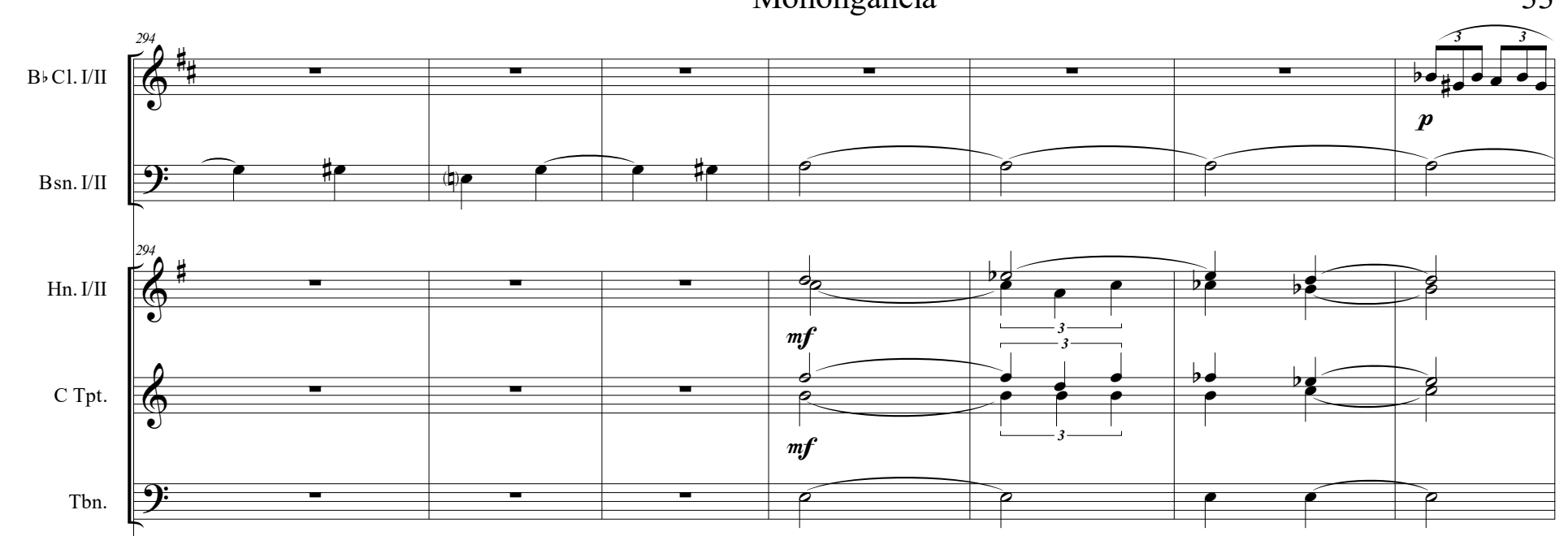

Vla. Solo

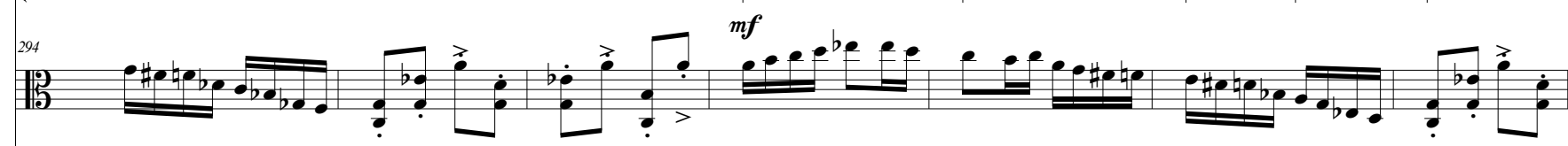

Vln. I

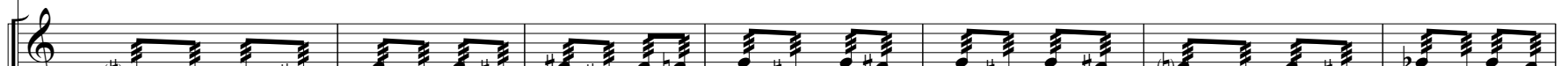

Vln. II

Q)



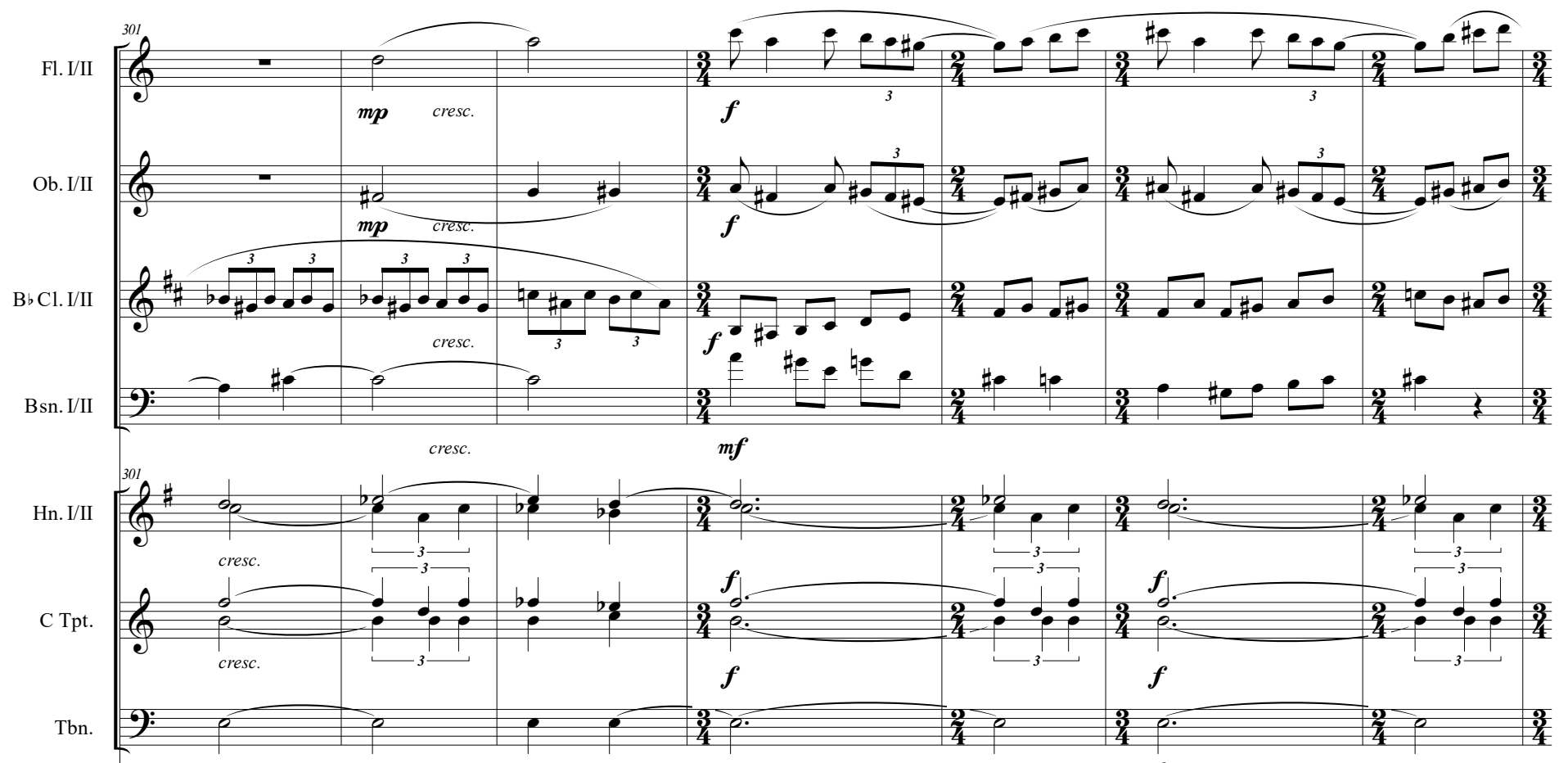

Vla. Solo
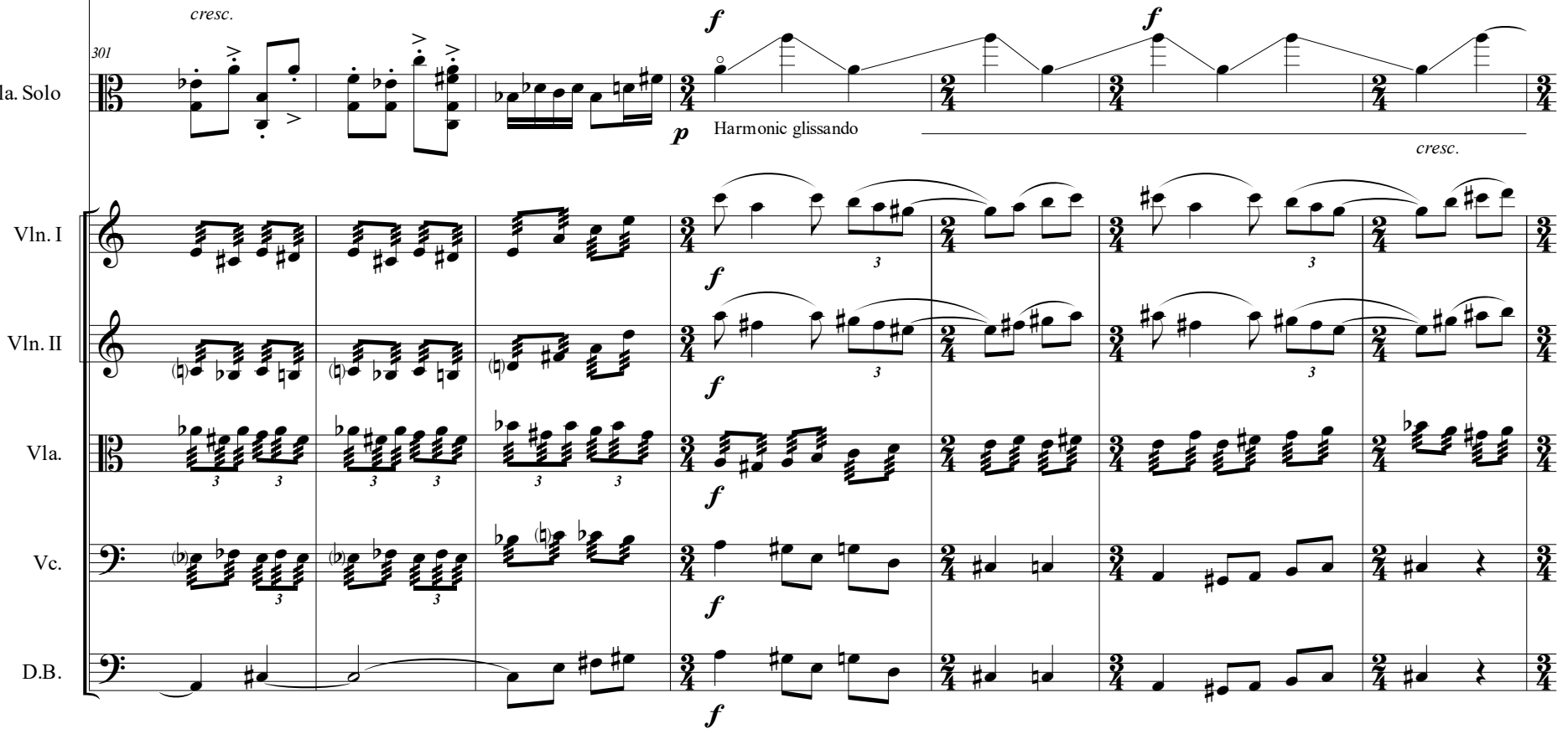


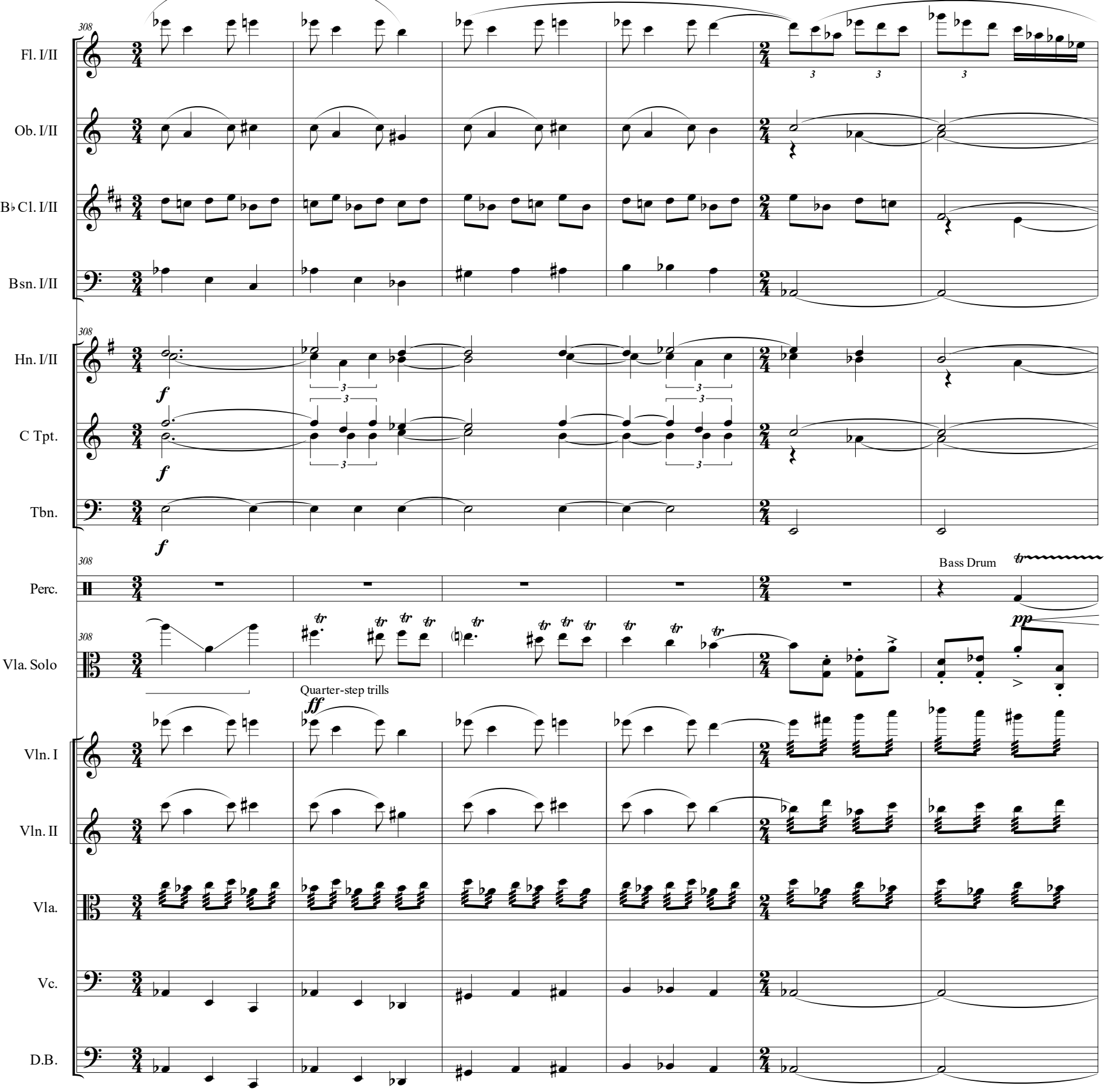




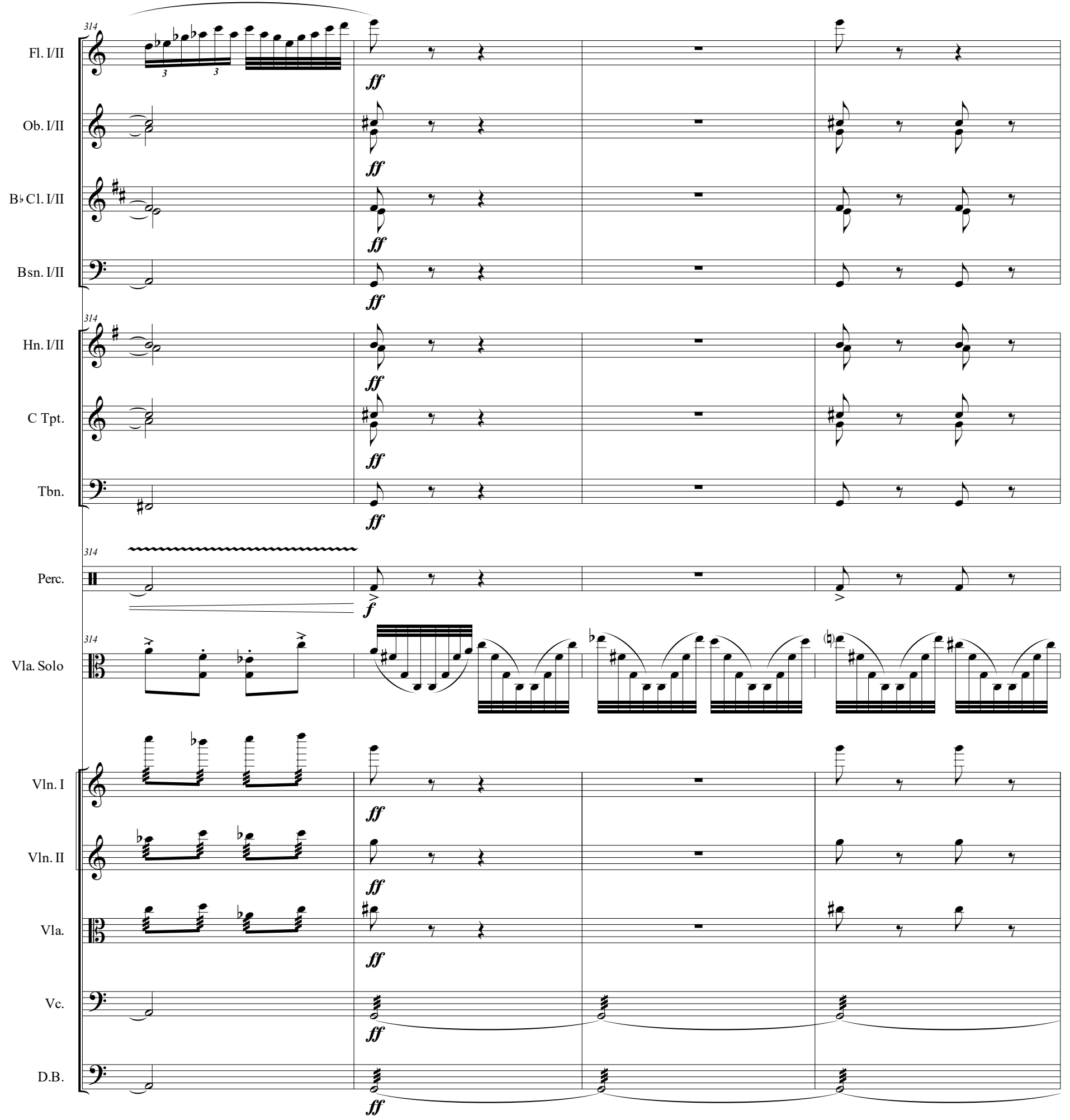




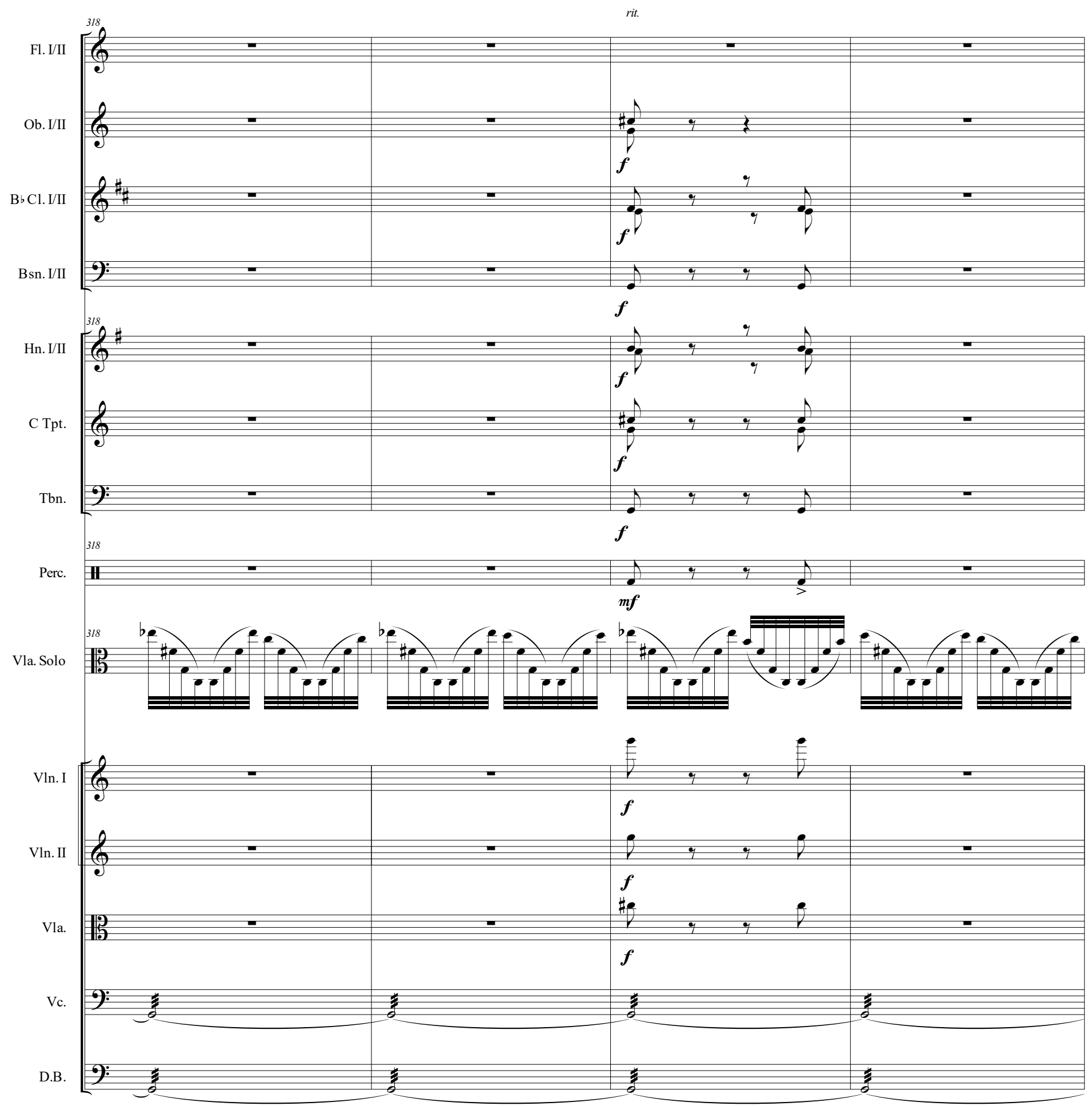




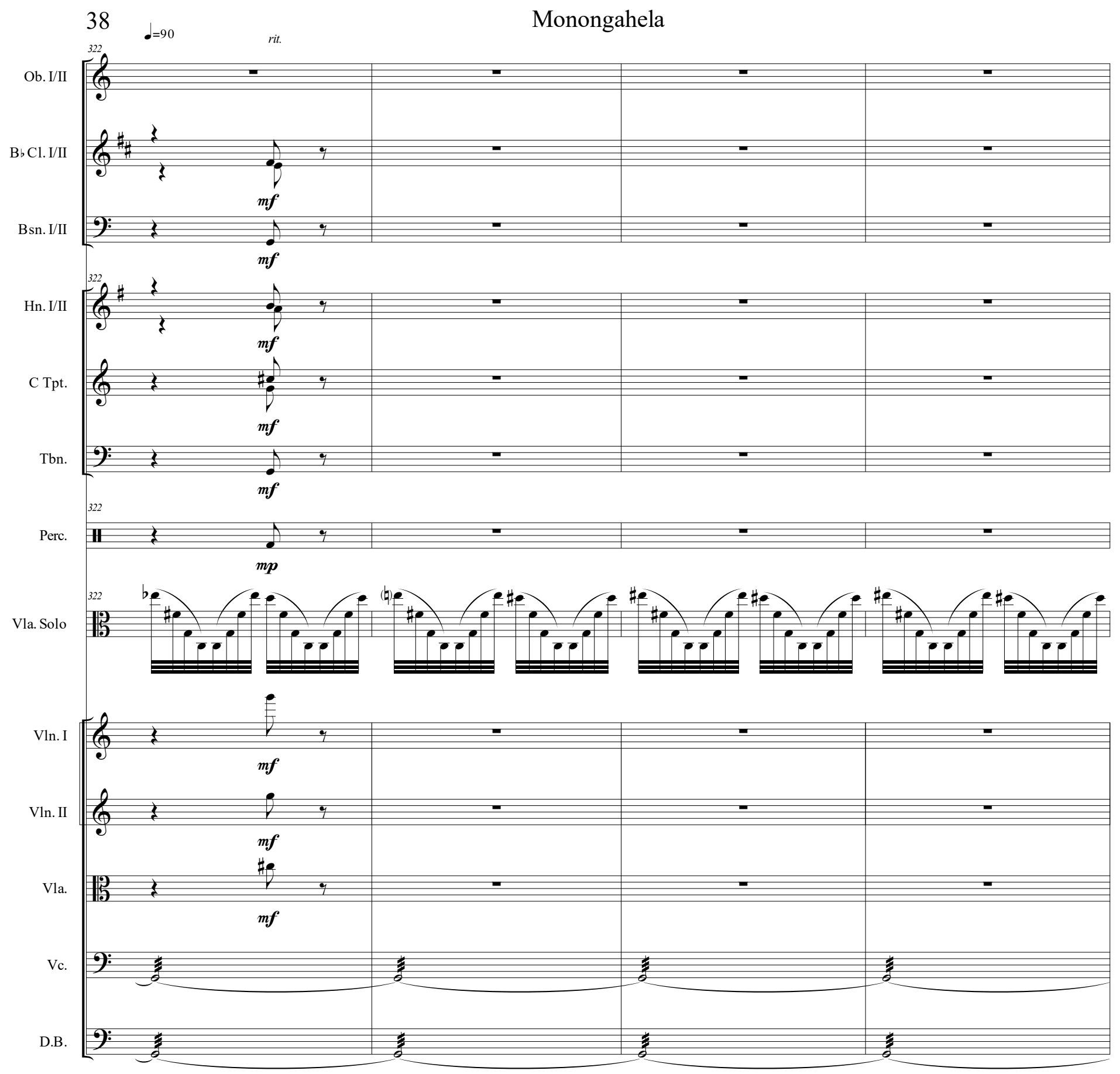




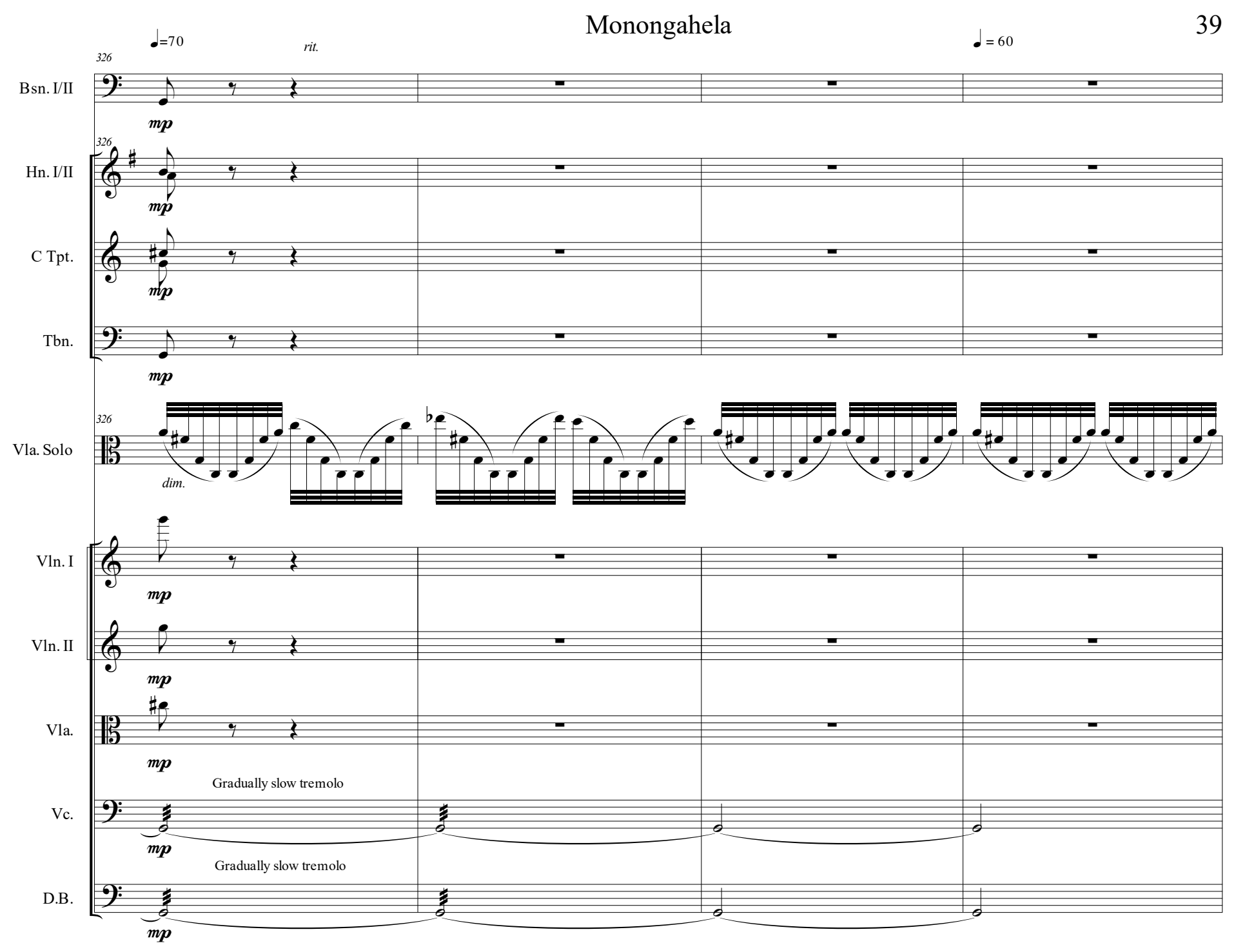




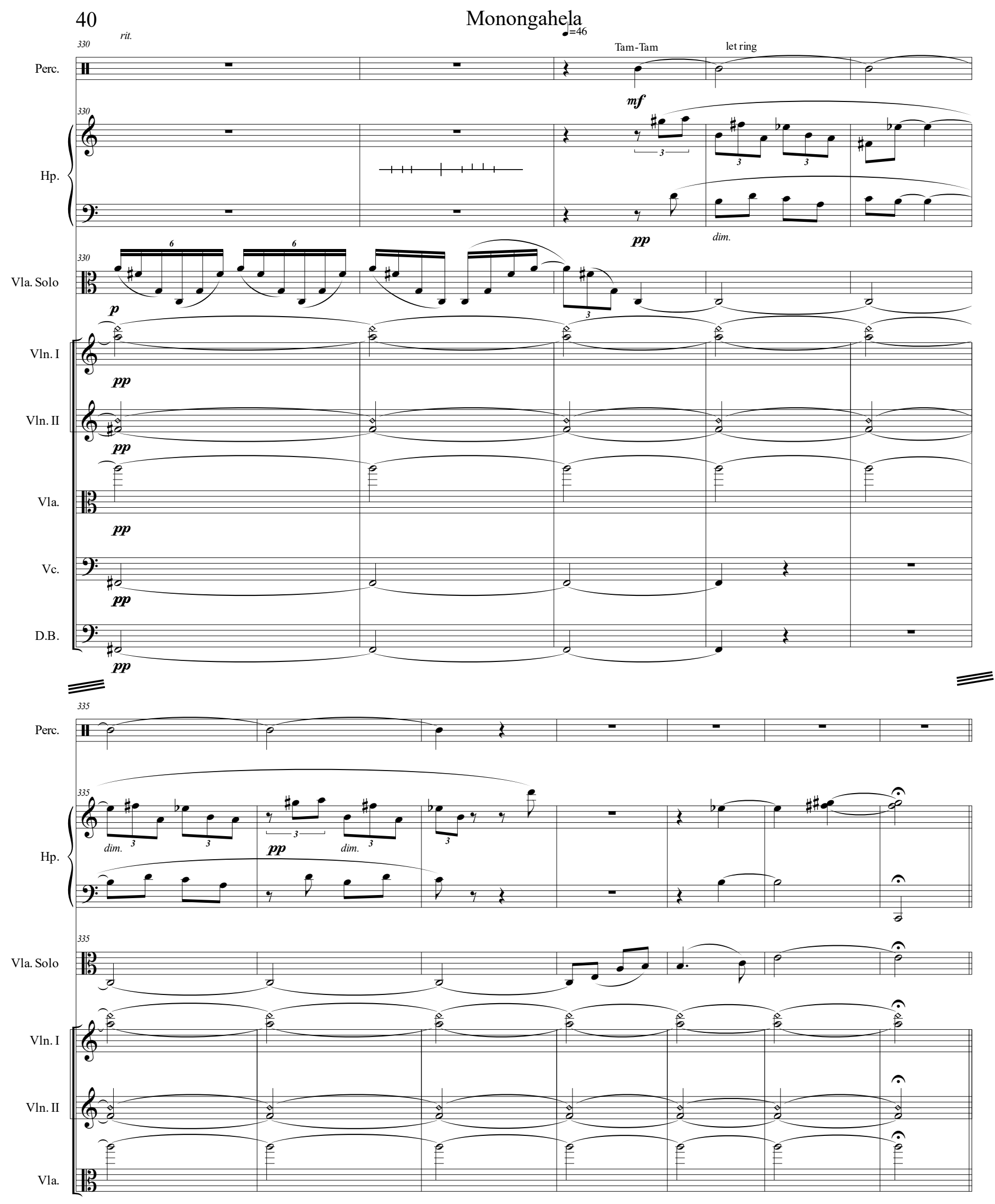


Monongahela

Fl. I/II

Ob. I/II

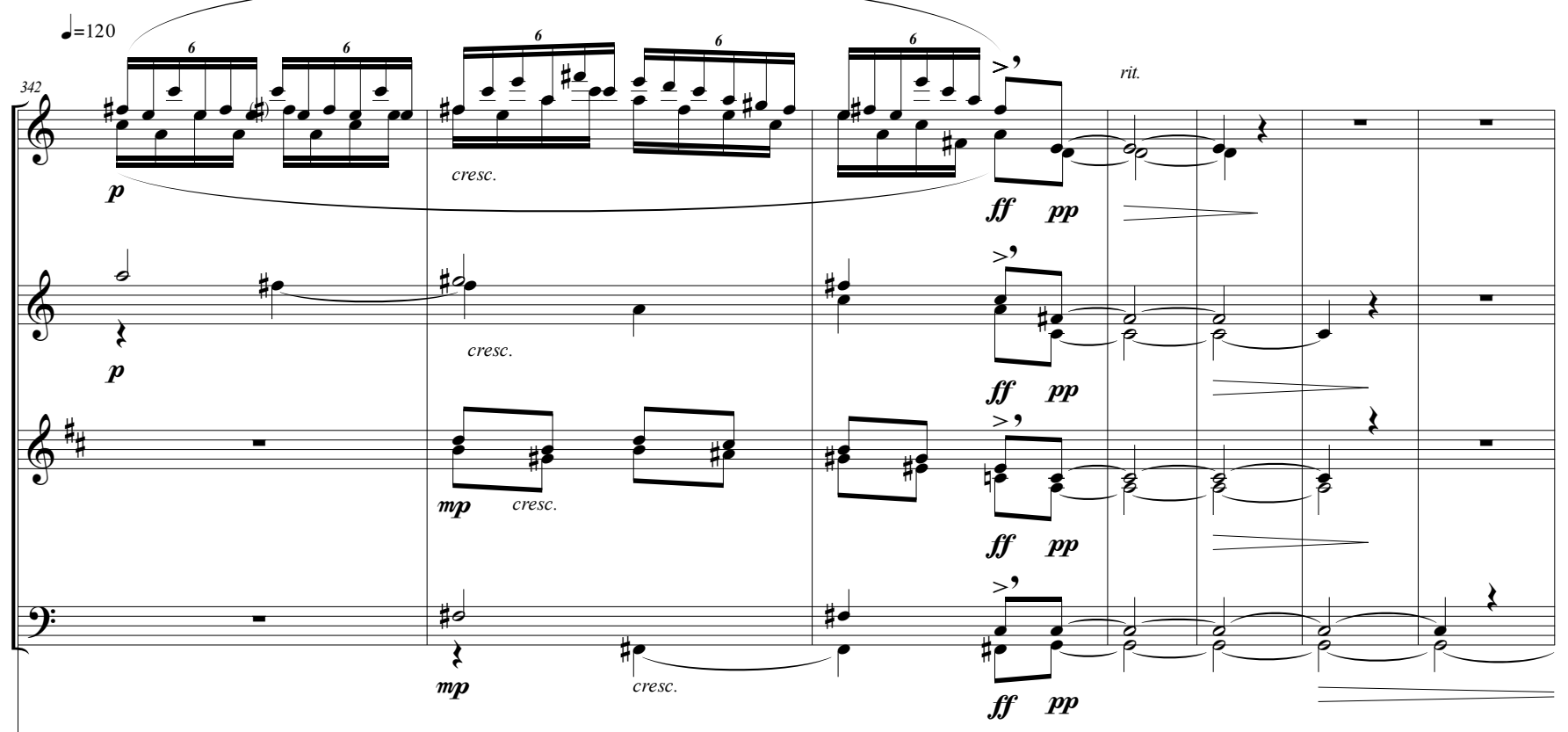

$\mathrm{B}, \mathrm{Cl}$. I/II

Bsn. I/II

Hn. I/II
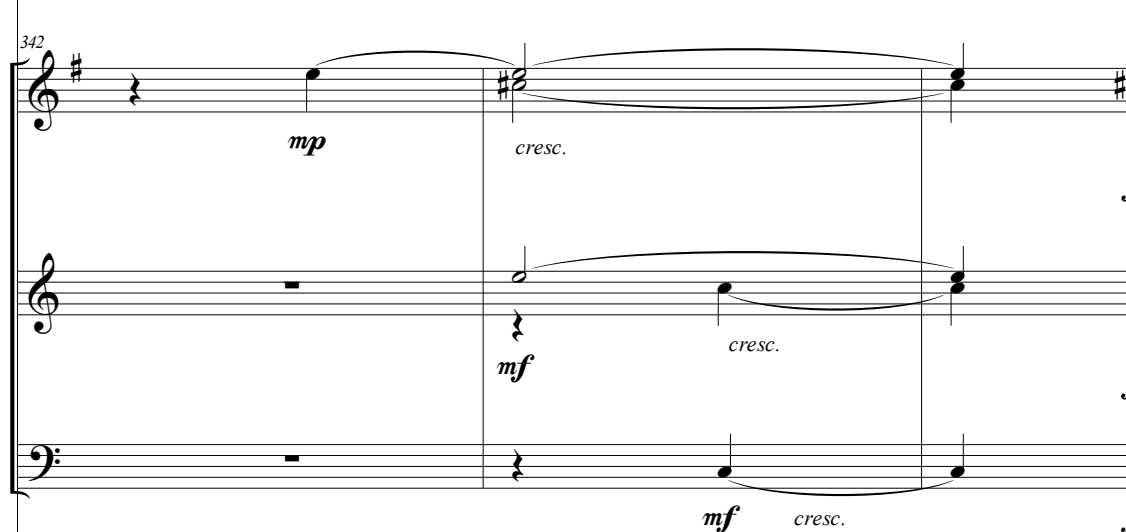

C Tpt.

Tbn.

Vla. Solo

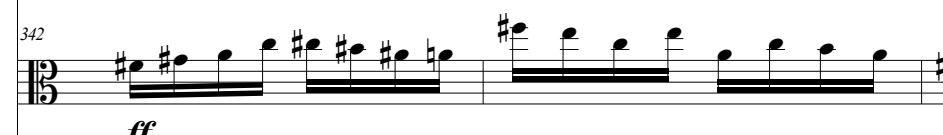

Vln. I
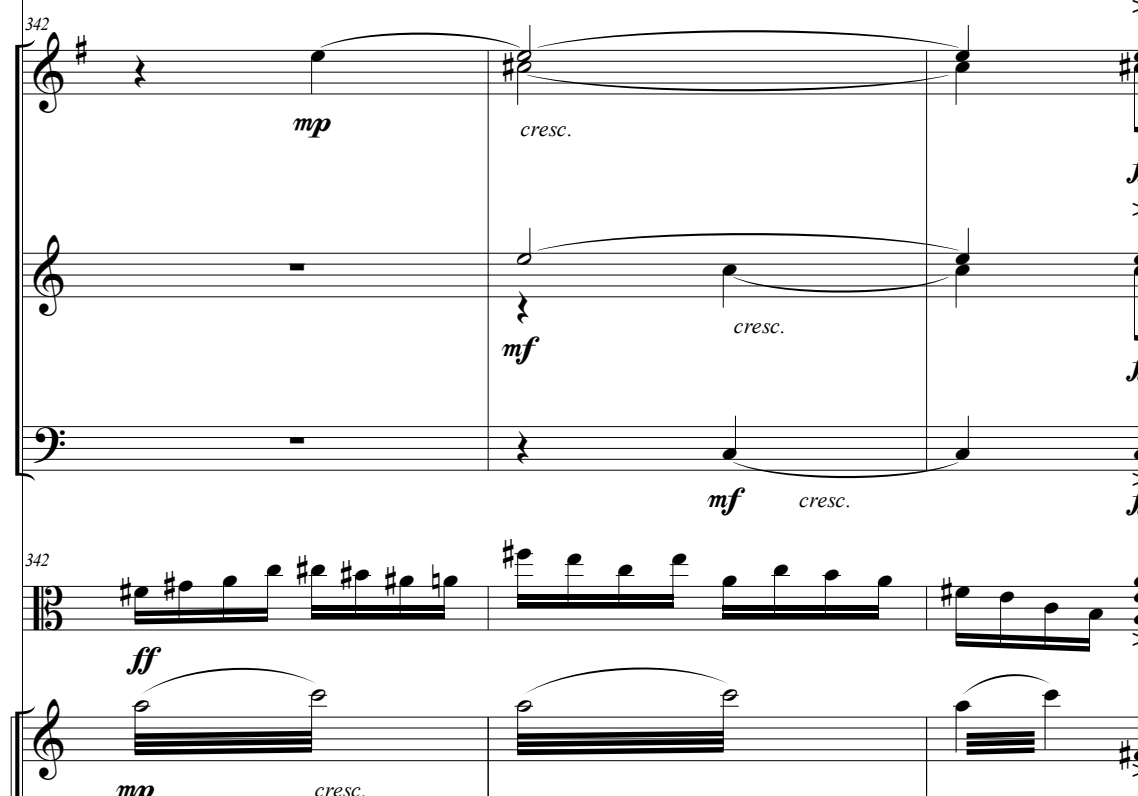

$>$
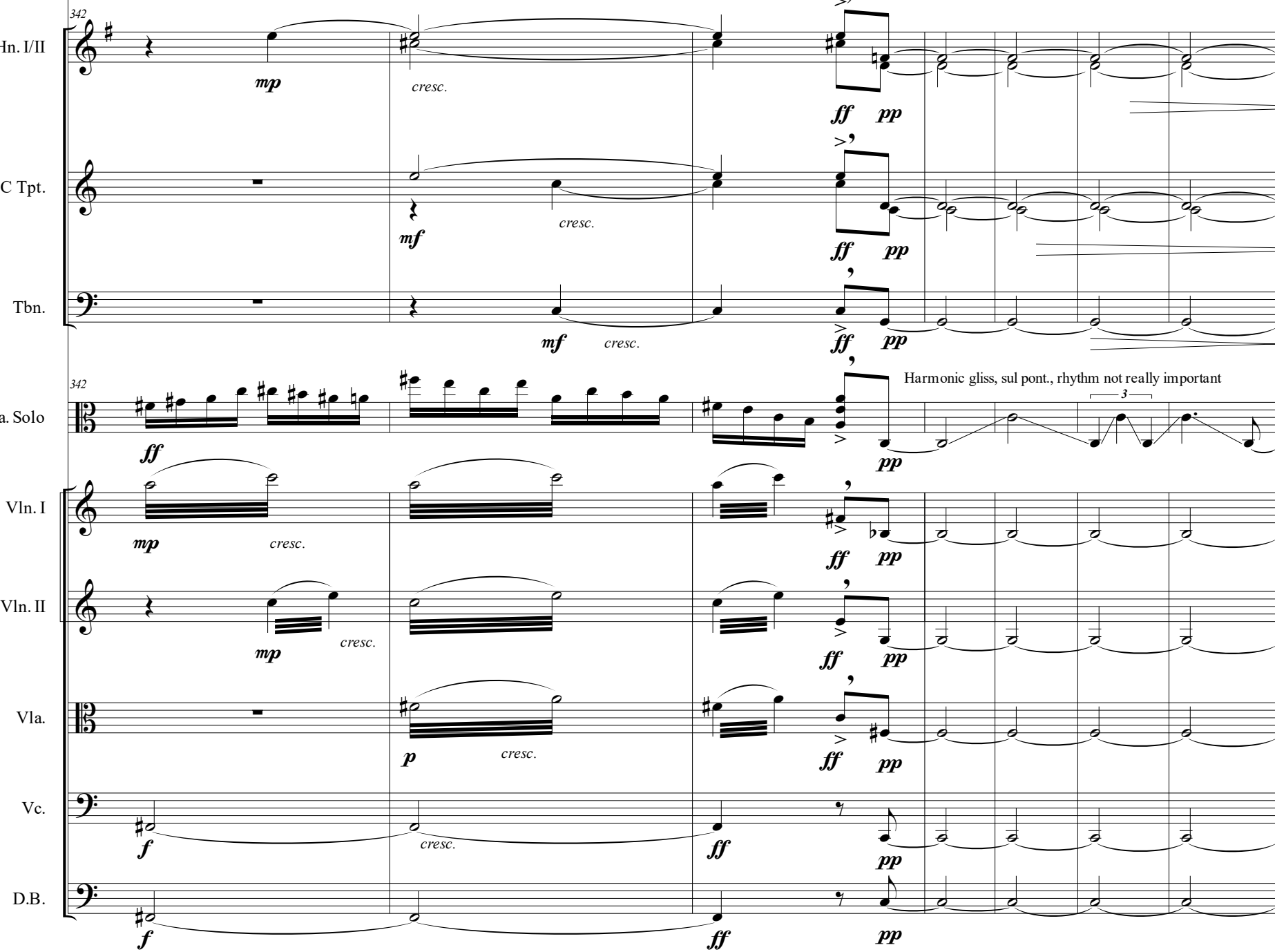

Harmonic gliss, sul pont., rhythm not really important 


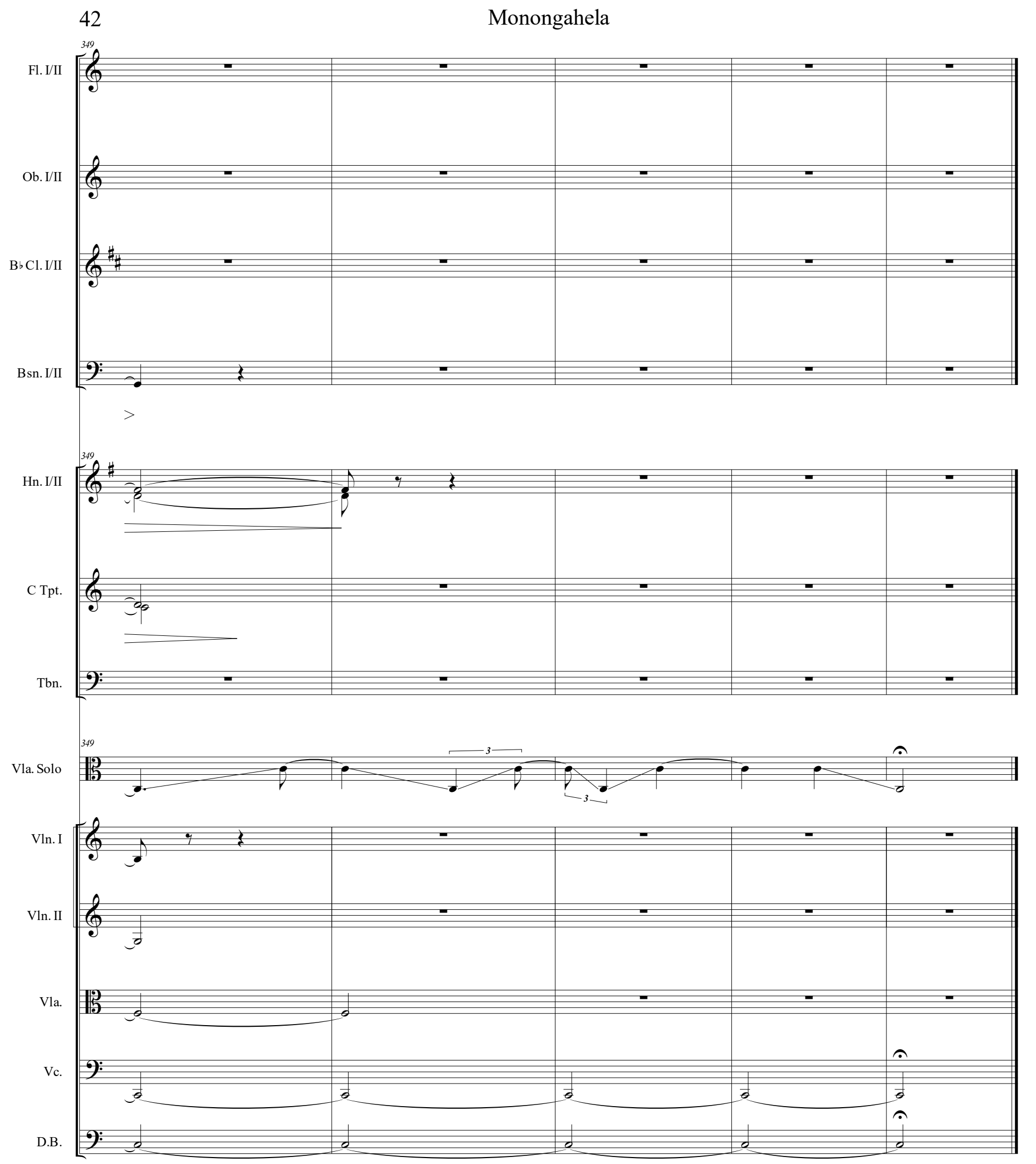

